\title{
Photosensitive and Photoswitchable TRPA1 Agonists Optically Control Pain
}

\section{through Channel Desensitization}

Zhen Qiao ${ }^{1}$, Jiajie Luo ${ }^{1}$, Yi-Quan Tang ${ }^{2}$, Qiqi Zhou ${ }^{4}$, Hang Qi ${ }^{1}$, Zhengji Yin ${ }^{1}$, Xiaowen Tang ${ }^{1}$, Wei Zhu ${ }^{1}$, Yanru Zhang ${ }^{1,3 *}$, Ningning Wei ${ }^{1,3 *}$ and KeWei Wang ${ }^{1,3}$

1. Departments of Pharmacology and Pharmaceutical Analysis, School of Pharmacy, Qingdao University Medical College, \#1 Ningde Road, Qingdao 266073, China

2. State Key Laboratory of Medical Neurobiology and MOE Frontiers Center for Brain Science, Institutes of Brain Science, Fudan University, Shanghai 200032, China

3. Institute of Innovative Drug, Qingdao University, Qingdao 266021, China

4. Department of Pharmacology, Qilu Medical University School of Pharmacy, Zibo 255300, China

${ }^{*}$ Correspondence: yanru.zhang@.qdu.edu.cn (Y. Z) and weiningning@qdu.edu.cn (N. W) 
Table of Contents

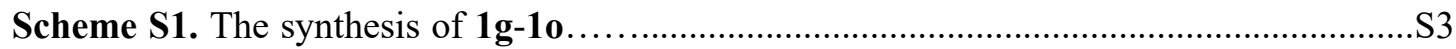

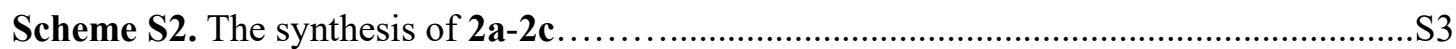

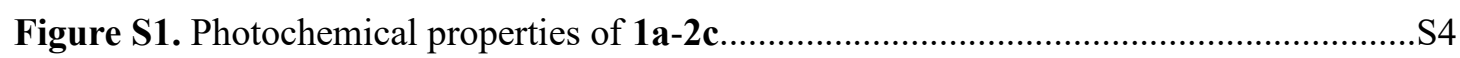

Figure S2. Time-dependent UV-vis absorbance of $\mathbf{1 a}$ to $\mathbf{2 c}$ (from A to R) in cyclohexane at maximal absorption wavelengths upon illumination with $365 \mathrm{~nm}$ light.

Figure S3. Confocal imaging of fluorescence and bright field images of probe A1CA $(10 \mu \mathrm{M})$ with 1a-2c $(10 \mu \mathrm{M})$ in TRPA1 overexpressed CHO cells.

Figure S4. Dose-dependent activation of TRPA1 current by $\mathbf{1 g}, \mathbf{1 h}, \mathbf{1 0}, \mathbf{2 b}$ and $\mathbf{2 c}$ with UV light.

Figure S5. The molecular binding mode of $\mathbf{1 h}, \mathbf{1 o}, \mathbf{2 b}$ and $\mathbf{2 c}$ in the TRPA1 binding sites..S10

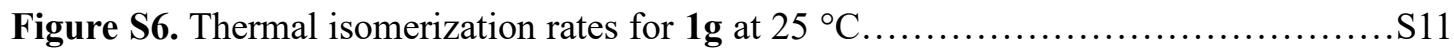

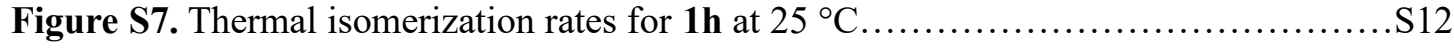

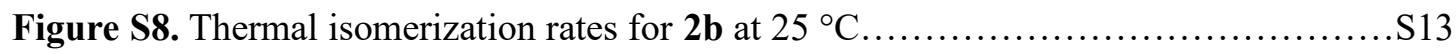

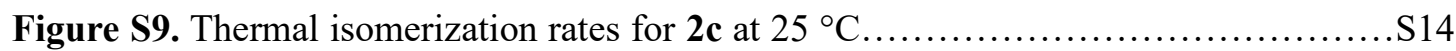

Figure S10. $1 \mathrm{~g}$ and $2 \mathrm{c}$ did not induce $\mathrm{Ca}^{2+}$ influx in untransfected HEK-293 cell...........S15

Figure S11. $1 \mathbf{h}$ induced $\mathrm{Ca}^{2+}$ influx in TRPA1-expressing HEK-293 cells...................S16

Figure S12. 10 induced $\mathrm{Ca}^{2+}$ influx in TRPA1-expressing HEK-293 cells........................ S17

Figure S13. 2b induced $\mathrm{Ca}^{2+}$ influx in TRPA1-expressing HEK-293 cells...........................S18

Figure S14. Liquid chromatogram of $\mathbf{1 h}, \mathbf{2 b}$ and $\mathbf{2 c}$ under irradiation with $365 \mathrm{~nm}$ or 415 nm....

Figure S15. Reversible photoisomerism of $\mathbf{1 h}, \mathbf{1 0}, \mathbf{2 b}$ and $\mathbf{2 c}$ after illumination with $365 \mathrm{~nm}$, $415 \mathrm{~nm}, 470 \mathrm{~nm}, 530 \mathrm{~nm}$, and daylight in $\mathrm{Ca}^{2+}$-free external solution.

Figure S16. Isomerization cycles of $\mathbf{1 h}, \mathbf{1 0}, \mathbf{2 b}$ and $\mathbf{2 c}$ upon illumination with $365 \mathrm{~nm}$ and 415

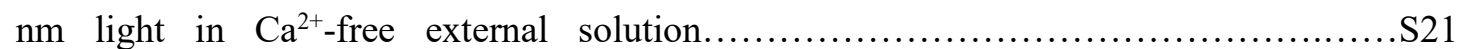

Figure S17. ${ }^{1} \mathrm{H}$ NMR of $\mathbf{1 g}$ at dark, 365, 415, 470, $530 \mathrm{~nm}$ PSS......................S22

Figure S18. ${ }^{1} \mathrm{H}$ NMR of $\mathbf{1 h}$ at dark, 365, 415, 470, $530 \mathrm{~nm}$ PSS........................ 25

Figure S19. ${ }^{1} \mathrm{H}$ NMR of $\mathbf{2 b}$ at dark, 365, 415, 470, $530 \mathrm{~nm}$ PSS....................... 28

Figure S20. ${ }^{1} \mathrm{H}$ NMR of $\mathbf{2 c}$ at dark, 365, 415, 470, $530 \mathrm{~nm}$ PSS........................ 31

Figure S21. Cheek model test of $\mathbf{1 g}$ and $\mathbf{2 c}$ without $365 \mathrm{~nm}$ light in mice..................S34

Figure S22. Genotyping of TRPA $1^{(+/)}$, TRPA1 ${ }^{(-/+)}$and TRPA1 $1^{(-)}$mice by PCR..........S35

Figure S23. Selective activation of TRPA1 by $1 \mathbf{g}$ and $\mathbf{2 c}$ upon illumination with UV light over

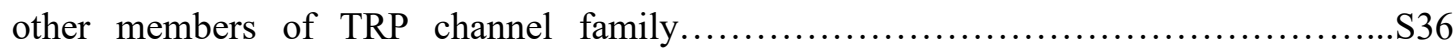

Figure S24. Selectivity evaluation for TRPA1 activation by $1 \mathrm{~g}$ and $\mathbf{2 c}$ over voltage-gate sodium

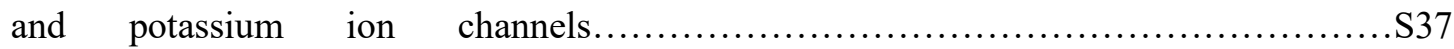

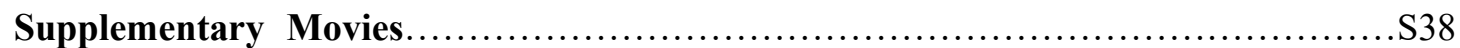

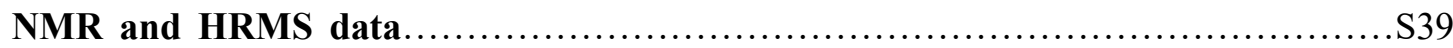

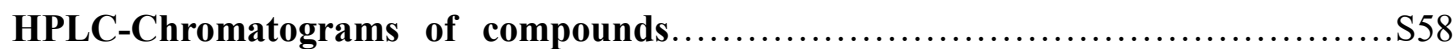




\section{Supplemental Schemes}

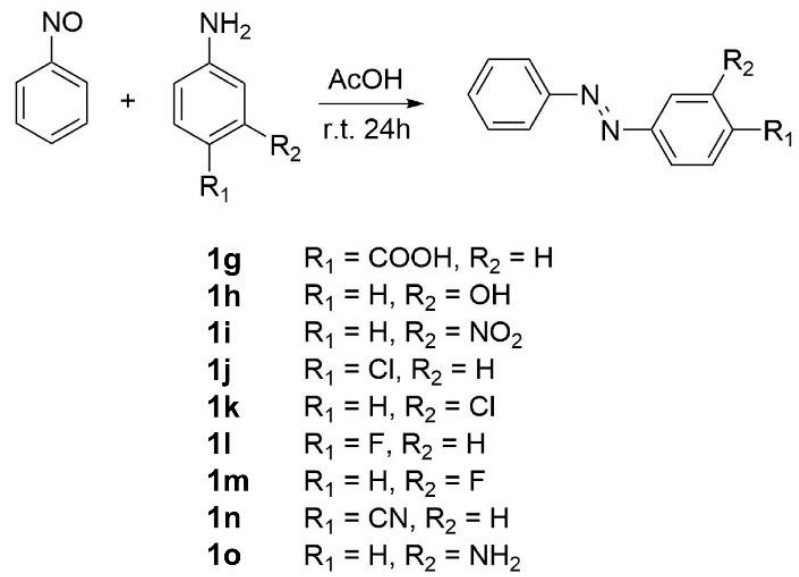

Scheme S1. The synthesis of 1g-10.

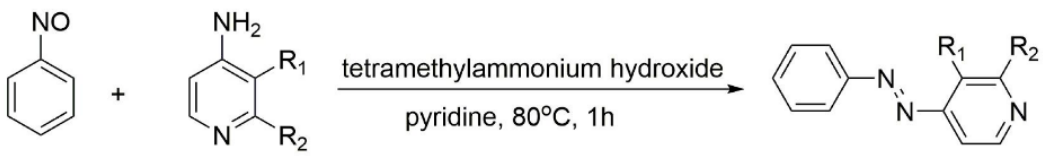

$$
\begin{array}{ll}
\text { 2a } & \mathrm{R}_{1}=\mathrm{H}, \mathrm{R}_{2}=\mathrm{H} \\
\text { 2b } & \mathrm{R}_{1}=\mathrm{CH}_{3}, \mathrm{R}_{2}=\mathrm{H} \\
\text { 2c } & \mathrm{R}_{1}=\mathrm{H}, \mathrm{R}_{2}=\mathrm{OCH}_{3}
\end{array}
$$

Scheme S2. The synthesis of 2a-2c. 


\section{Supplemental Figures}
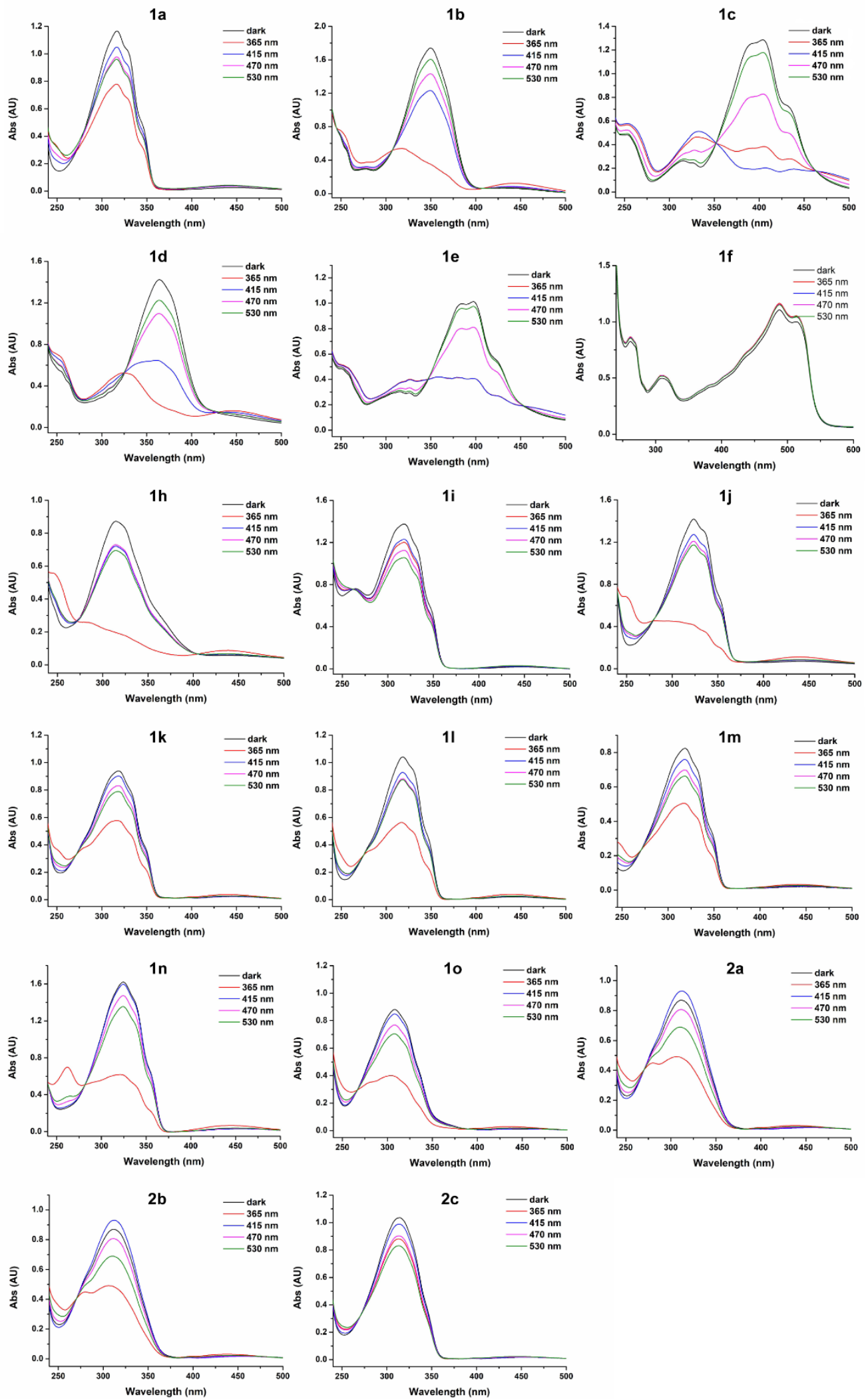

Figure S1. Photochemical properties of 1a-2c. UV-vis spectra of series 1 and $2(50 \mu \mathrm{M})$ in cyclohexane either in the dark, or under illumination with $365 \mathrm{~nm}, 415 \mathrm{~nm}, 470 \mathrm{~nm}$ or $530 \mathrm{~nm}$ light. 
A

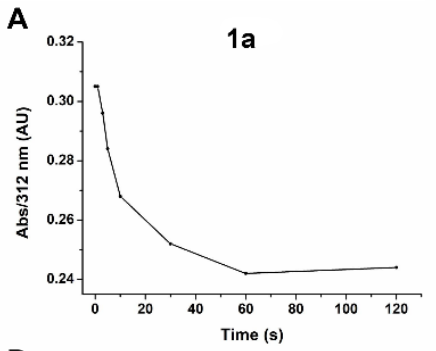

D

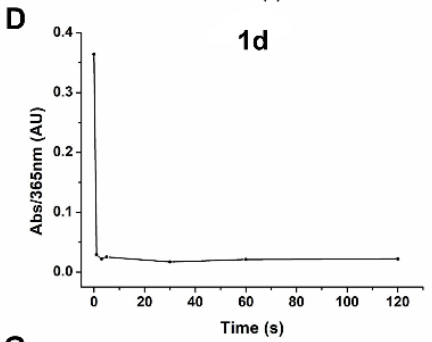

G

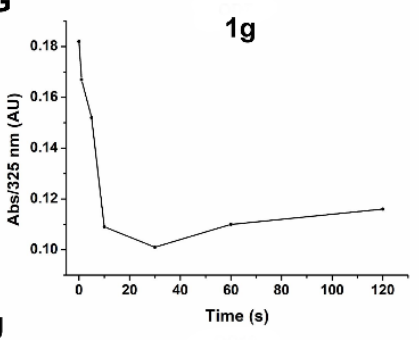

$J$
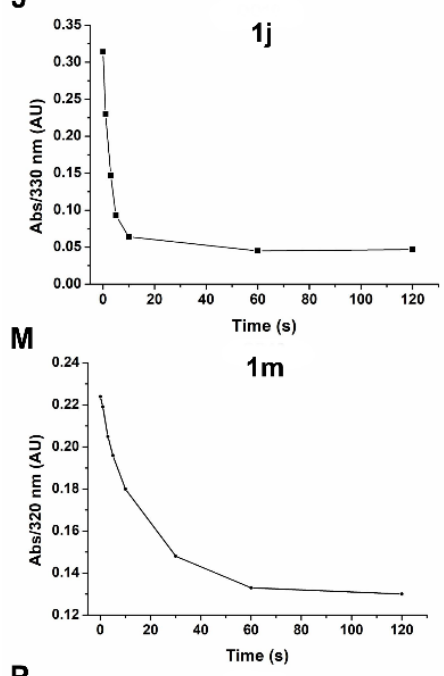

P

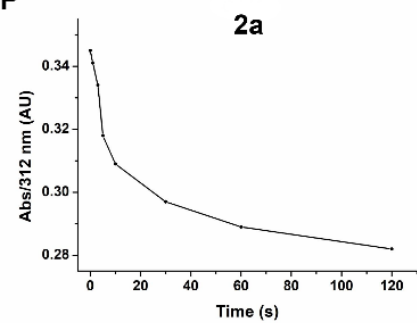

B

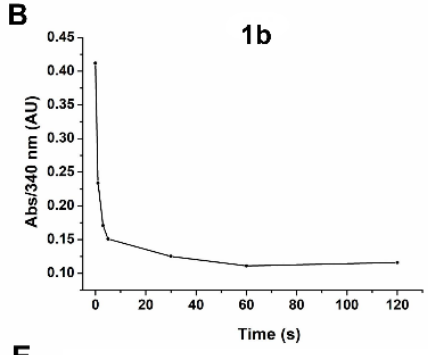

E

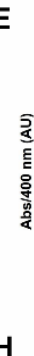

H

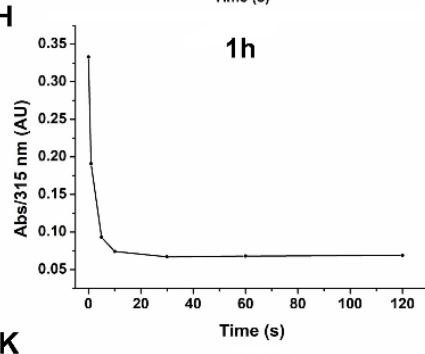

C $1 c$

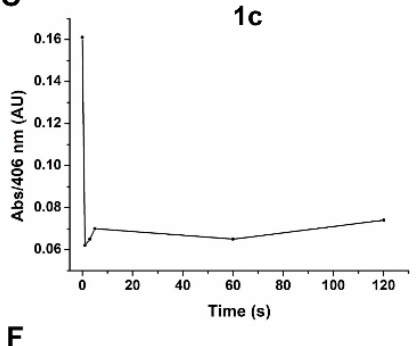

$\mathbf{F}$

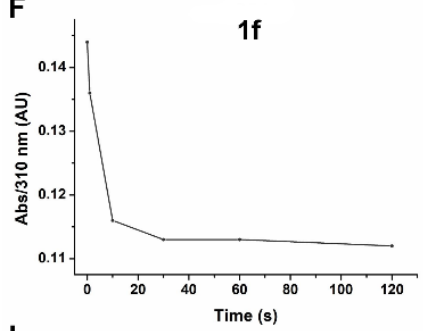

I
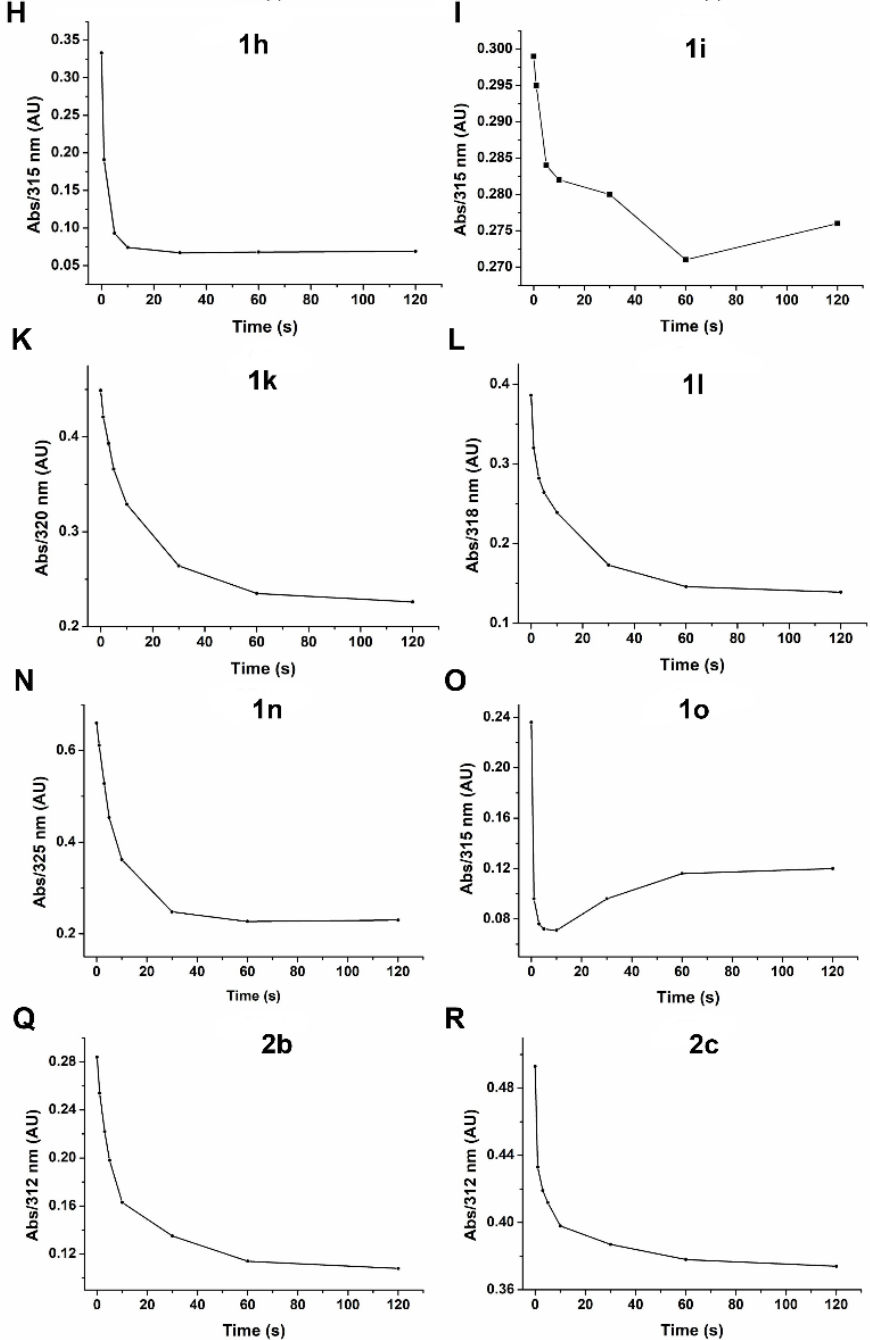

Figure S2. Time-dependent UV-vis absorbance of $50 \mu \mathrm{M}$ series 1 and 2 (from A to R) in cyclohexane at maximal absorption wavelengths upon illumination with $365 \mathrm{~nm}$ light. 

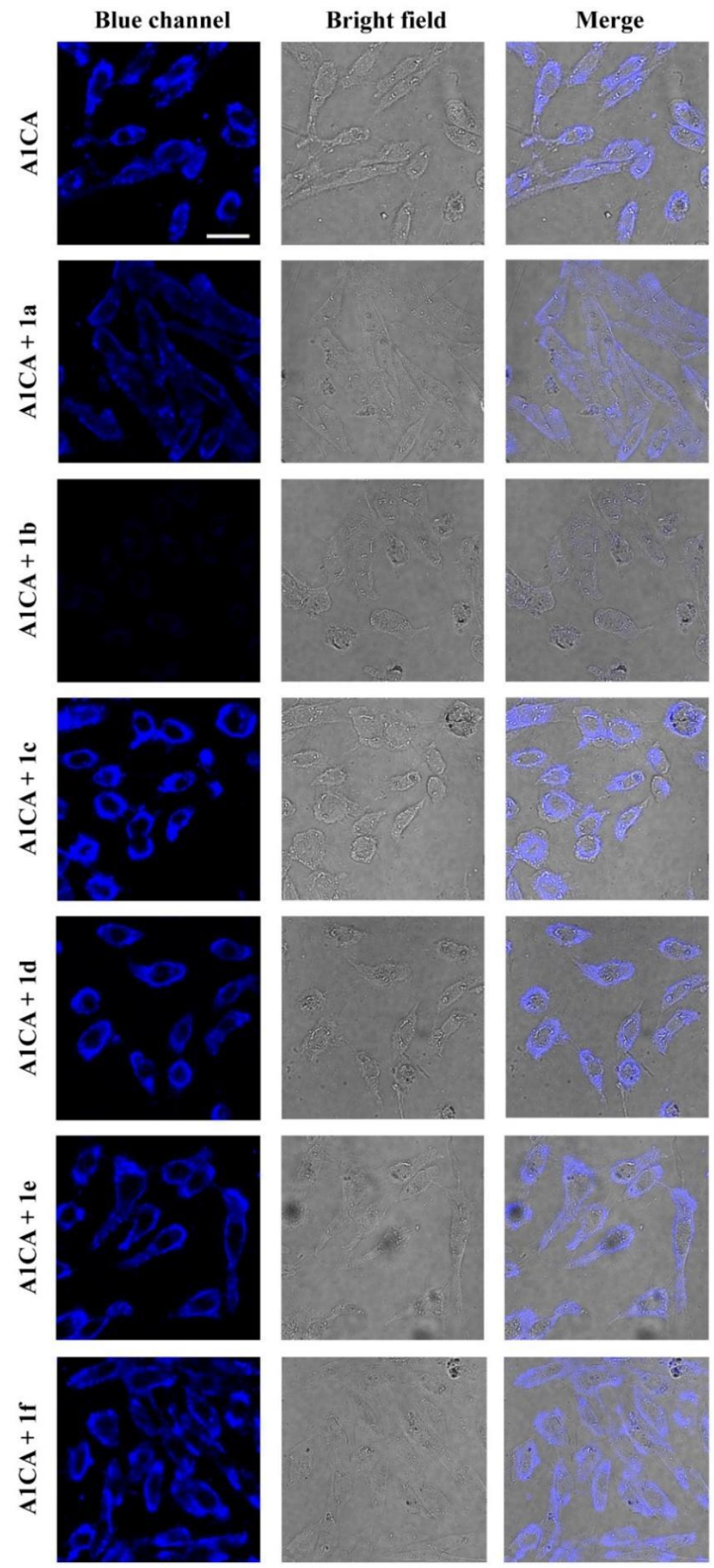
Continued
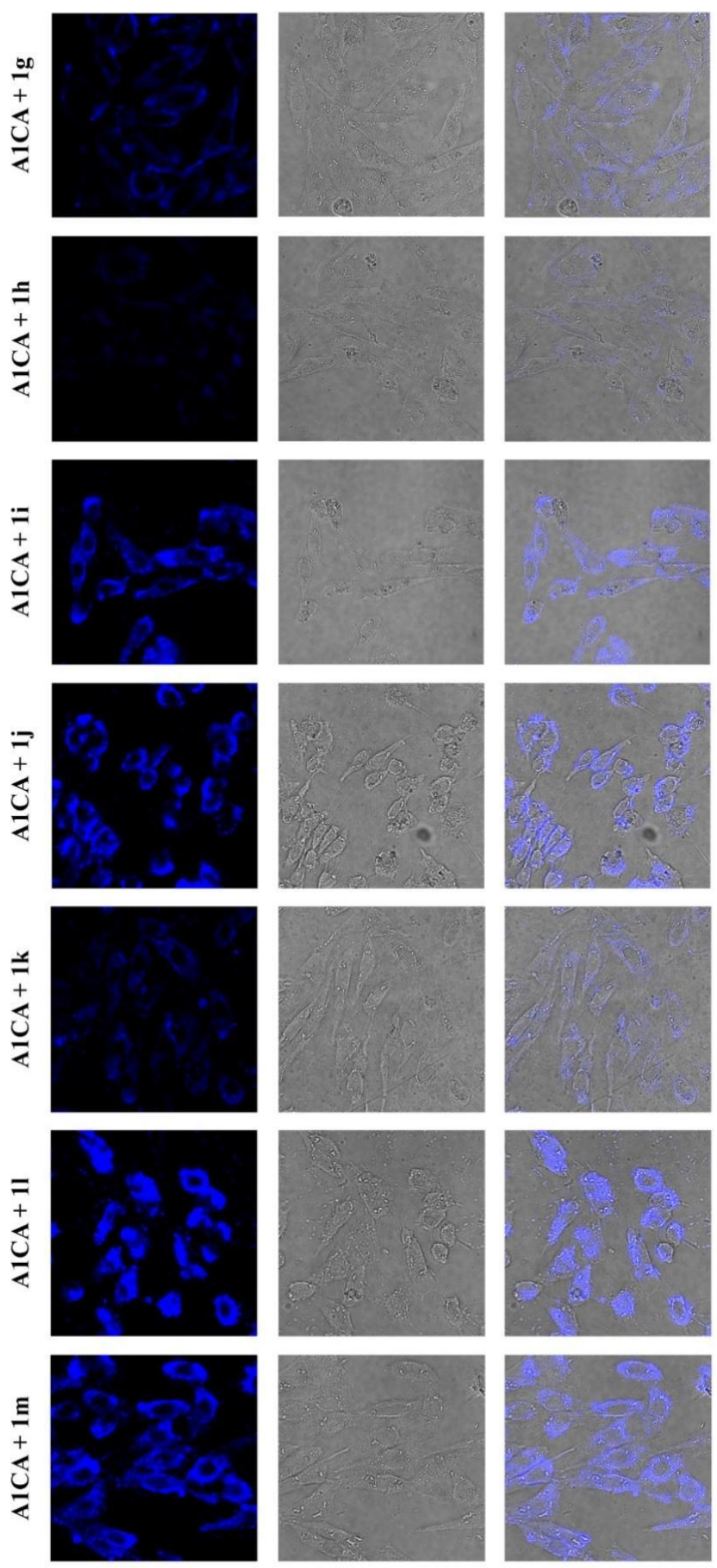
Continued
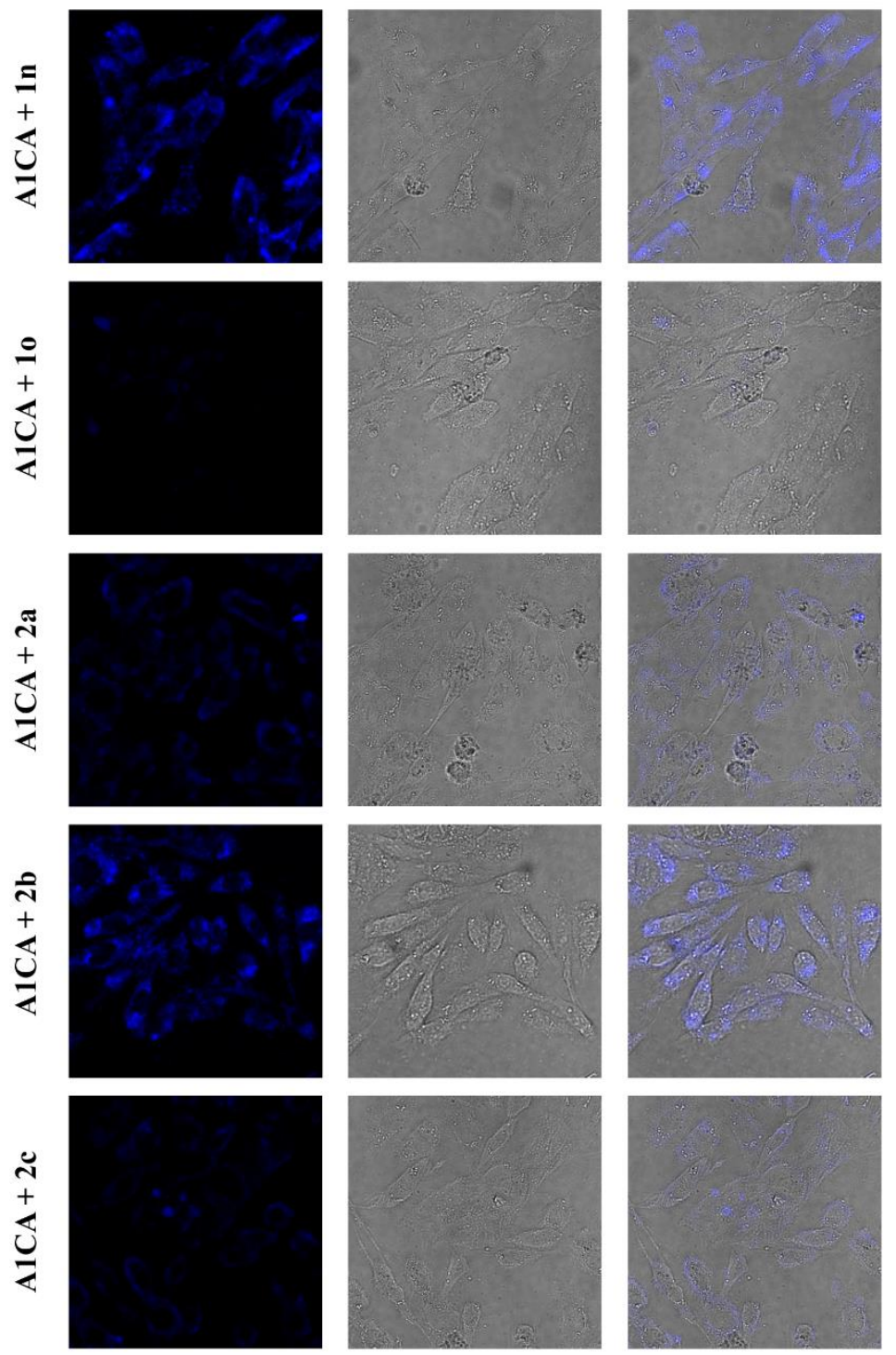

Figure S3. Confocal imaging of fluorescence and bright field images of probe A1CA (10 $\mu \mathrm{M})$ with 1a-1o and 2a-2c $(10 \mu \mathrm{M})$ in TRPA1 overexpressed CHO cells. Scale bars (white): $50 \mu \mathrm{m}$. 
A

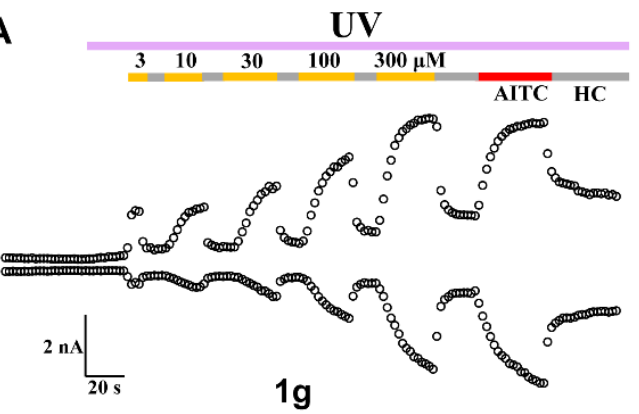

C
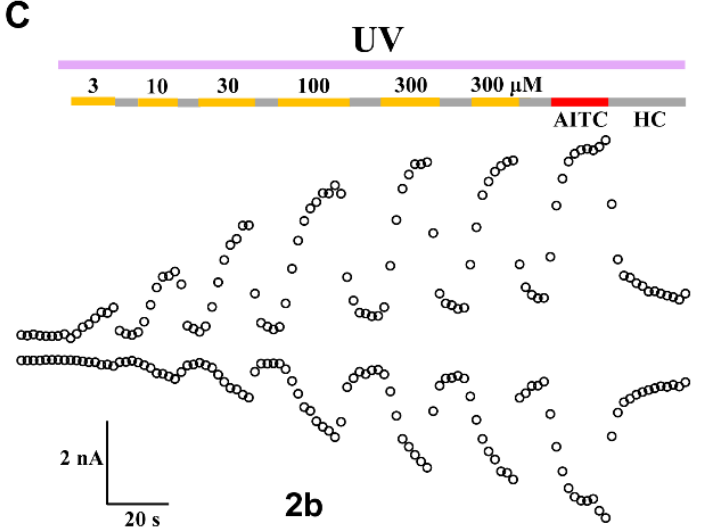

E

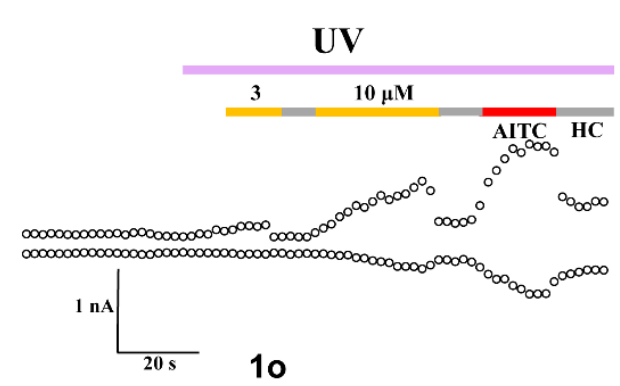

B
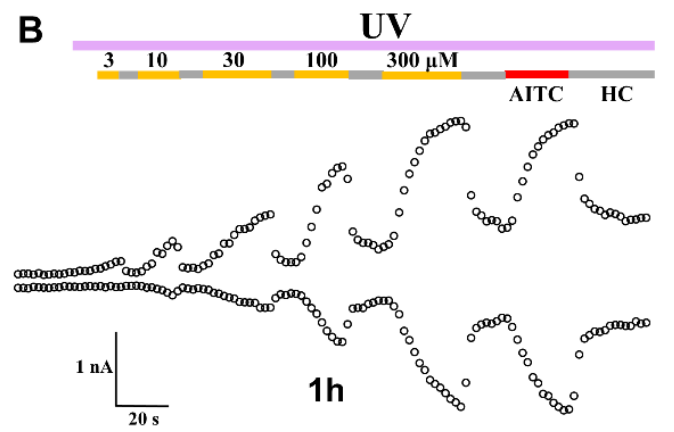

D
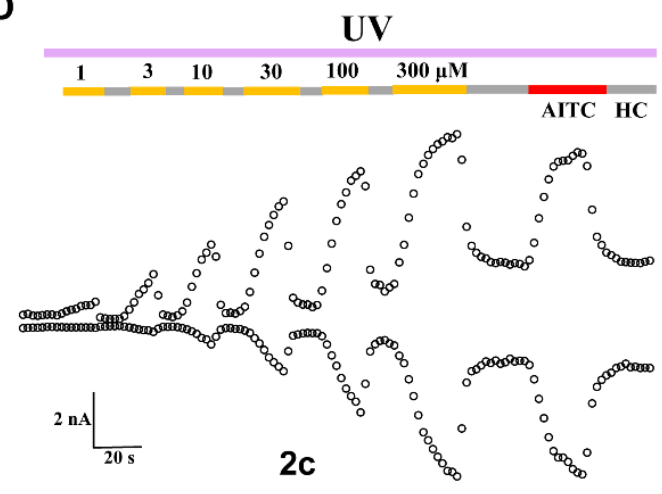

$\mathbf{F}$

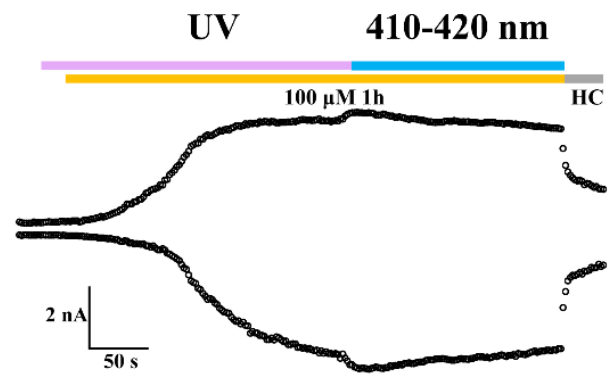

Figure S4. Dose-dependent activation of TRPA1 current by $1 \mathbf{g}, \mathbf{1 h}, \mathbf{1 o}, \mathbf{2 b}$ and $2 \mathbf{c}$ with UV light. Whole-cell currents of TRPA1 channels activated by increasing the concentrations of $\mathbf{1 g}(\mathrm{A}), \mathbf{1 h}$ (B), $2 \mathbf{b}(\mathrm{C}), \mathbf{2 c}$ (D) and $\mathbf{1 0}$ (E) from $3 \mu \mathrm{M}$ to $300 \mu \mathrm{M}$. (F) The activated TRPA1 current is irreversible with the application of 410-420 nm light. HC (HC-030031, a selective TRPA1 inhibitor) and AITC (a TRPA1 agonist). 

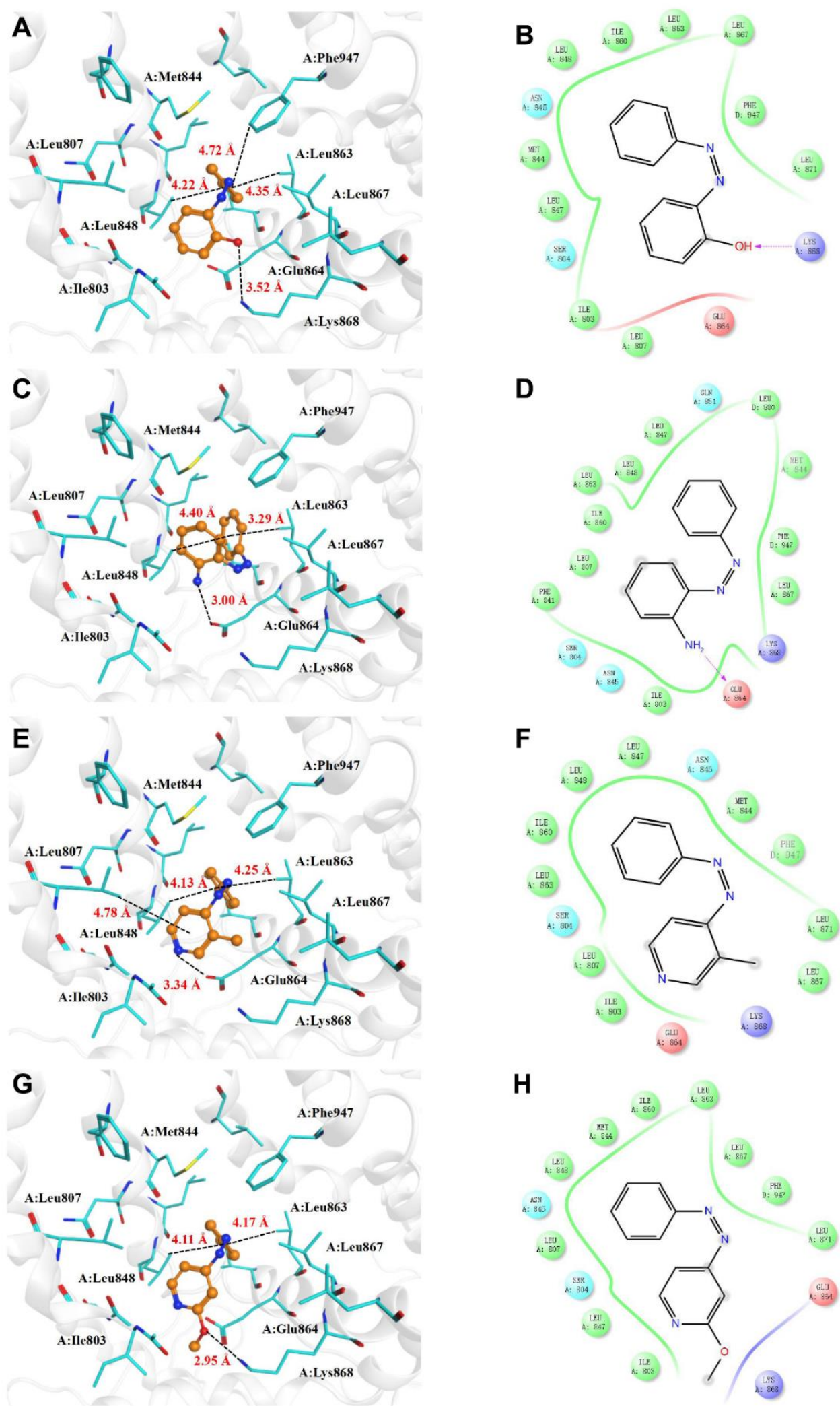

Figure S5. The molecular binding mode of $\mathbf{1 h}, \mathbf{1 o}, \mathbf{2} \mathbf{b}$ and $\mathbf{2 c}$ in the TRPA1 binding sites. Putative binding mode of $c i s-\mathbf{1 h}(\mathrm{A}), \mathbf{1 0}(\mathrm{C}), \mathbf{2 b}(\mathrm{E})$ and $\mathbf{2 c}(\mathrm{G})$ at the binding site of the TRPA1 model. Simplified representation of ligand-receptor interactions between $c i s-\mathbf{1 h}(\mathrm{B}), \mathbf{1 0}(\mathrm{D}), \mathbf{2 b}(\mathrm{F})$ or $\mathbf{2 c}$ (H) and TRPA1. PDB ID code: 3J9P. 
A

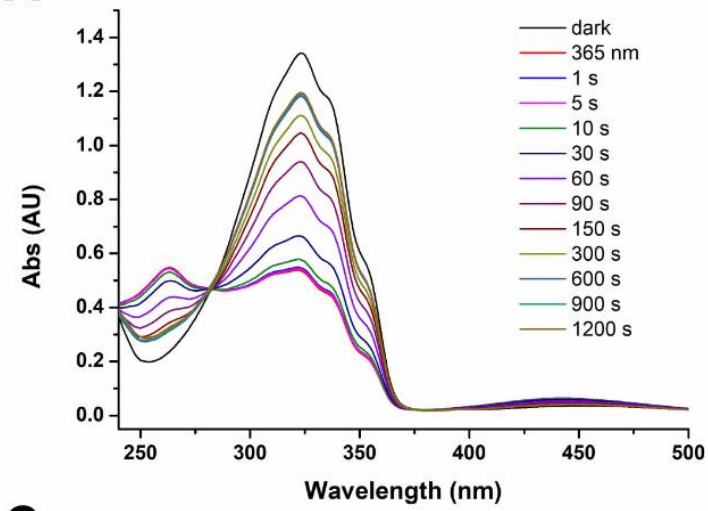

C

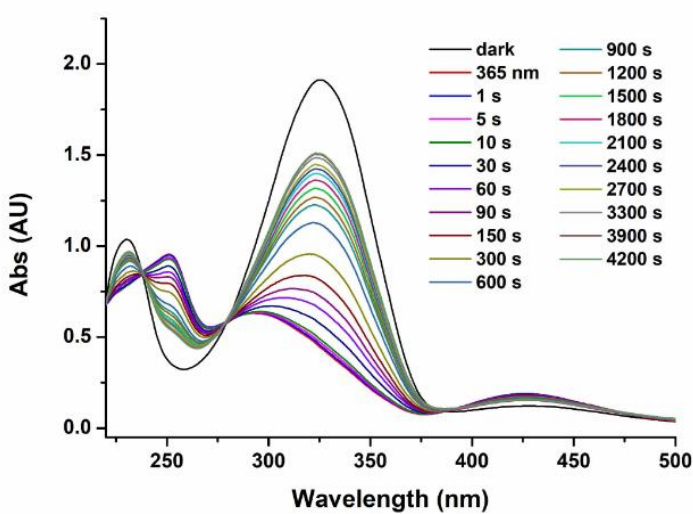

B

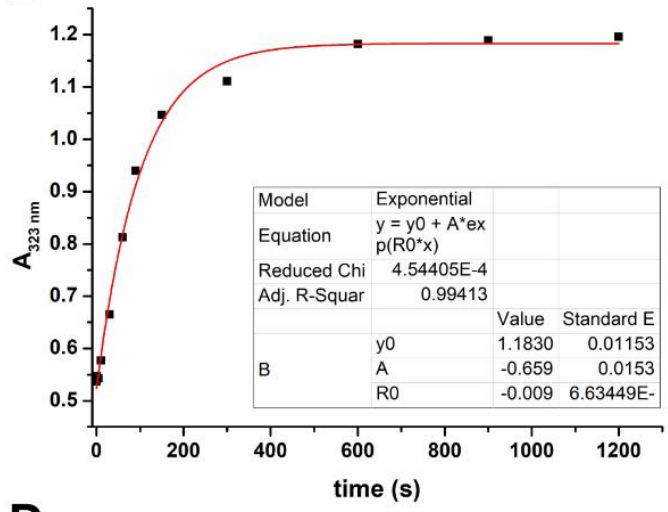

D

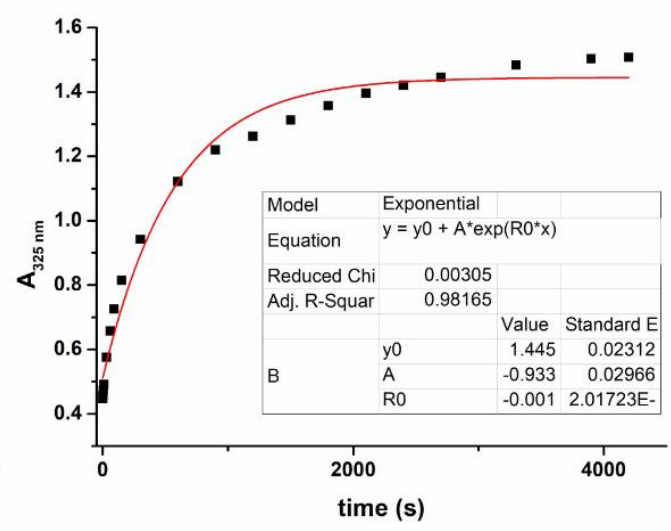

Figure S6. Thermal isomerization rates for $1 \mathrm{~g}(50 \mu \mathrm{M})$ in cyclohexane (A and B) and external solution $(\mathrm{C}$ and $\mathrm{D})$ at $25^{\circ} \mathrm{C}$. 
A

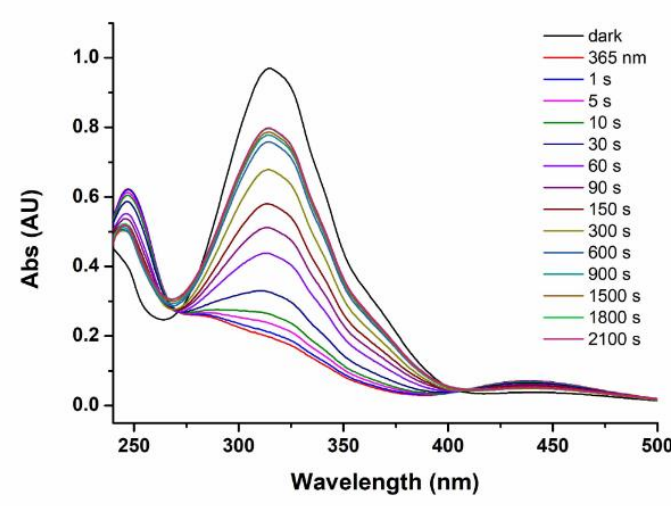

C

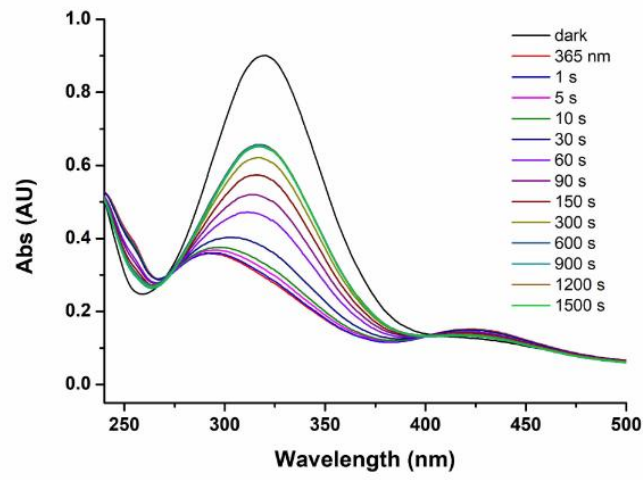

B

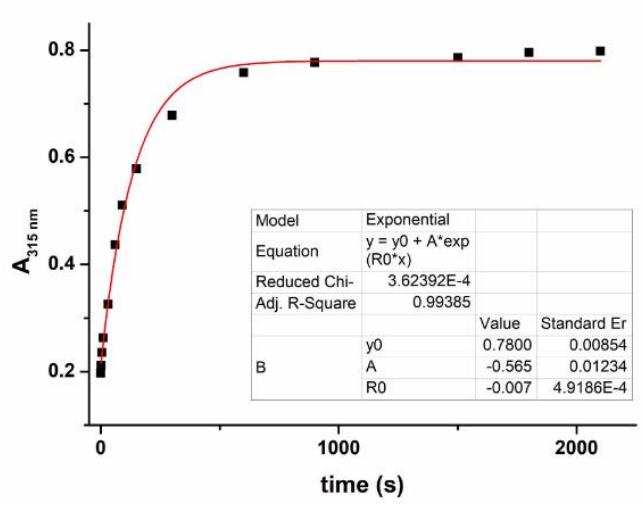

D

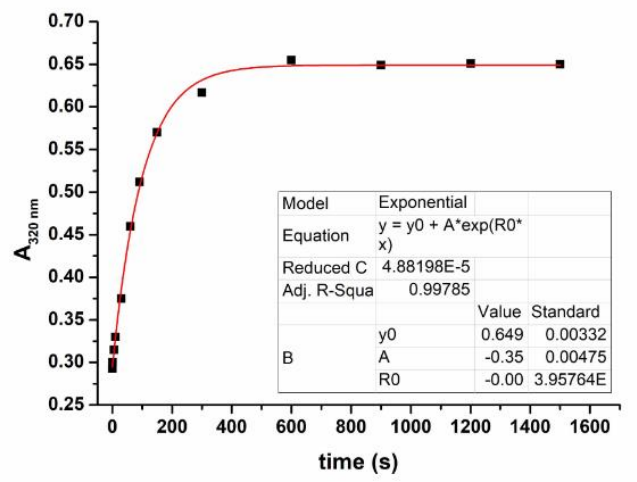

Figure S7. Thermal isomerization rates for $1 \mathbf{h}(50 \mu \mathrm{M})$ in cyclohexane (A and B) and external solution $(\mathrm{C}$ and $\mathrm{D})$ at $25^{\circ} \mathrm{C}$. 
A

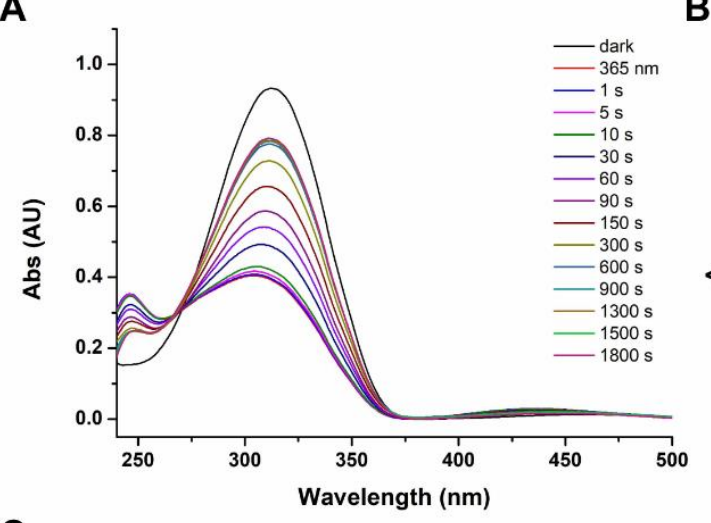

C

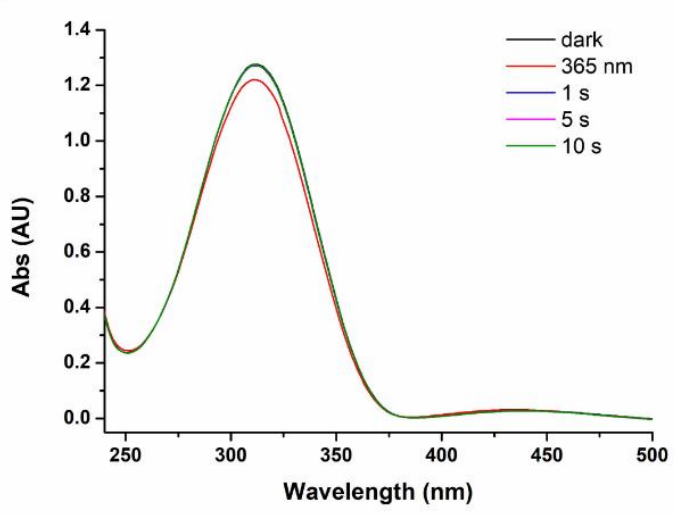

B

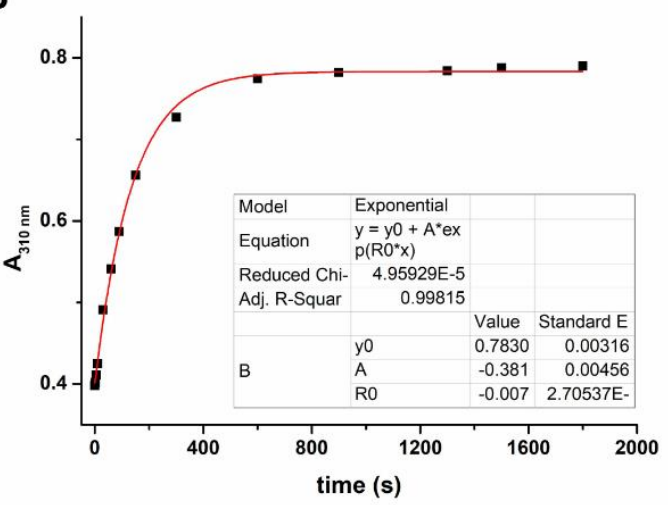

Figure S8. Thermal isomerization rates for $\mathbf{2 b}(50 \mu \mathrm{M})$ in cyclohexane (A and B) and external solution $(\mathrm{C}$ and $\mathrm{D})$ at $25^{\circ} \mathrm{C}$. 
A
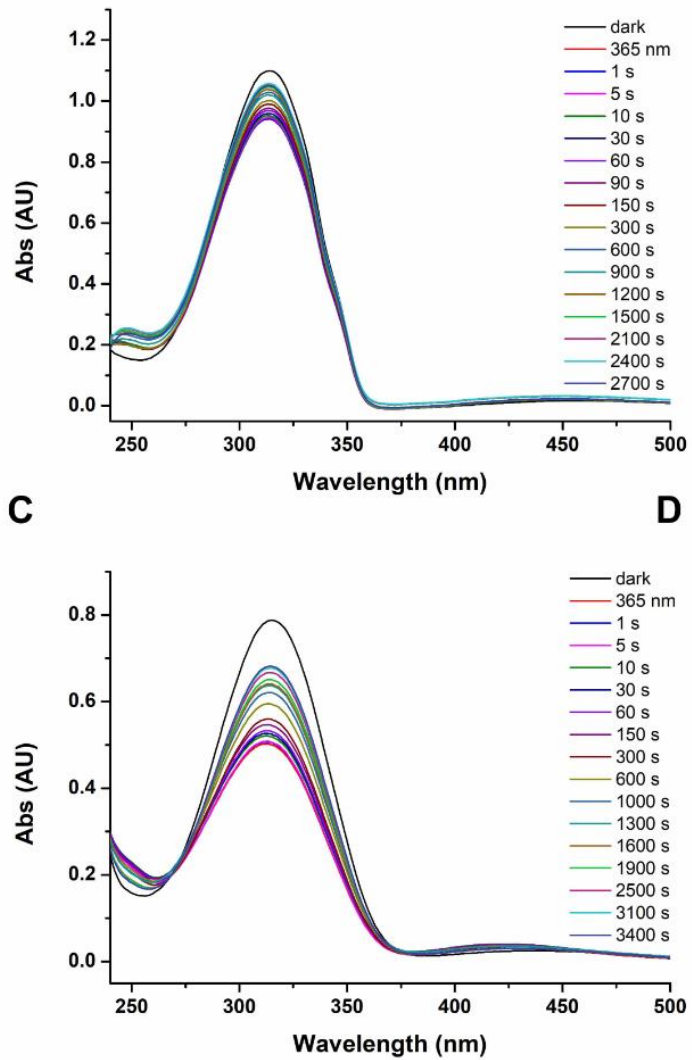

B

D
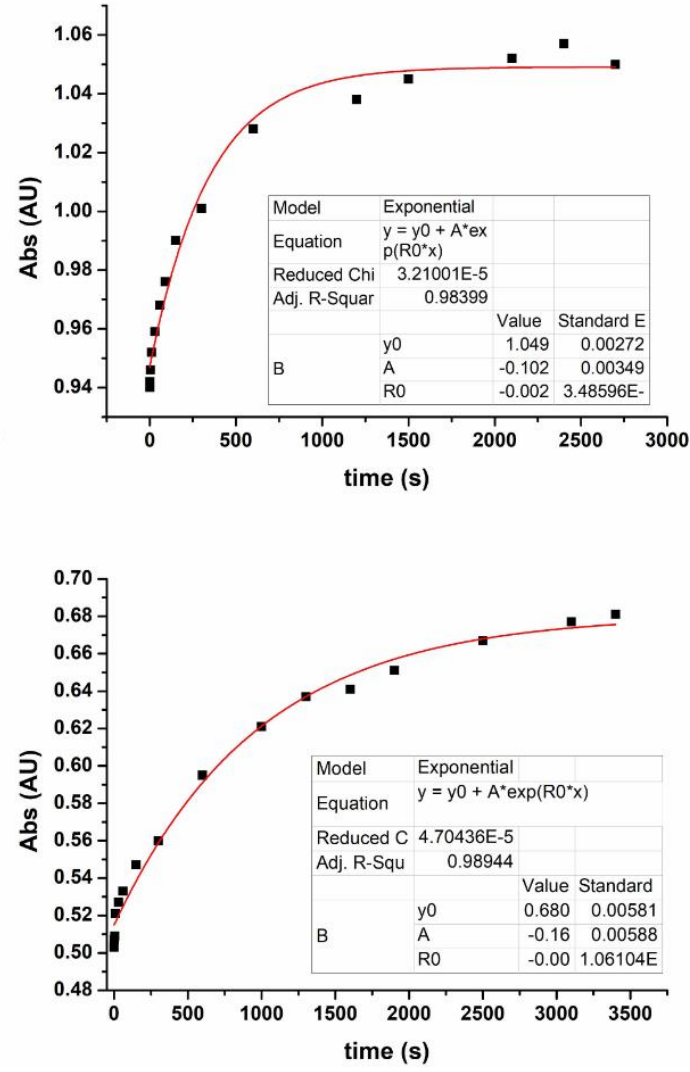

Figure S9. Thermal isomerization rates for $2 \mathbf{c}(50 \mu \mathrm{M})$ in cyclohexane (A and B) and external solution $(\mathrm{C}$ and $\mathrm{D})$ at $25^{\circ} \mathrm{C}$. 

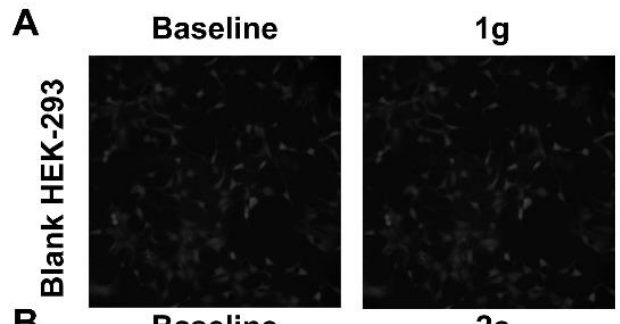

$1 \mathrm{~g}+365 \mathrm{~nm}$

B

Baseline

2c

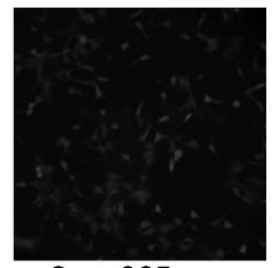

$2 \mathrm{c}+365 \mathrm{~nm}$

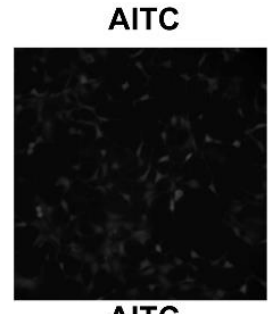

AITC Ionomycin
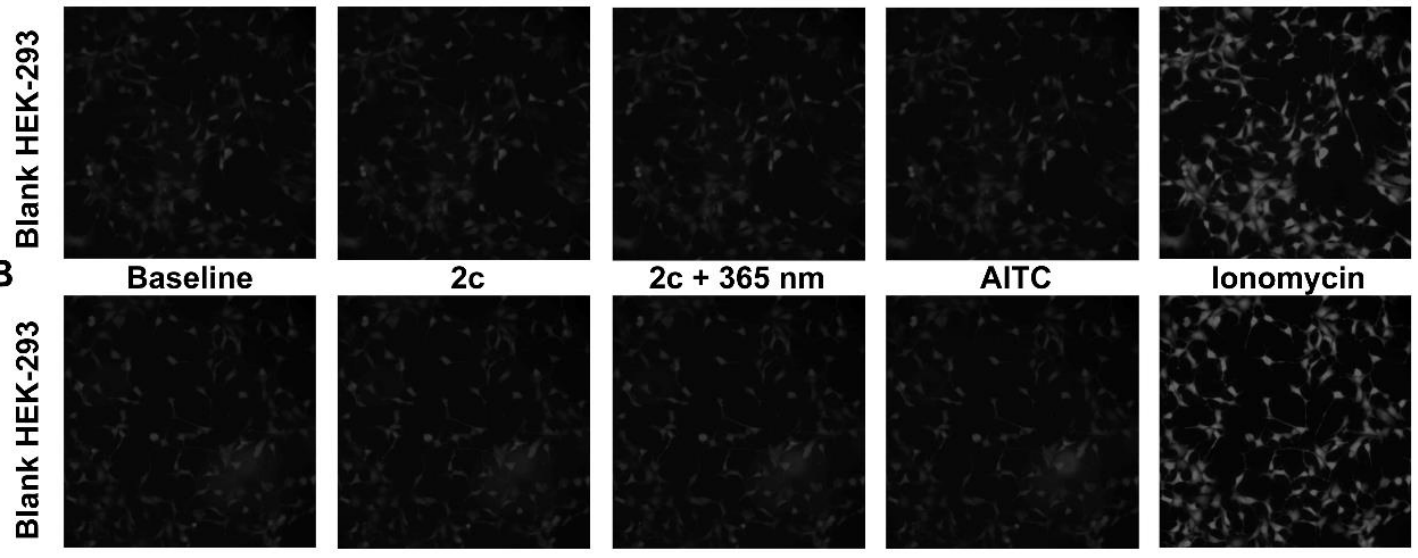

Ionomycin

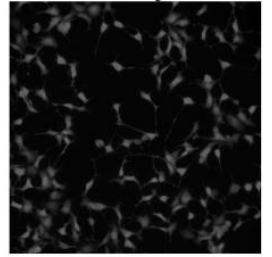

Figure S10. 1g and 2c did not induce $\mathrm{Ca}^{2+}$ influx in untransfected HEK-293 cell. (A) Confocal imaging of untransfected HEK-293 cells in response to application of $1 \mathrm{~g}(10 \mu \mathrm{M})$ in the dark or with $365 \mathrm{~nm}$ UV light or AITC (300 $\mu \mathrm{M}$, TRPA1 agonist) or ionomycin $\left(10 \mu \mathrm{M}, \mathrm{Ca}^{2+}\right.$ salt). (B) Confocal imaging of untransfected HEK-293 cells in response to application of $2 \mathbf{c}(10 \mu \mathrm{M})$ in the dark or with $365 \mathrm{~nm}$ UV light or AITC (300 $\mu \mathrm{M}$, TRPA1 agonist) or ionomycin $\left(10 \mu \mathrm{M}, \mathrm{Ca}^{2+}\right.$ salt). Scale bar: $100 \mu \mathrm{m}$. 
A
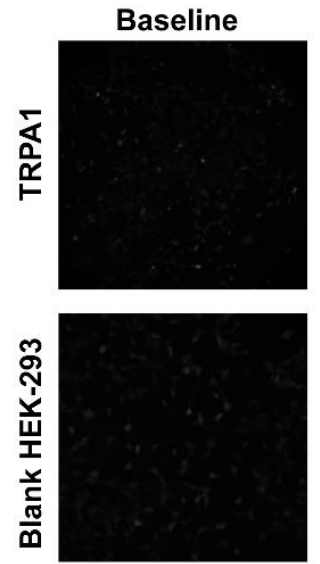

B
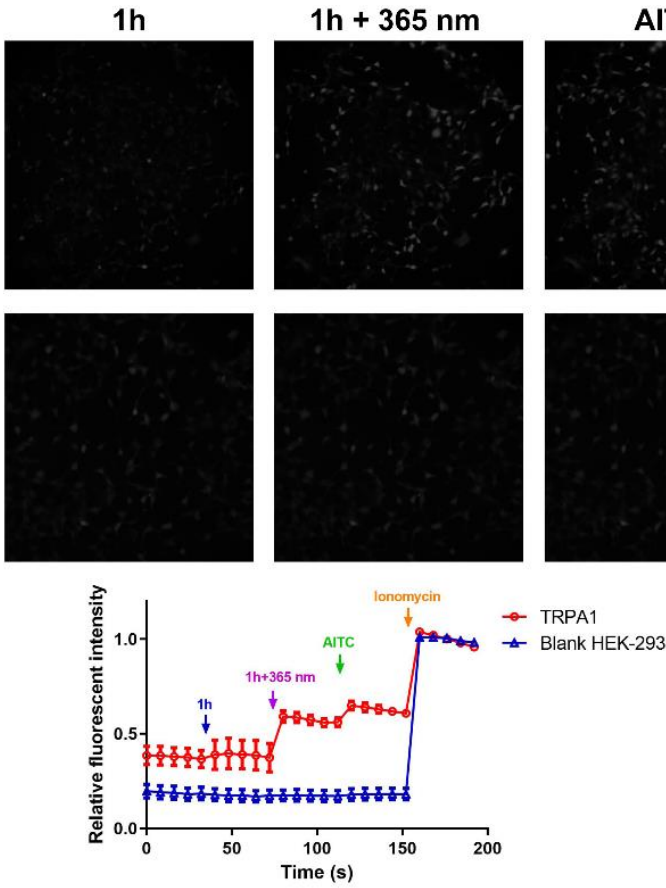

Figure S11. 1h induced $\mathrm{Ca}^{2+}$ influx in TRPA1-expressing HEK-293 cells. (A) Confocal imaging of TRPA1 expressed HEK-293 cells (top panels) and untransfected HEK-293 cells (bottom panels) in response to application of $\mathbf{1 h}(10 \mu \mathrm{M})$ in the dark or with $365 \mathrm{~nm}$ UV light or AITC (300 $\mu \mathrm{M}$, TRPA1 agonist) or ionomycin $\left(10 \mu \mathrm{M}, \mathrm{Ca}^{2+}\right.$ salt). (B) Relative fluorescent intensity of Fluo-8 induced by $\mathbf{1 h}$ in the dark (blue arrow), $365 \mathrm{~nm}$ illumination (purple arrow), AITC (green arrow) and ionomycin (orange arrow) in TRPA1-expressing HEK-293 cells (red circle) and untransfected cells (blue triangle), red arrows in Figure S7A. Fluorescent intensity was normalized with the maximal value of ionomycin $(10 \mu \mathrm{M})$. Scale bar: $100 \mu \mathrm{m}$. 
A
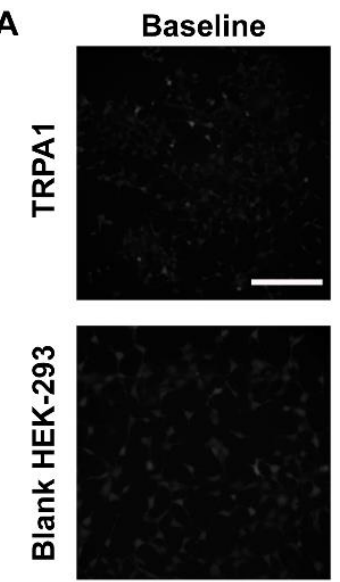

B
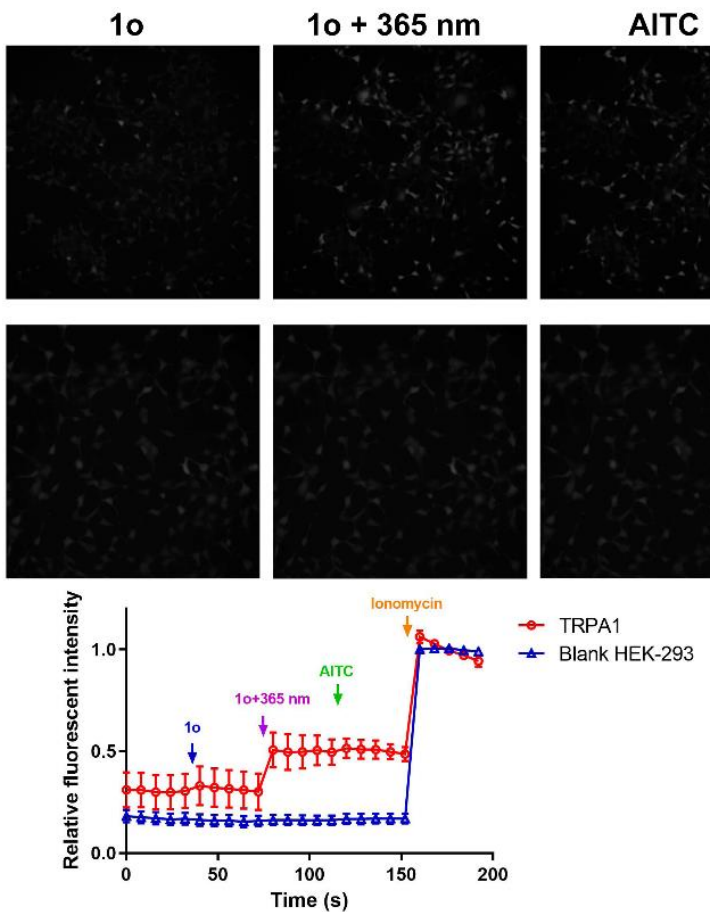

Figure S12. 10 induced $\mathrm{Ca}^{2+}$ influx in TRPA1-expressing HEK-293 cells. (A) Confocal imaging of hTRPA1 expressed HEK-293 cells (top panels) and untransfected HEK-293 cells (bottom panels) in response to application of $10(10 \mu \mathrm{M})$ in the dark or with $365 \mathrm{~nm}$ UV light or AITC $(300 \mu \mathrm{M}$, TRPA1 agonist) or ionomycin $\left(10 \mu \mathrm{M}, \mathrm{Ca}^{2+}\right.$ salt). (B) Relative fluorescent intensity of Fluo- 8 induced by 10 in the dark (blue arrow), $365 \mathrm{~nm}$ illumination (purple arrow), AITC (green arrow) and ionomycin (orange arrow) in TRPA1-expressing HEK-293 cells (red circle) and untransfected cells (blue triangle), red arrows in Figure S8A. Fluorescent intensity was normalized with the maximal value of ionomycin $(10 \mu \mathrm{M})$. Scale bar: $100 \mu \mathrm{m}$. 

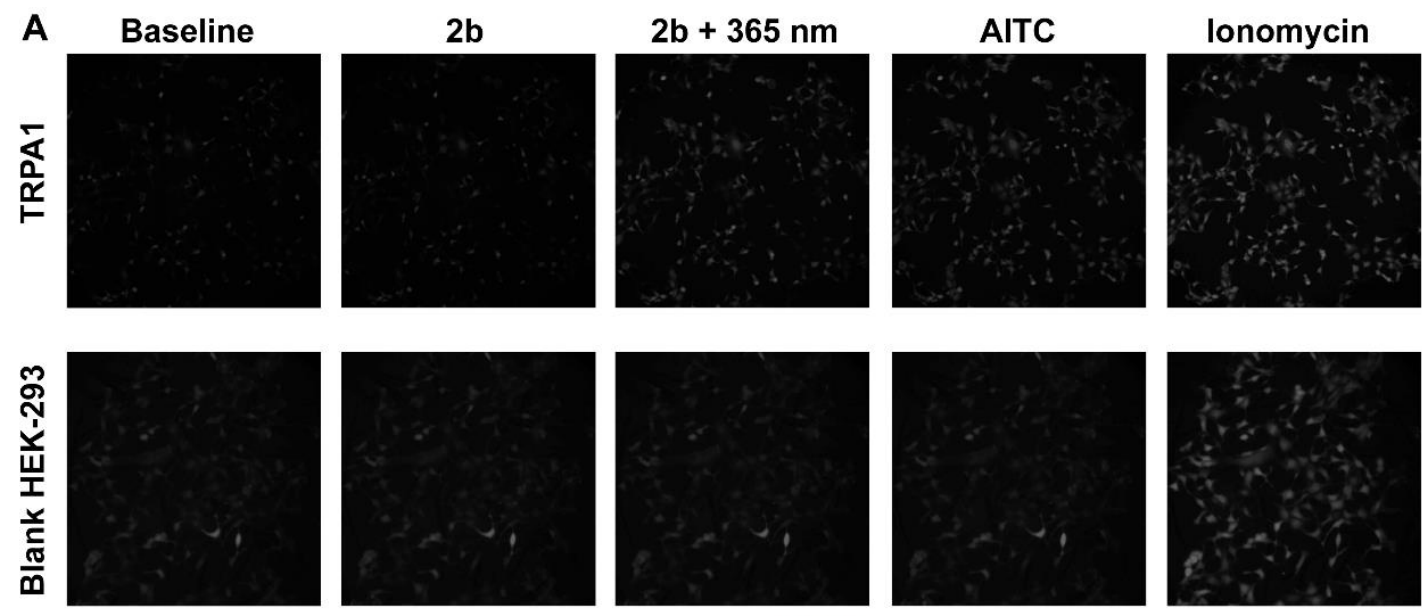

B
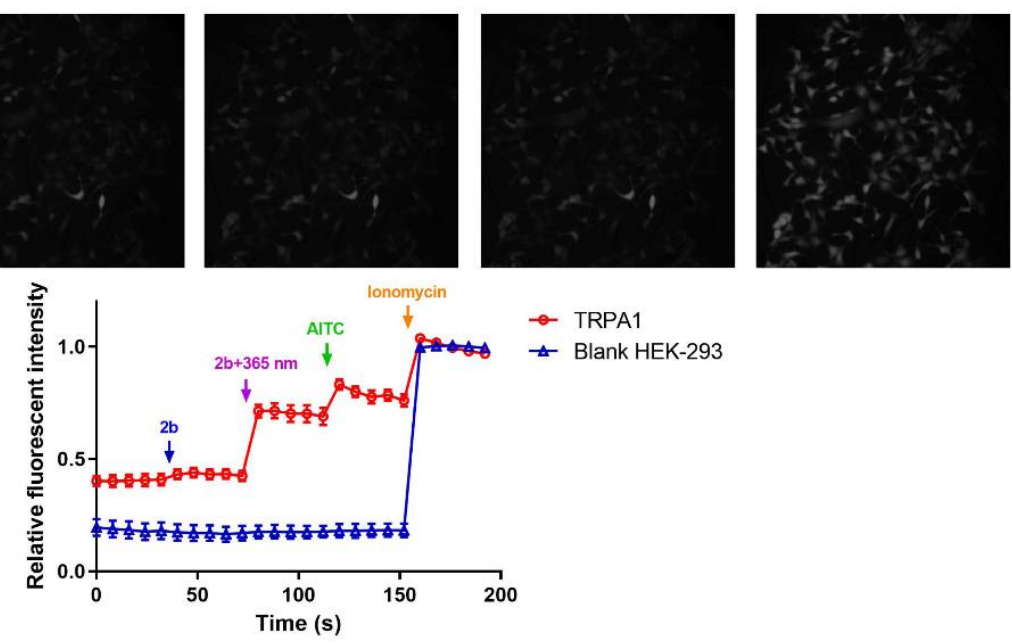

Figure S13. 2b induced $\mathrm{Ca}^{2+}$ influx in TRPA1-expressing HEK-293 cells. (A) Confocal imaging of hTRPA1 expressed HEK-293 cells (top panels) and untransfected HEK-293 cells (bottom panels) in response to application of $\mathbf{2 b}(10 \mu \mathrm{M})$ in the dark or with $365 \mathrm{~nm}$ UV light or AITC $(300 \mu \mathrm{M}$, TRPA1 agonist) or ionomycin $\left(10 \mu \mathrm{M}, \mathrm{Ca}^{2+}\right.$ salt). (B) Relative fluorescent intensity of Fluo- 8 induced by $\mathbf{2 b}$ in the dark (blue arrow), $365 \mathrm{~nm}$ illumination (purple arrow), AITC (green arrow) and ionomycin (orange arrow) in TRPA1-expressing HEK-293 cells (red circle) and untransfected cells (blue triangle), red arrows in Figure S9A. Fluorescent intensity was normalized with the maximal value of ionomycin $(10 \mu \mathrm{M})$. Scale bar: $100 \mu \mathrm{m}$. 
A

$1 \mathrm{~h}$

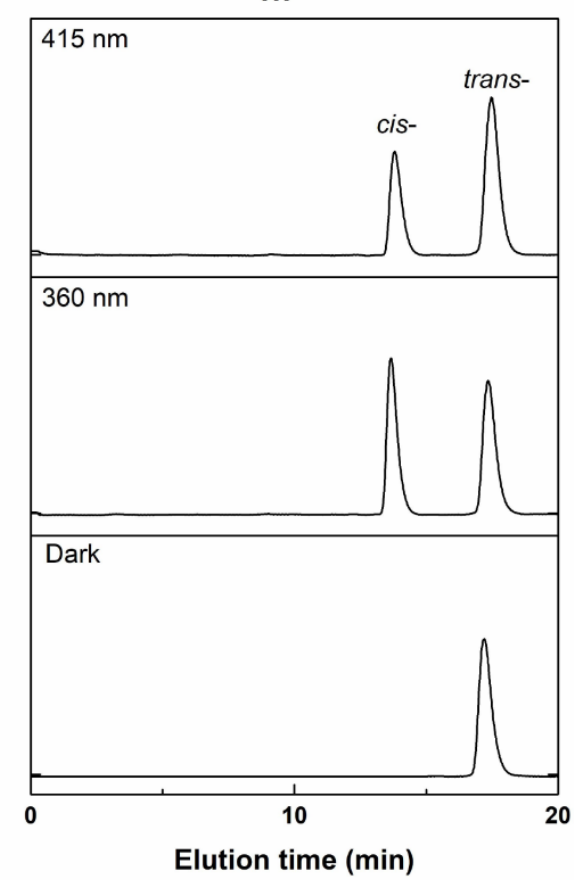

C

$2 b$

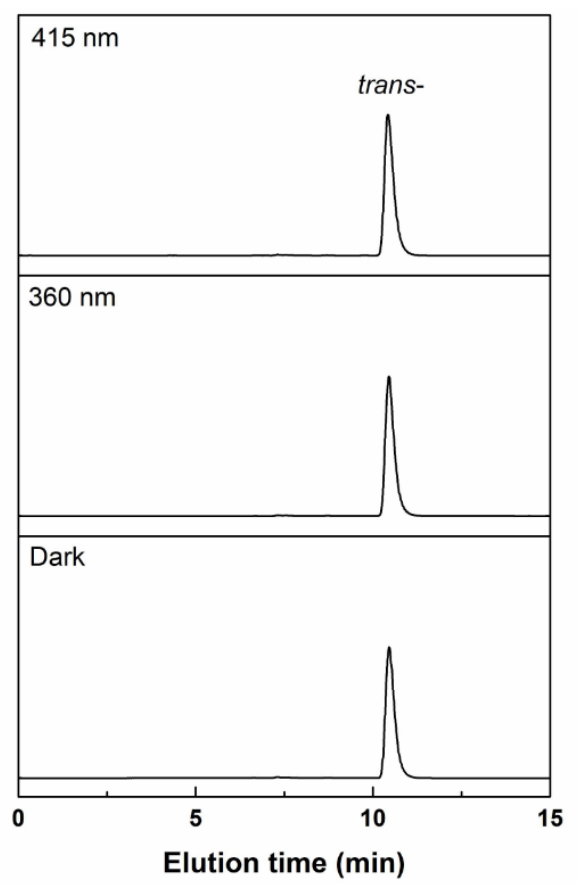

B

10

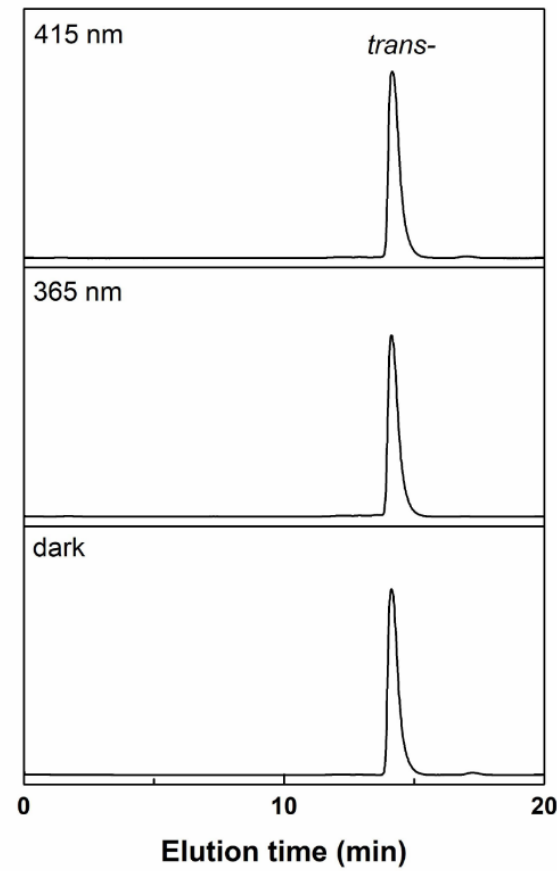

D

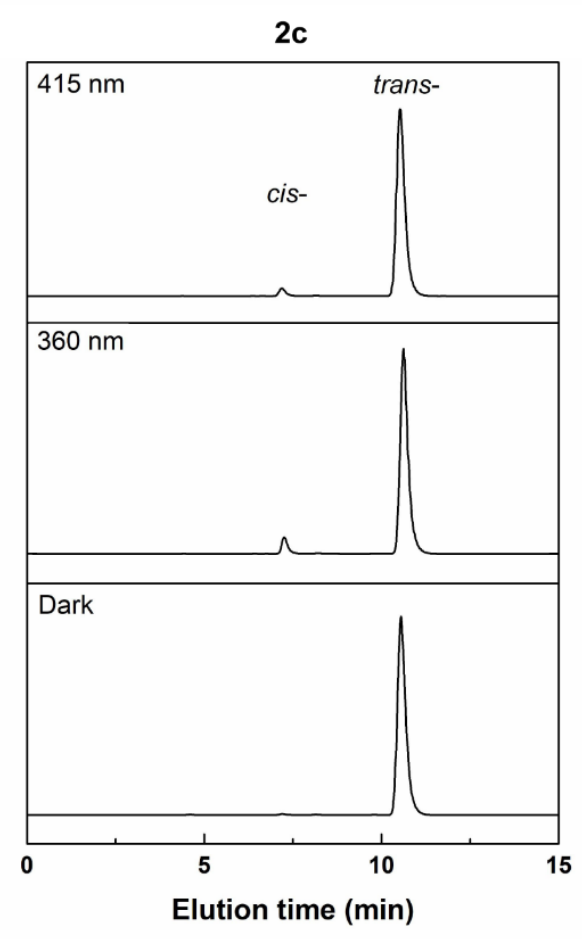

Figure S14. Liquid chromatogram of $\mathbf{1 h}, \mathbf{1 0}, \mathbf{2 b}$ and $2 \mathbf{c}(50 \mu \mathrm{M})$ under irradiation with $365 \mathrm{~nm}$ or $415 \mathrm{~nm}$. (A) HPLC chromatograms of $\mathbf{1 h}$ with $365 \mathrm{~nm}$ or $415 \mathrm{~nm}$ radiation $\left(85 \% \mathrm{MeOH} / \mathrm{H}_{2} \mathrm{O}\right.$, at 1 $\mathrm{mL} \mathrm{m^{-1 }}$ flow rate). (B) HPLC chromatograms of 10 with $365 \mathrm{~nm}$ or $415 \mathrm{~nm}$ radiation (85\% $\mathrm{MeOH} / \mathrm{H}_{2} \mathrm{O}$, at $2 \mathrm{~mL} \mathrm{~min}^{-1}$ flow rate). (C) HPLC chromatograms of $2 \mathbf{b}$ with $365 \mathrm{~nm}$ or $415 \mathrm{~nm}$ radiation $\left(90 \% \mathrm{MeOH} / \mathrm{H}_{2} \mathrm{O}\right.$, at $2 \mathrm{~mL} \mathrm{~min}^{-1}$ flow rate). (D) HPLC chromatograms of $2 \mathbf{c}$ with $365 \mathrm{~nm}$ or $415 \mathrm{~nm}$ radiation $\left(90 \% \mathrm{MeOH} / \mathrm{H}_{2} \mathrm{O}\right.$, at $2 \mathrm{~mL} \mathrm{~min}^{-1}$ flow rate) 
A

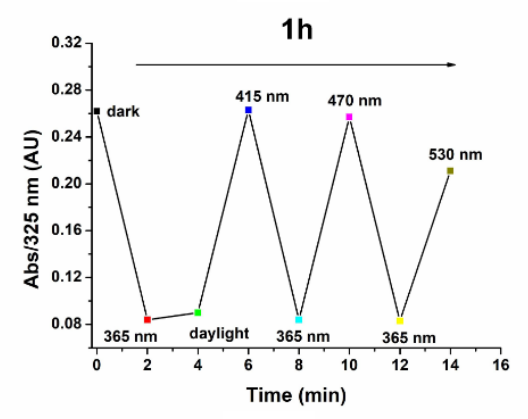

C

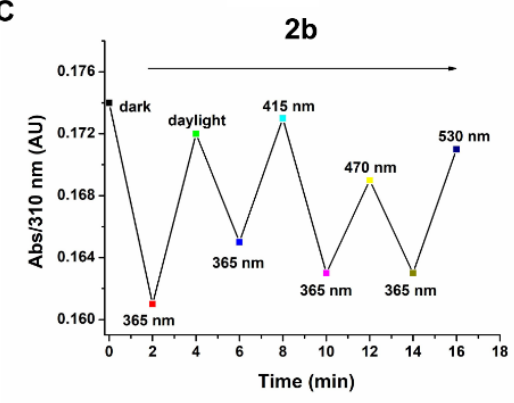

B

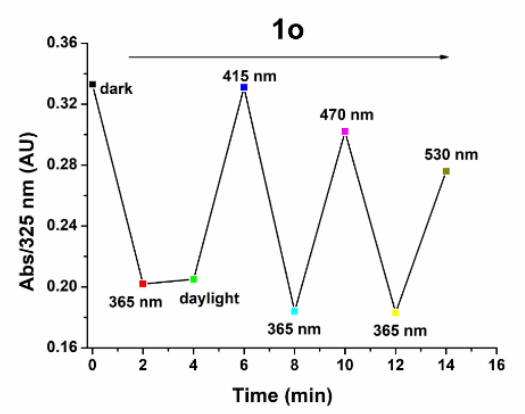

D

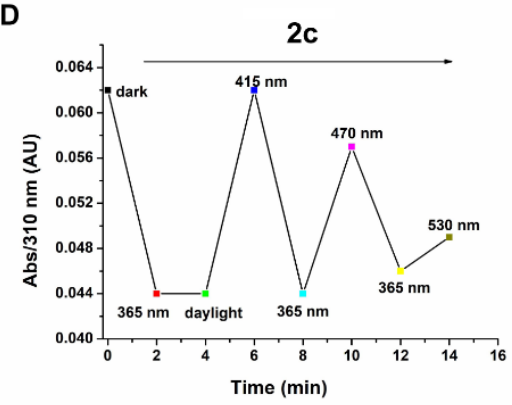

Figure S15. Reversible photoisomerism of $\mathbf{1 h}, \mathbf{1 0}, \mathbf{2 b}$ and $\mathbf{2 c}(50 \mu \mathrm{M})$ after illumination with 365 $\mathrm{nm}, 415 \mathrm{~nm}, 470 \mathrm{~nm}, 530 \mathrm{~nm}$, and daylight in $\mathrm{Ca}^{2+}$-free external solution $(130 \mathrm{mM} \mathrm{NaCl}, 0.2 \mathrm{mM}$ EDTA, and 3 mM HEPES, pH 7.2-7.4). 


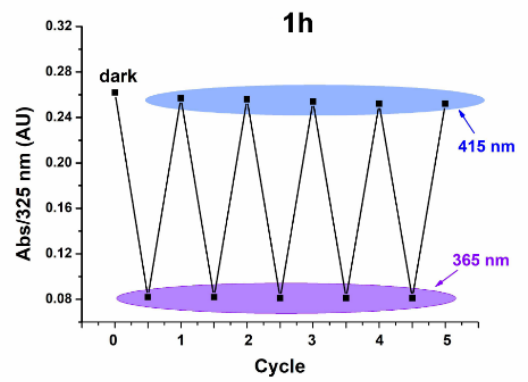

C

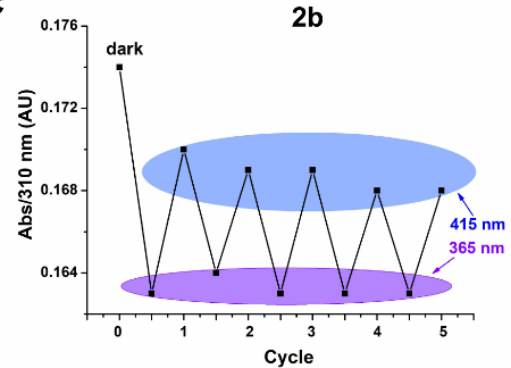

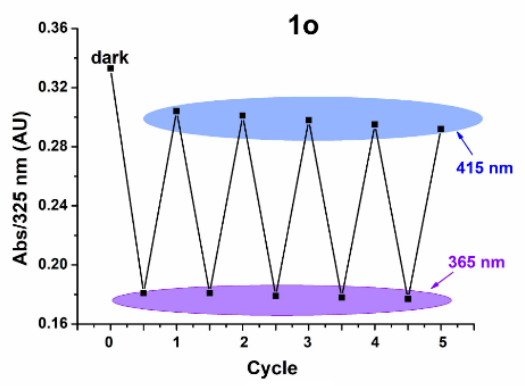

D

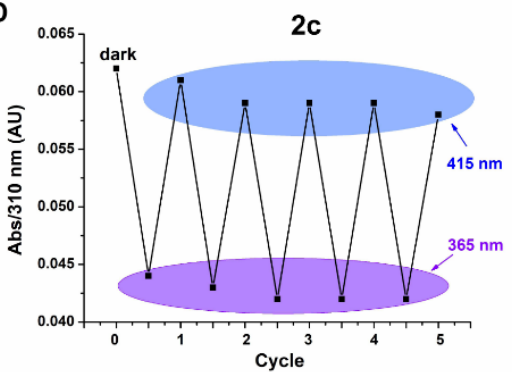

Figure S16. Isomerization cycles of $\mathbf{1 h}, \mathbf{1 0}, \mathbf{2 b}$ and $\mathbf{2 c}(50 \mu \mathrm{M})$ upon illumination with $365 \mathrm{~nm}$ and $415 \mathrm{~nm}$ light in $\mathrm{Ca}^{2+}$-free external solution $(130 \mathrm{mM} \mathrm{NaCl}, 0.2 \mathrm{mM}$ EDTA, and $3 \mathrm{mM}$ HEPES, $\mathrm{pH}$ 7.2-7.4). 

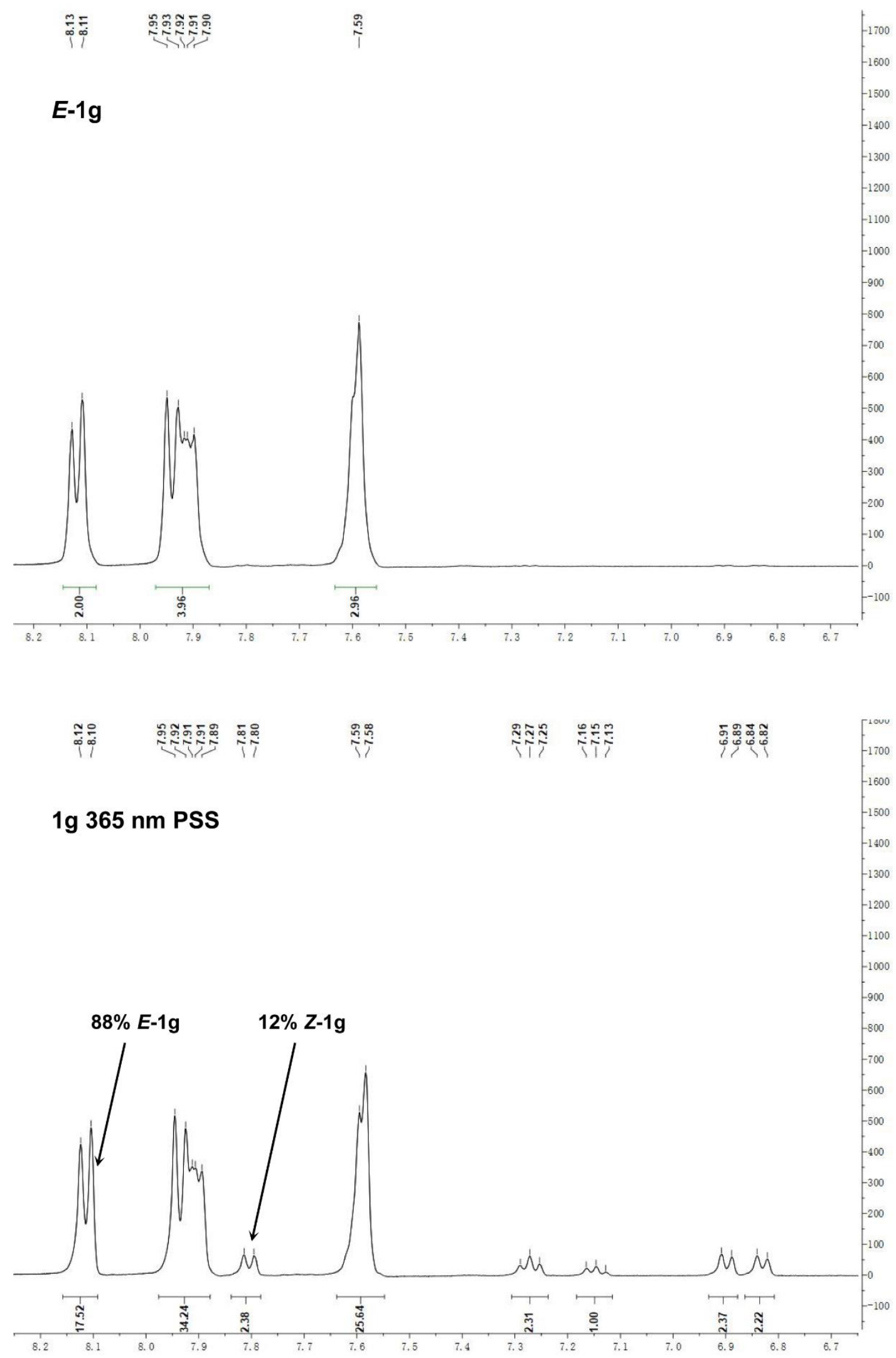


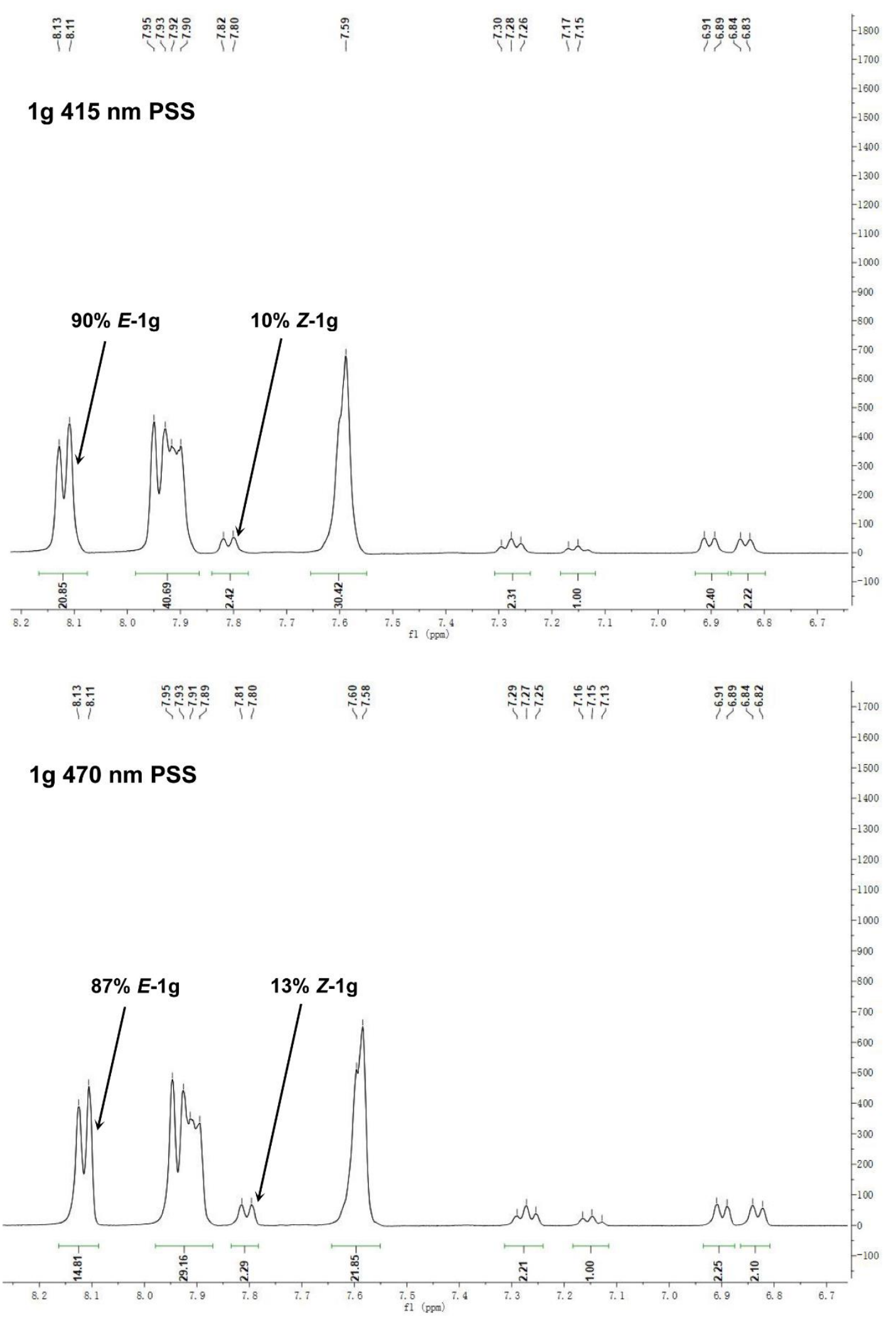




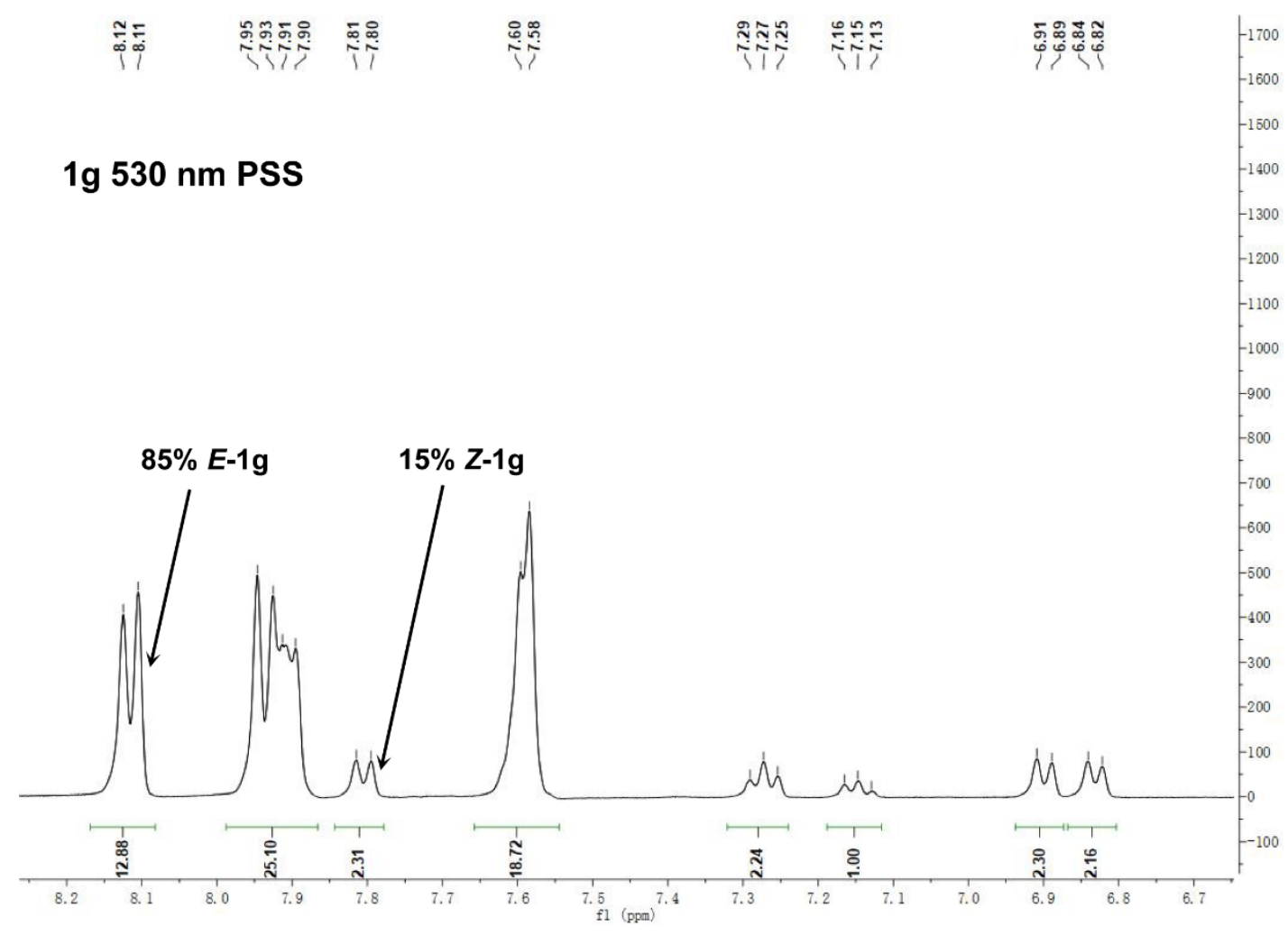

Figure S17. ${ }^{1} \mathrm{H}$ NMR of $\mathbf{1 g}$ at dark, 365, 415, 470, $530 \mathrm{~nm}$ PSS. 


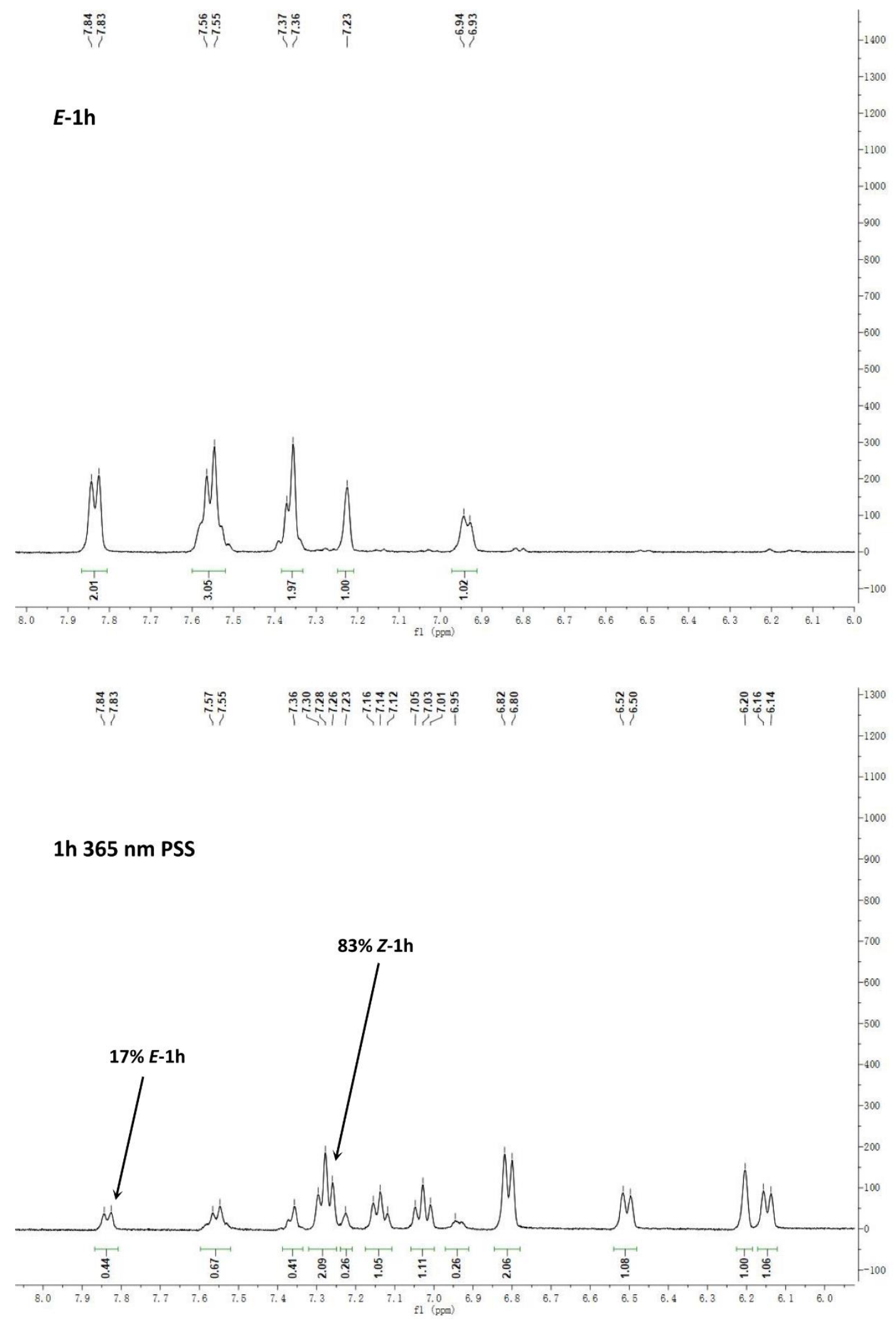




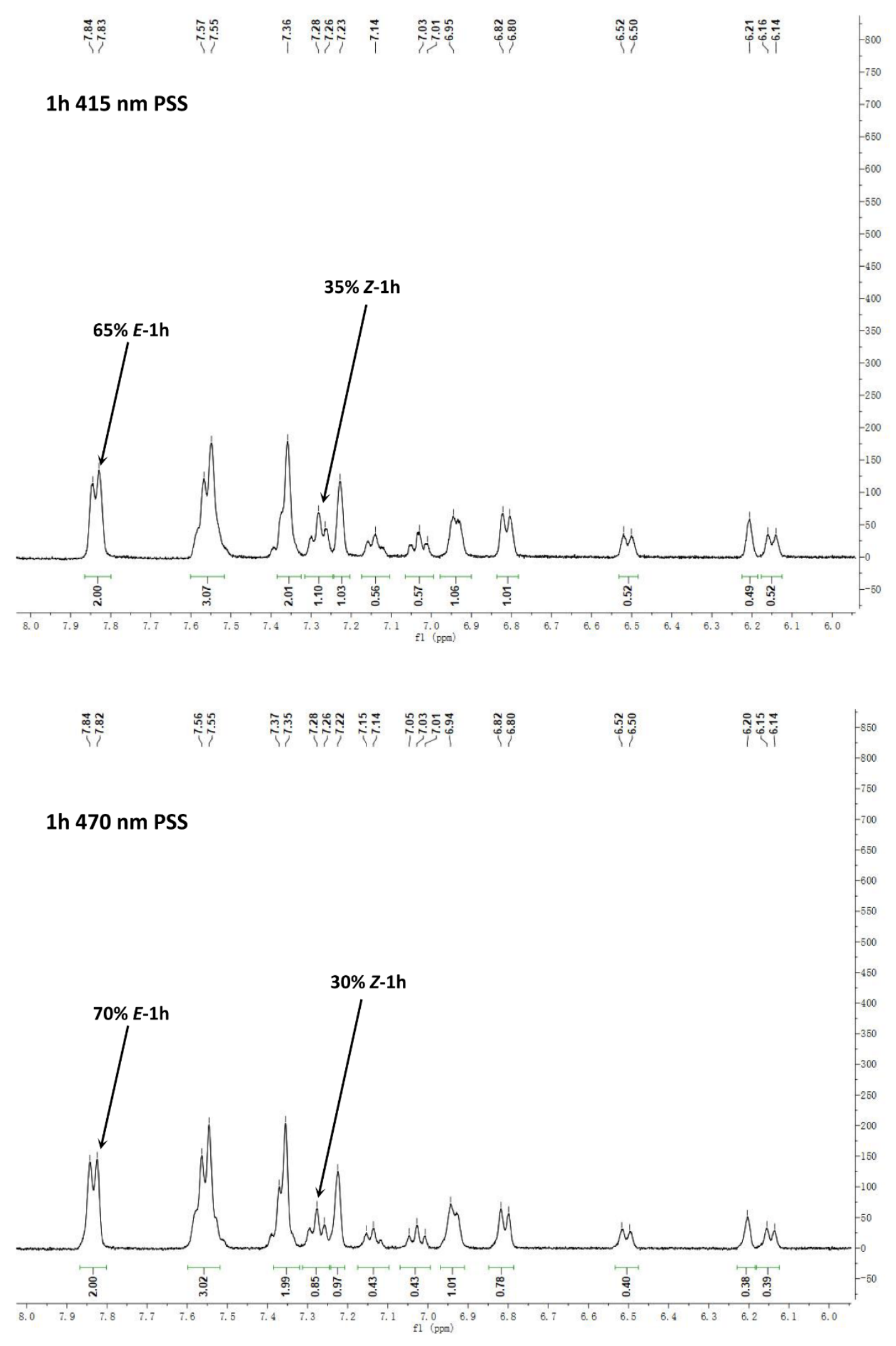




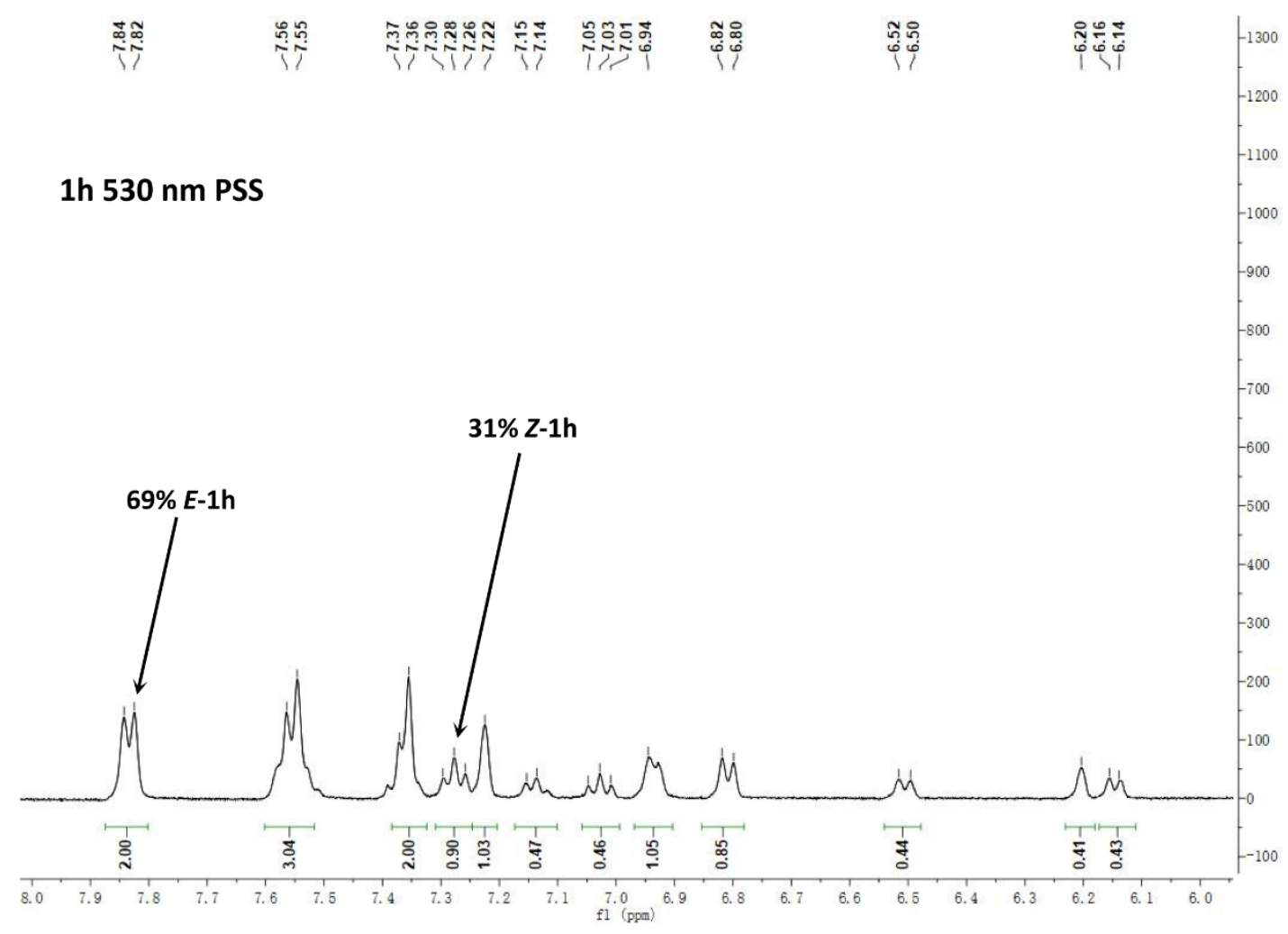

Figure S18. ${ }^{1} \mathrm{H}$ NMR of $\mathbf{1 h}$ at dark, 365, 415, 470, $530 \mathrm{~nm}$ PSS. 

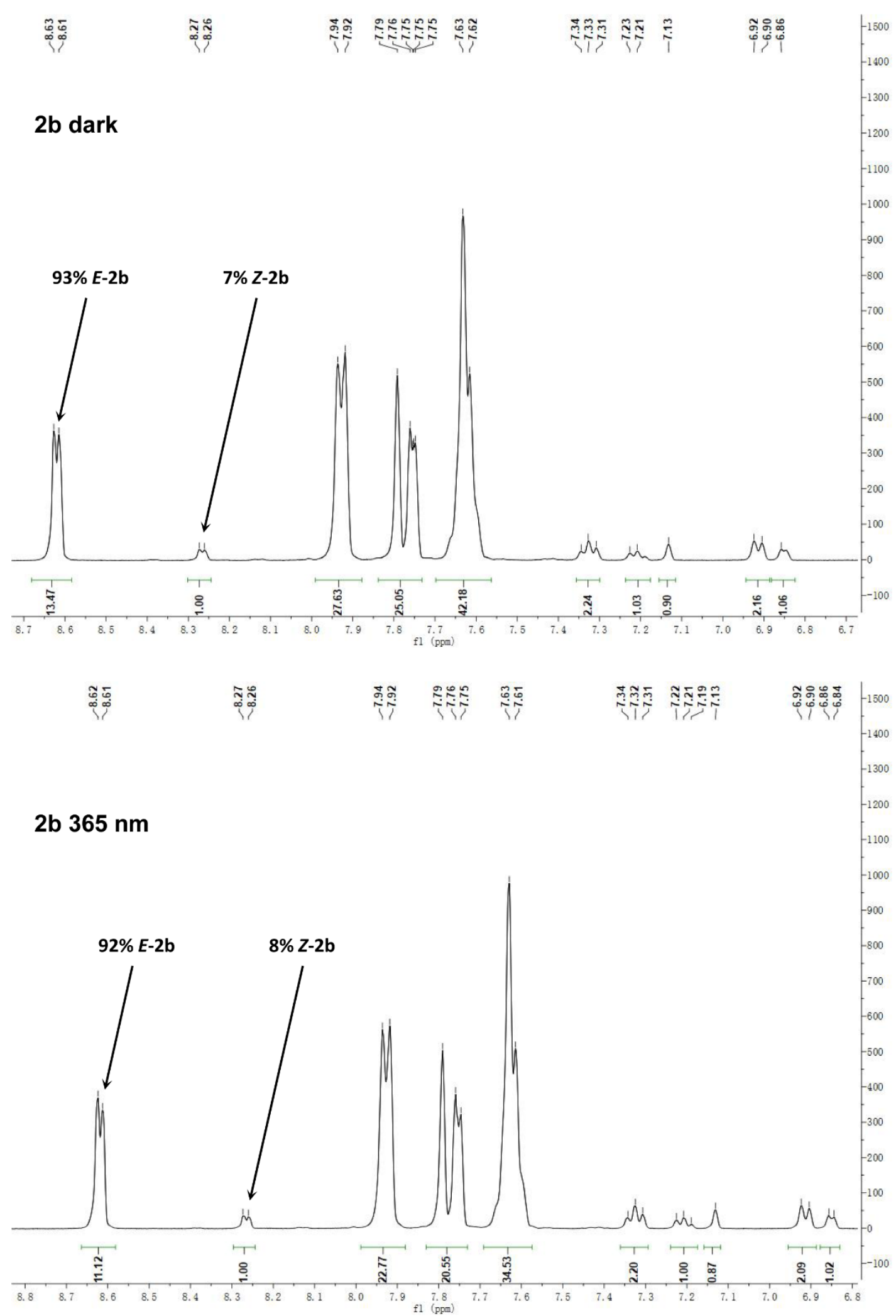


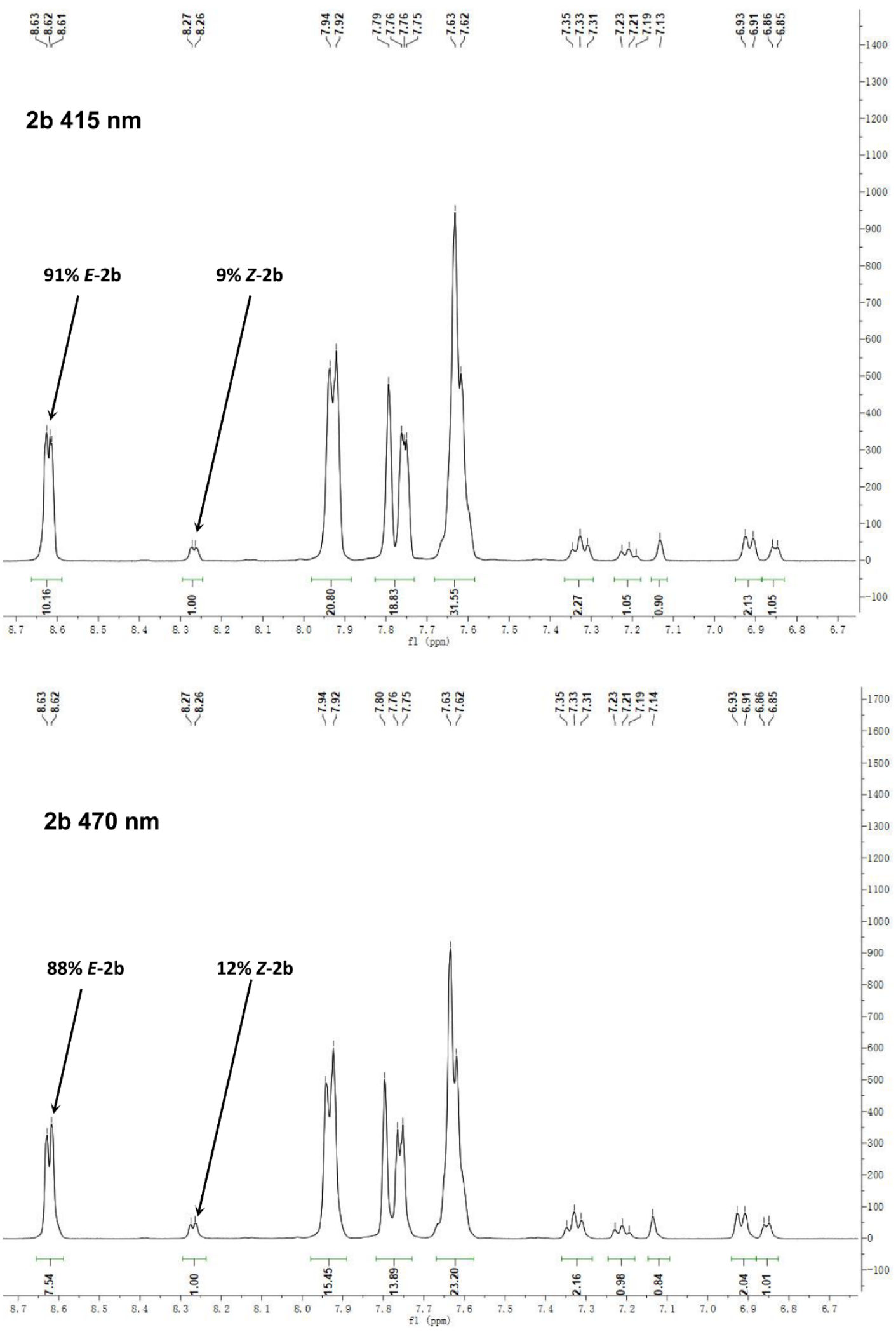




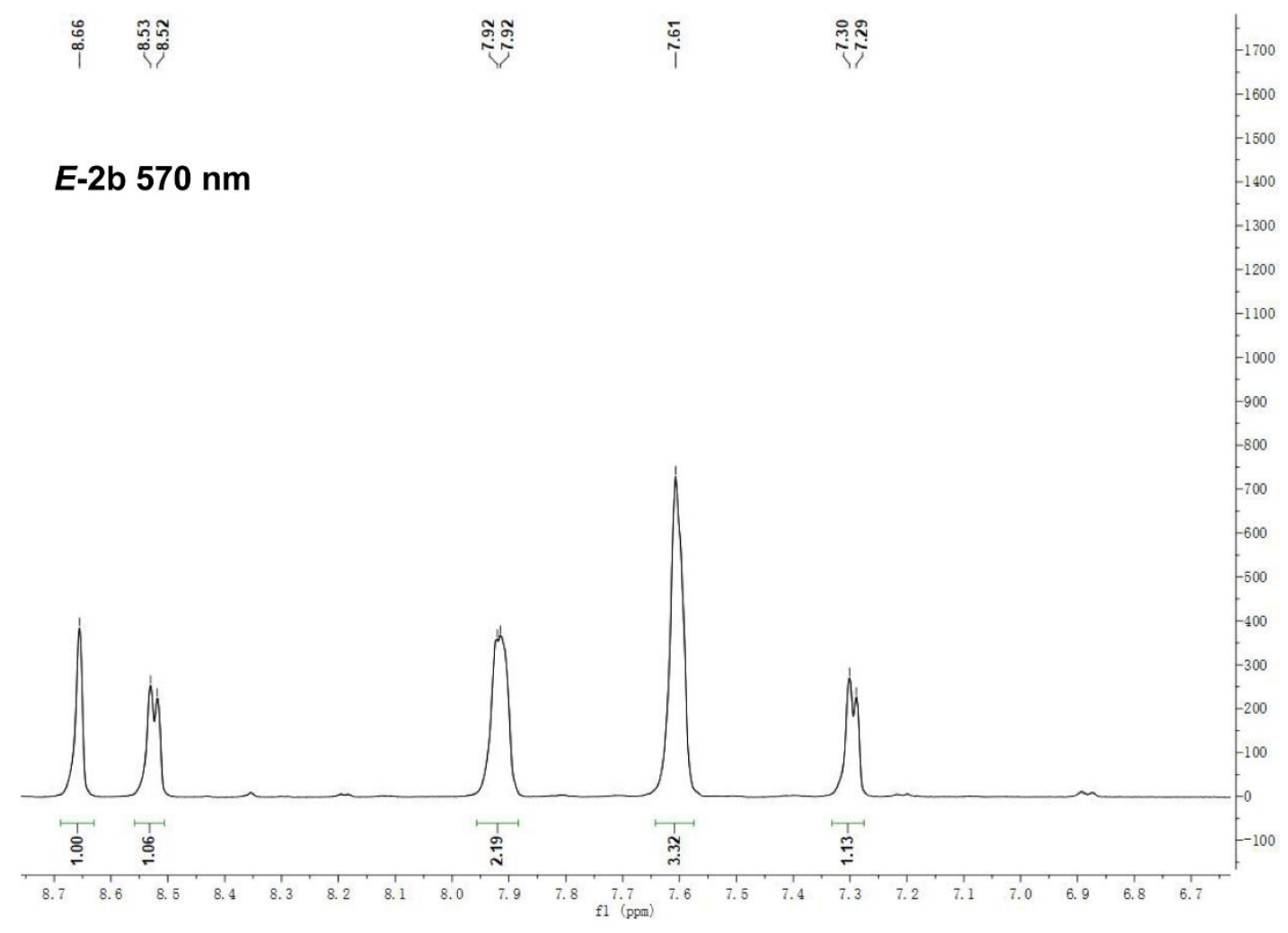

Figure S19. ${ }^{1} \mathrm{H}$ NMR of $\mathbf{2 b}$ at dark, 365, 415, 470, $530 \mathrm{~nm}$ PSS. 

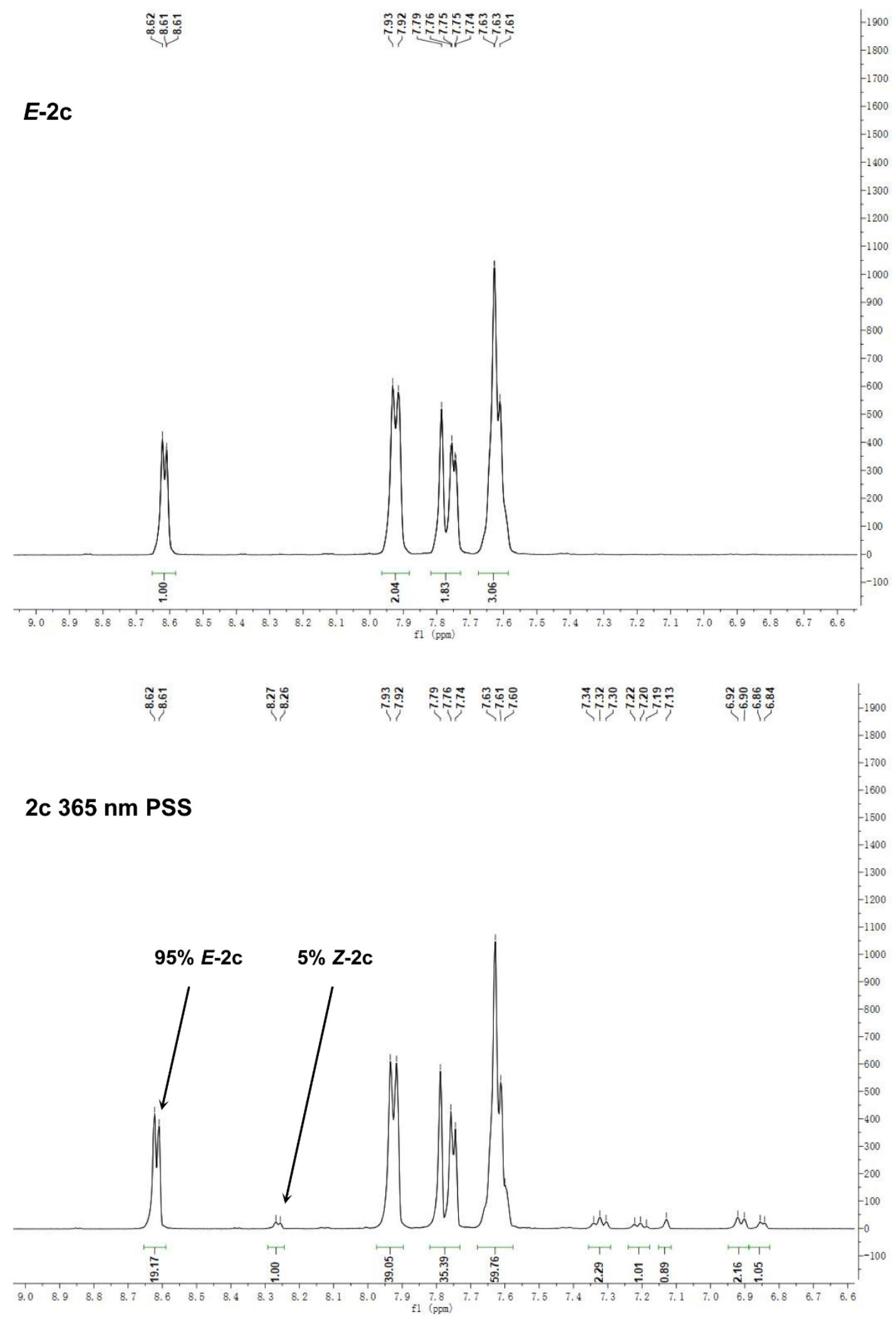

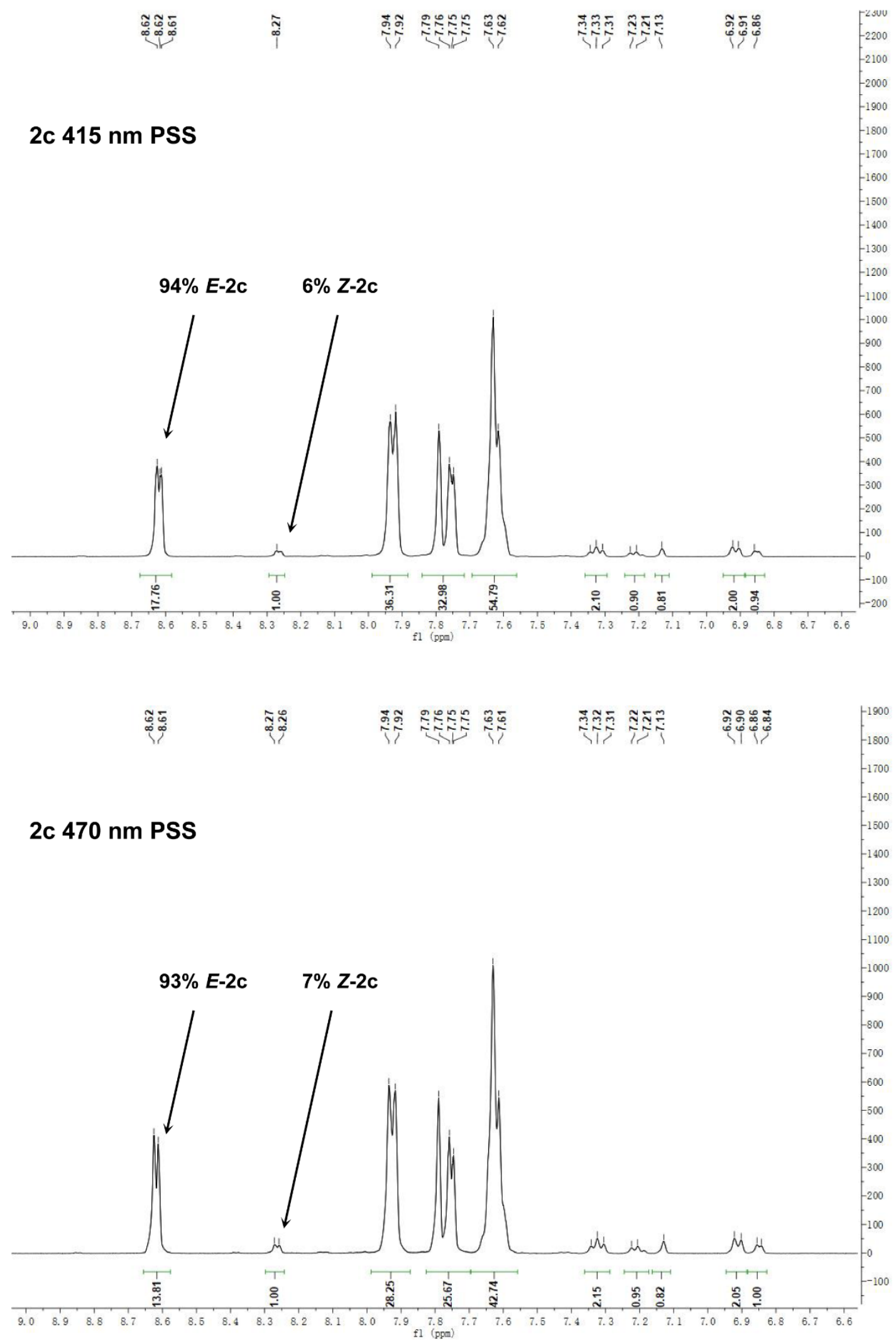


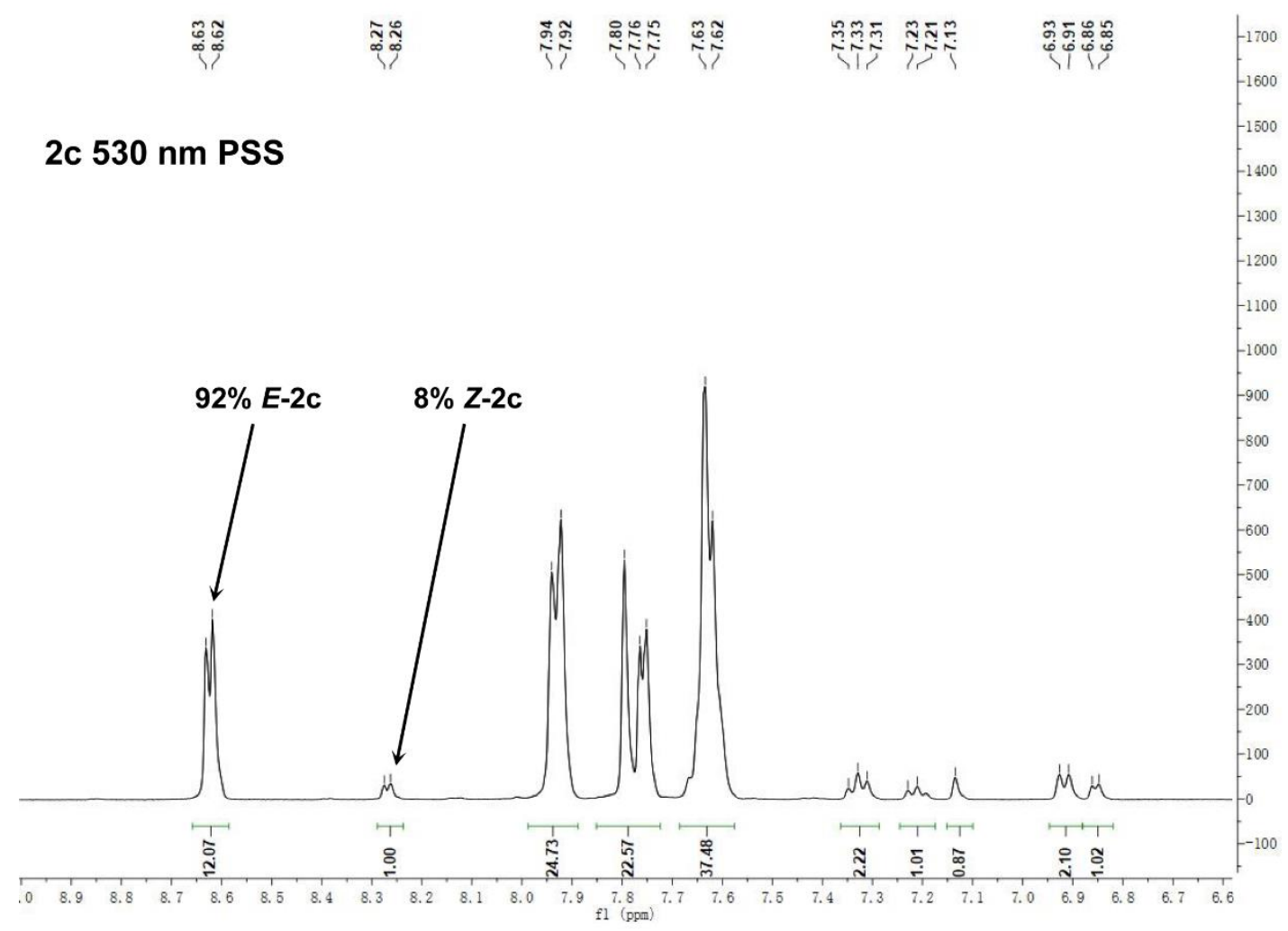

Figure S20. ${ }^{1} \mathrm{H}$ NMR of $\mathbf{2 c}$ at dark, 365, 415, 470, $530 \mathrm{~nm}$ PSS. 


\section{Cheek model test without $365 \mathrm{~nm}$ light}

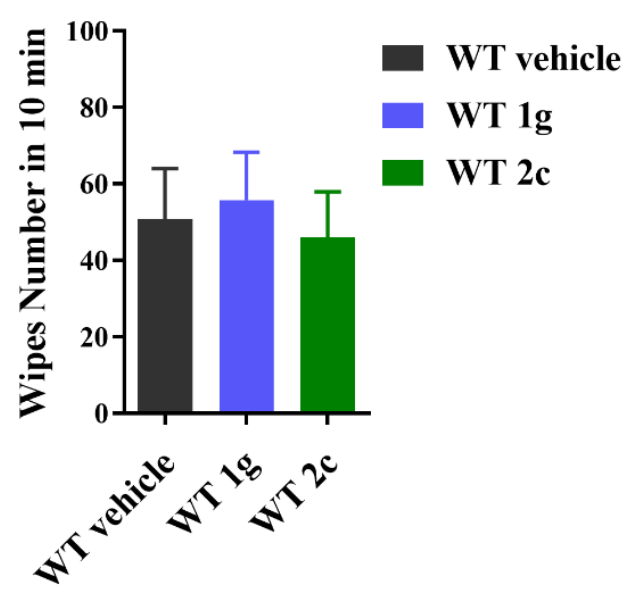

Figure S21. Cheek model test of $\mathbf{1 g}$ and $\mathbf{2 c}$ without $365 \mathrm{~nm}$ light in mice. Topical application of 1 $\mathrm{mM} 1 \mathrm{~g}$ and $\mathbf{2 c}$ had no significant effect on capsaicin-induced wiping in mice without the irradiation at $365 \mathrm{~nm}$ light. 


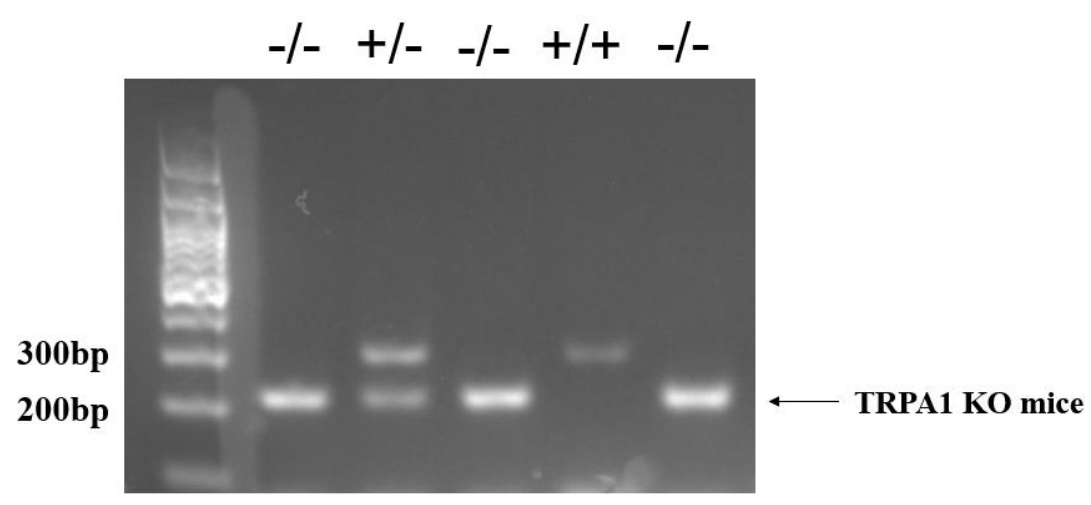

Figure S22. Genotyping of TRPA1 (+/+), TRPA1(+/-) and TRPA1(-/-) mice by PCR. 
A

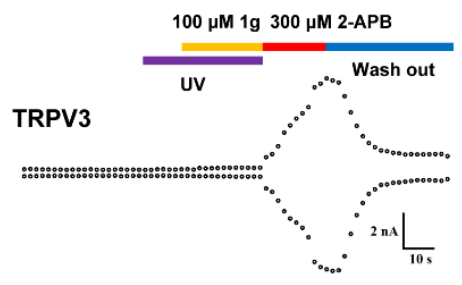

C

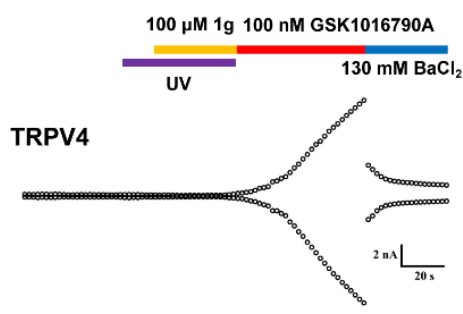

B

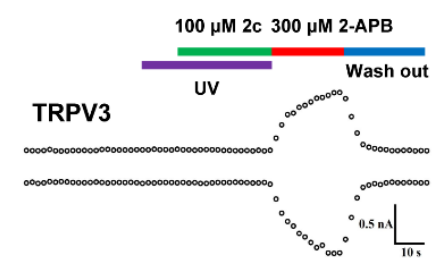

D

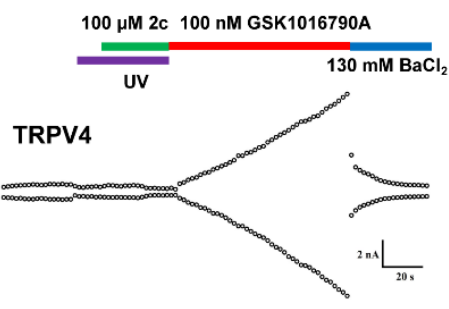

Figure S23. Selective activation of TRPA1 by $1 \mathrm{~g}$ and $\mathbf{2 c}$ upon illumination with UV light over other members of TRP channel family. (A and B) $100 \mu \mathrm{M} \mathbf{~ g}$ and $\mathbf{2 c}$ have no obvious activation effect on TRPV3 channels overexpressed in CHO cells after irradiation with UV light. (C and D) $100 \mu \mathrm{M} 1 \mathrm{~g}$ and $\mathbf{2 c}$ have no obvious activation effect on TRPV4 channels overexpressed in CHO cells after irradiation with UV light. 2-APB, a selective TRPV3 agonist, and GSK1016790A, a selective TRPV4 agonist and $\mathrm{BaCl}_{2}$, a TRPV4 blocker. 
A

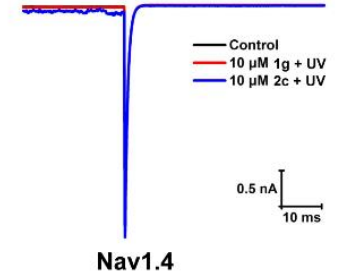

C

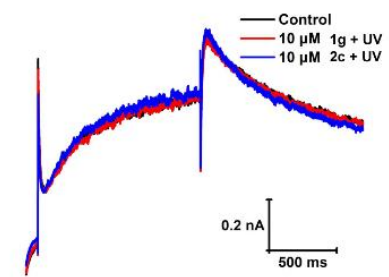

Kv11.1
B

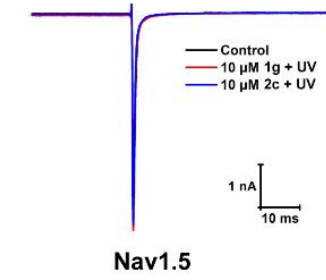

Figure S24. Selectivity evaluation for $1 \mathrm{~g}$ and $\mathbf{2 c}$ over voltage-gate sodium and potassium ion channels. (A, B, C) $1 \mathrm{~g}$ and $\mathbf{2 c}$ have no activation effects on Voltage-gated Nav1.4 (A) and Nav1.5 (B), and Kv11.1 (C) channels stably expressed in CHO cells after illumination with UV light. 


\section{Supplementary Movies}

Supplementary Movie 1. Movie of WT mouse in capsaicin-induced pain model without treated with compounds upon irradiation at $365 \mathrm{~nm}$ light.

Supplementary Movie 2. Movie of WT mouse in capsaicin-induced pain model treated with $\mathbf{2 b}$ (1 $\mathrm{mM}, 20 \mu \mathrm{L}$ ) upon irradiation at $365 \mathrm{~nm}$ light.

Supplementary Movie 3. Movie of WT mouse in capsaicin-induced pain model treated with $\mathbf{2 b}$ (1 $\mathrm{mM}, 20 \mu \mathrm{L}$ ) without $365 \mathrm{~nm}$ light. 


\section{NMR Spectra}

${ }^{1} \mathrm{H}$ NMR spectrum of $1 \mathrm{~g}$

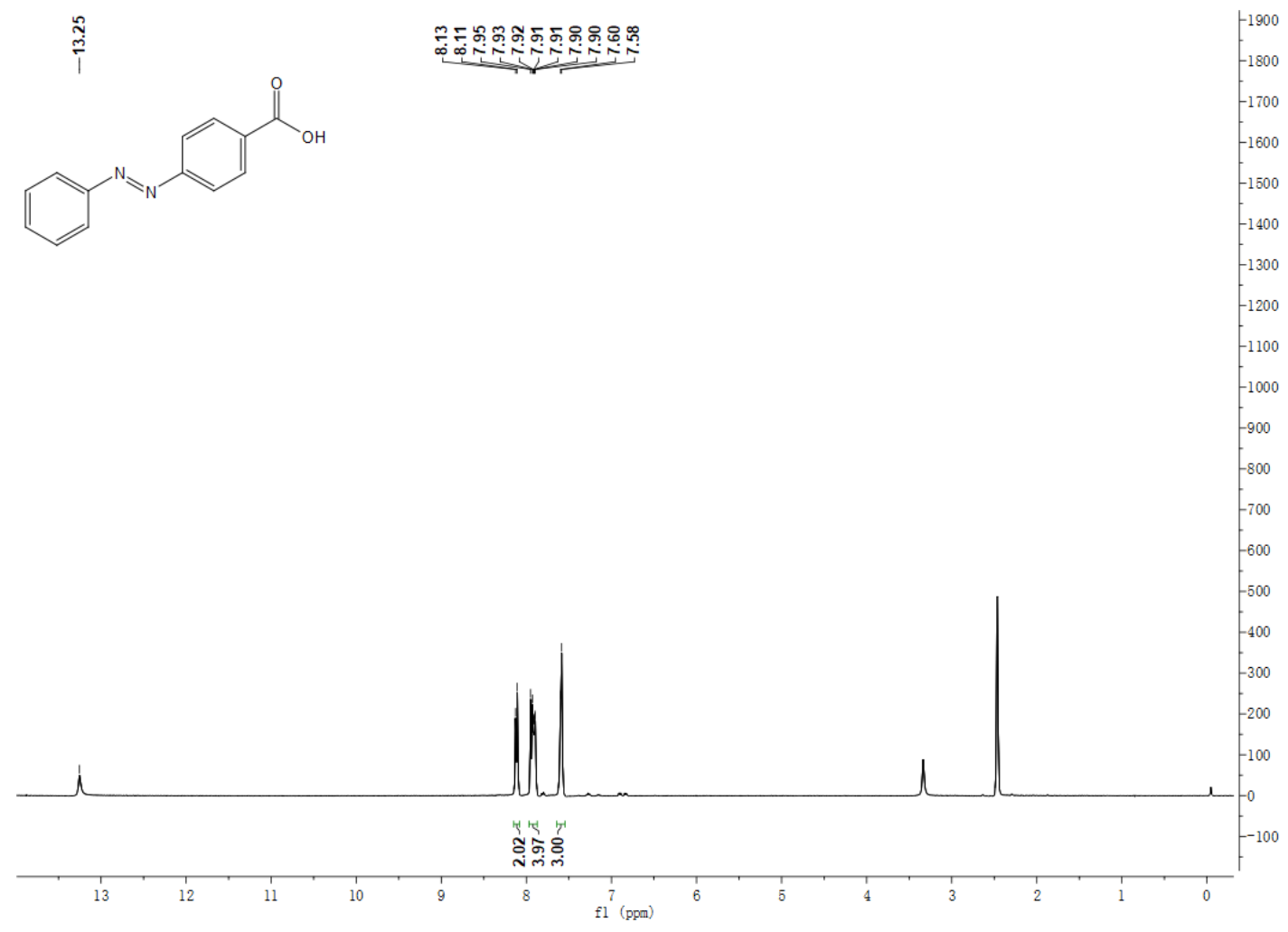

${ }^{13} \mathrm{C}$ NMR spectrum of $1 \mathrm{~g}$

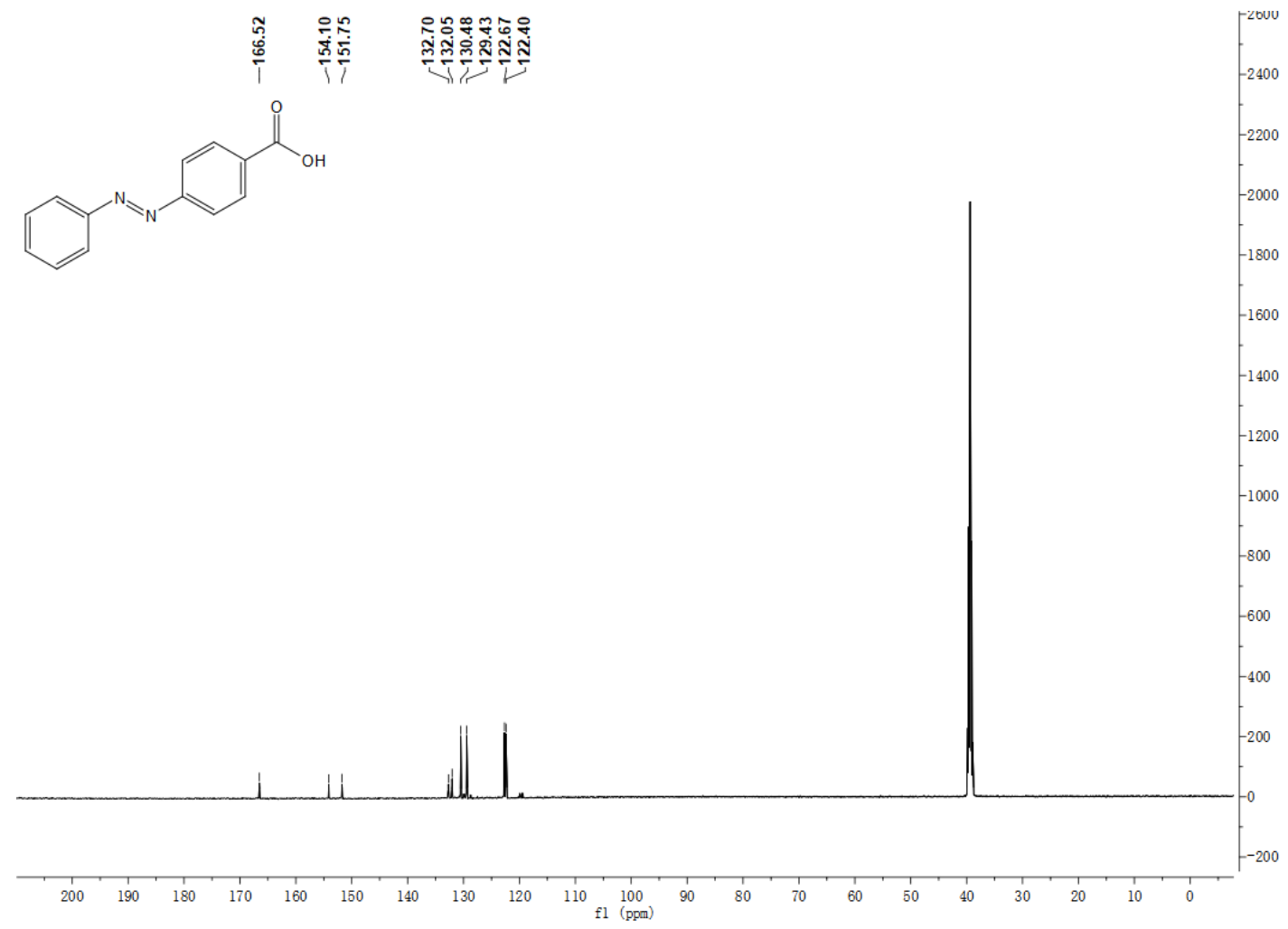


HRMS spectra of $1 \mathrm{~g}$

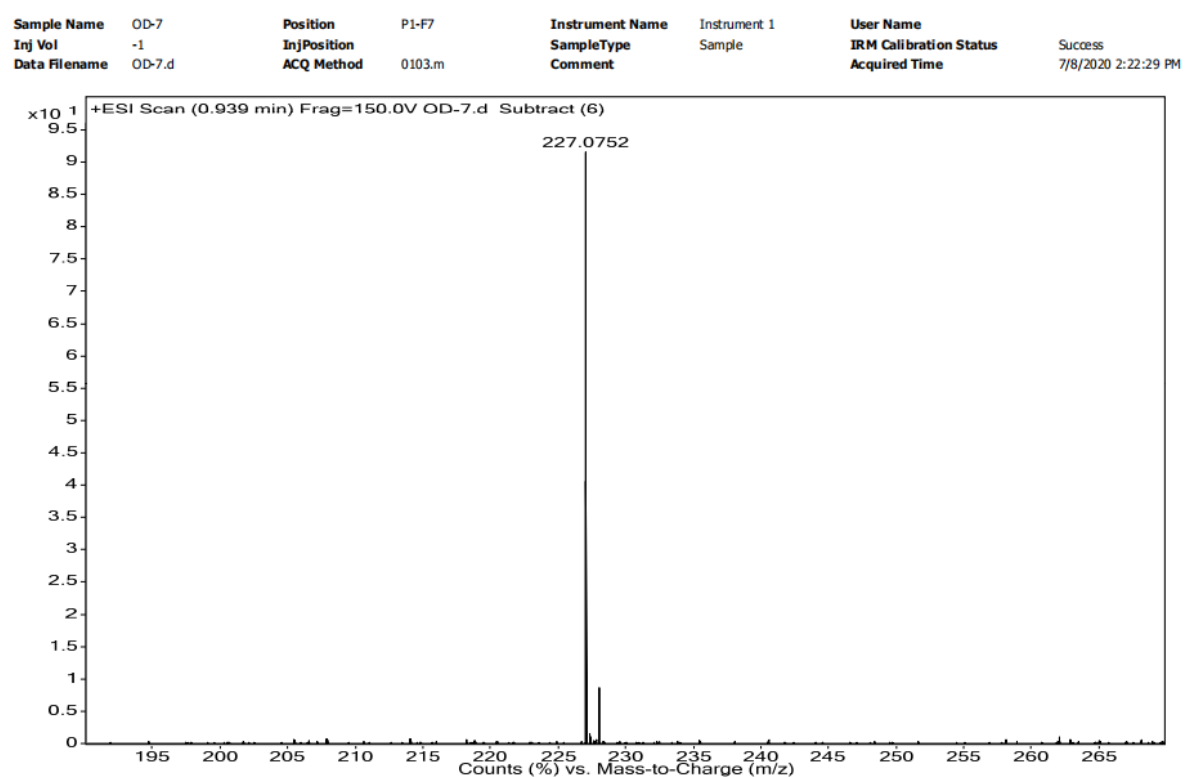

${ }^{1} \mathrm{H}$ NMR spectrum of $1 \mathrm{~h}$

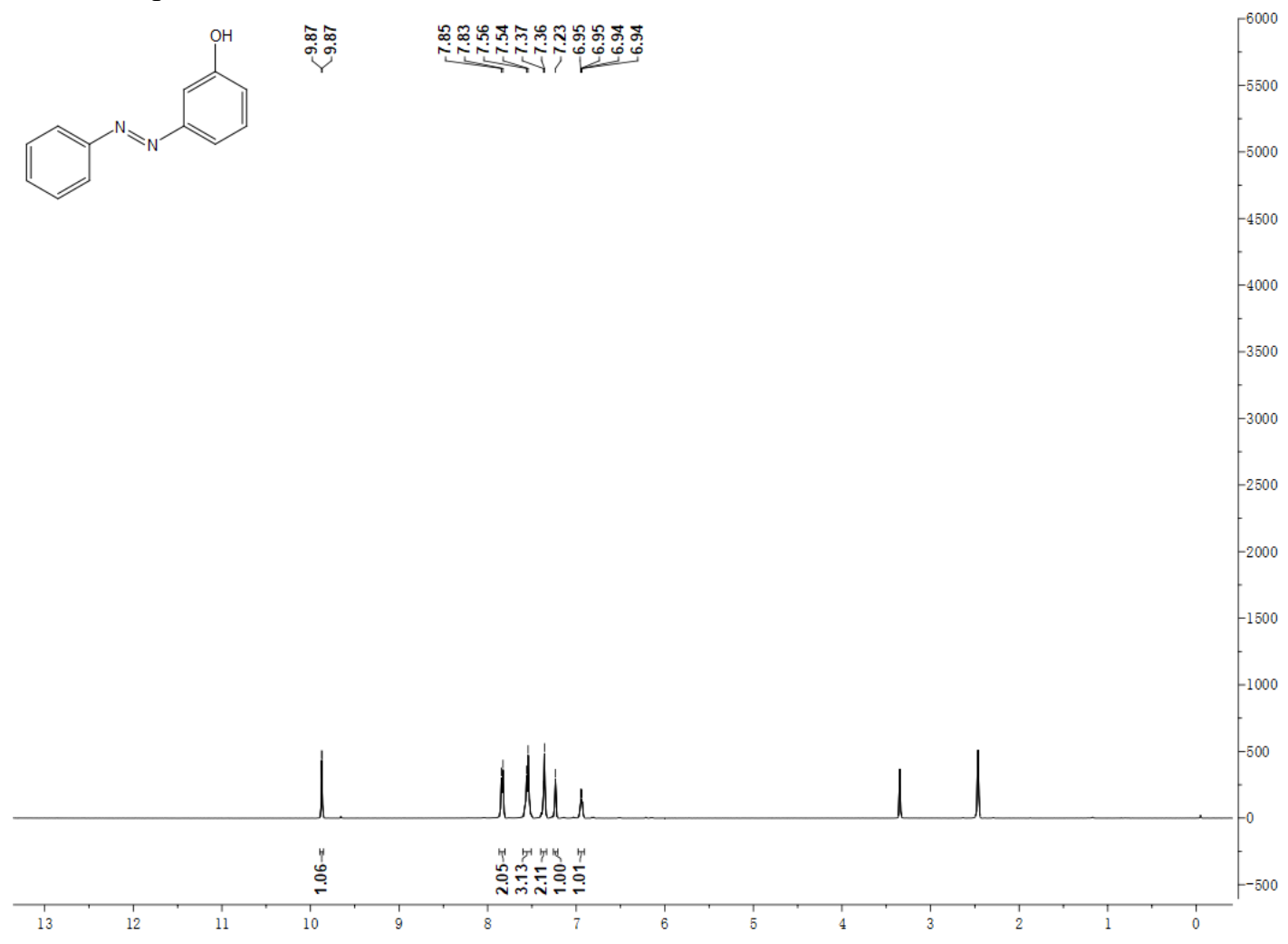


${ }^{13} \mathrm{C}$ NMR spectrum of $1 \mathrm{~h}$

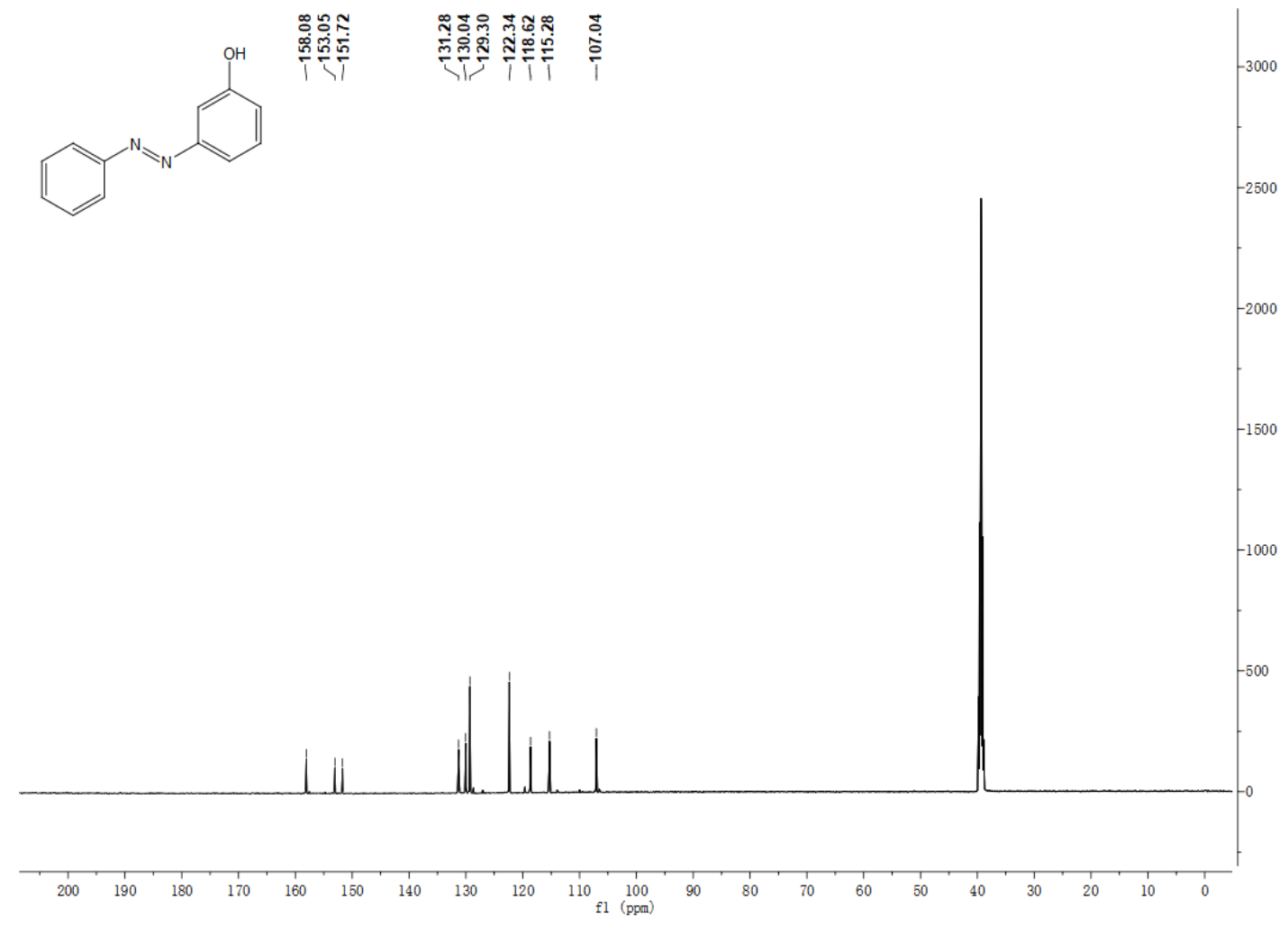

HRMS spectra of $1 \mathrm{~h}$

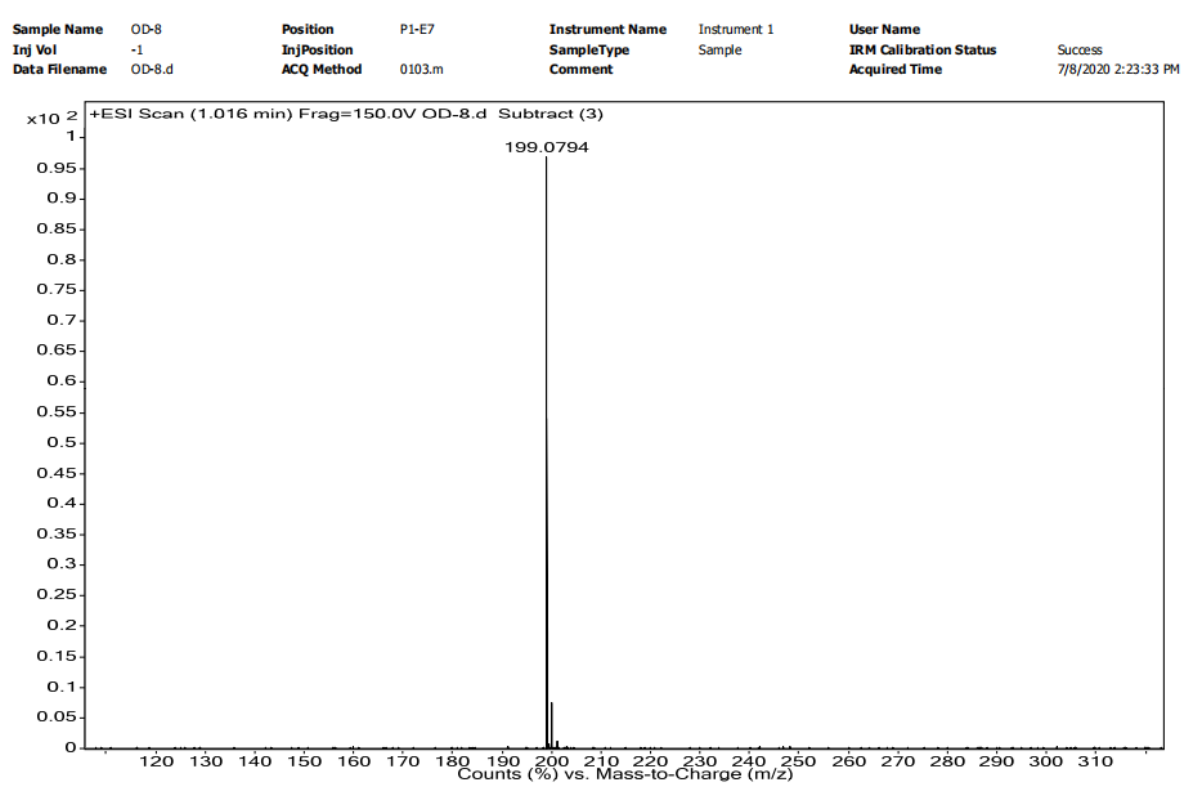


${ }^{1} \mathrm{H}$ NMR spectrum of $1 \mathrm{i}$

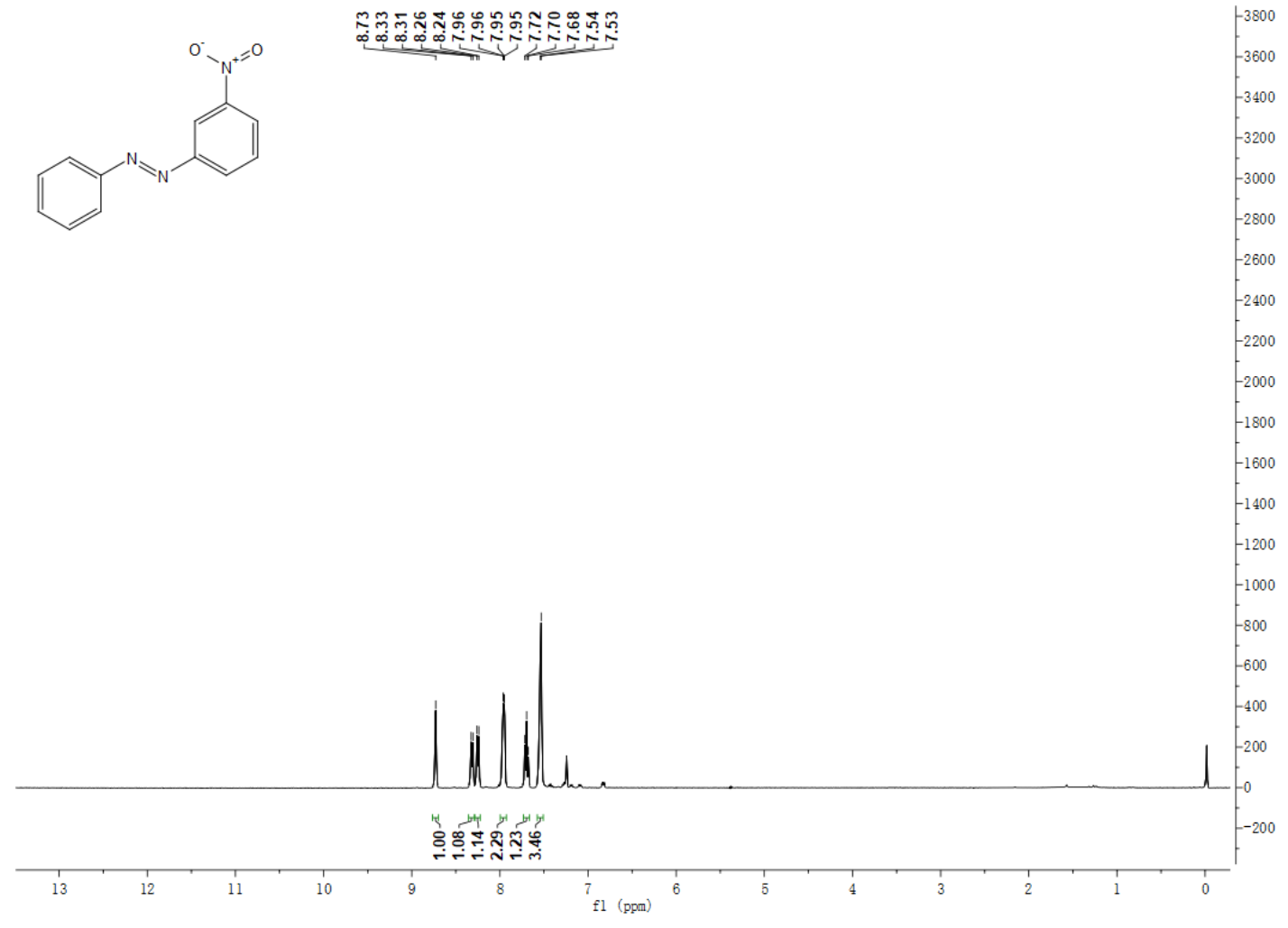

${ }^{13} \mathrm{C}$ NMR spectrum of $1 \mathrm{i}$

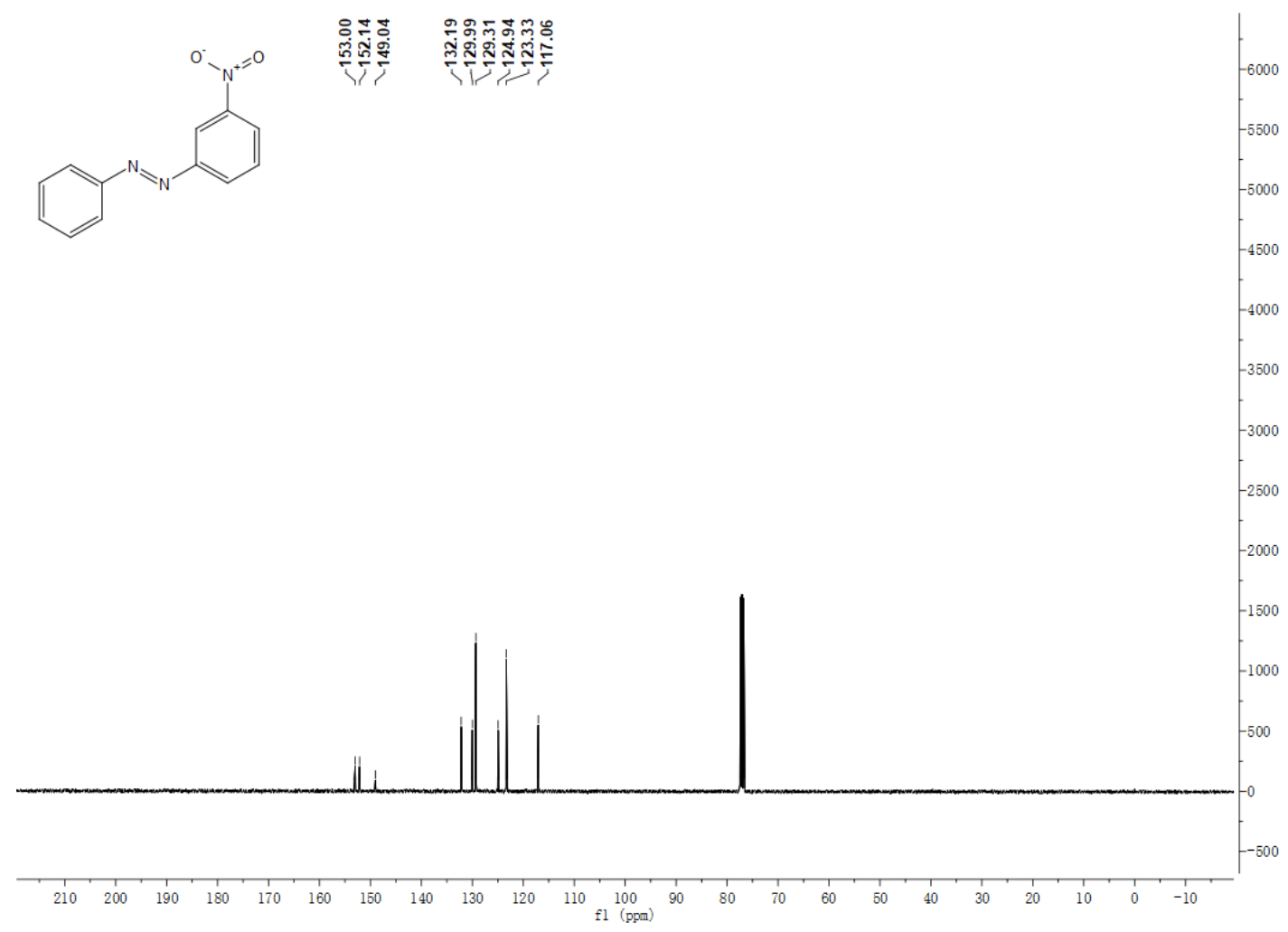


HRMS spectra of $1 \mathrm{i}$

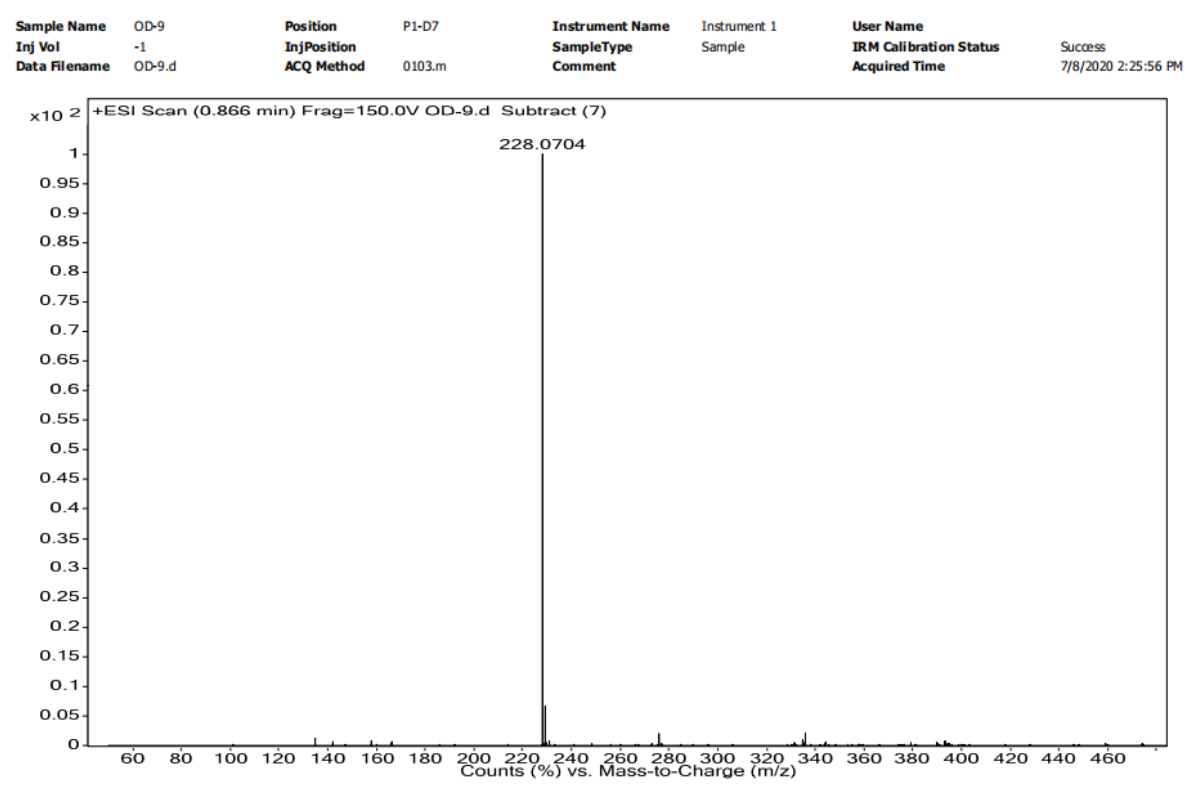

${ }^{1} \mathrm{H}$ NMR spectrum of $1 \mathrm{j}$

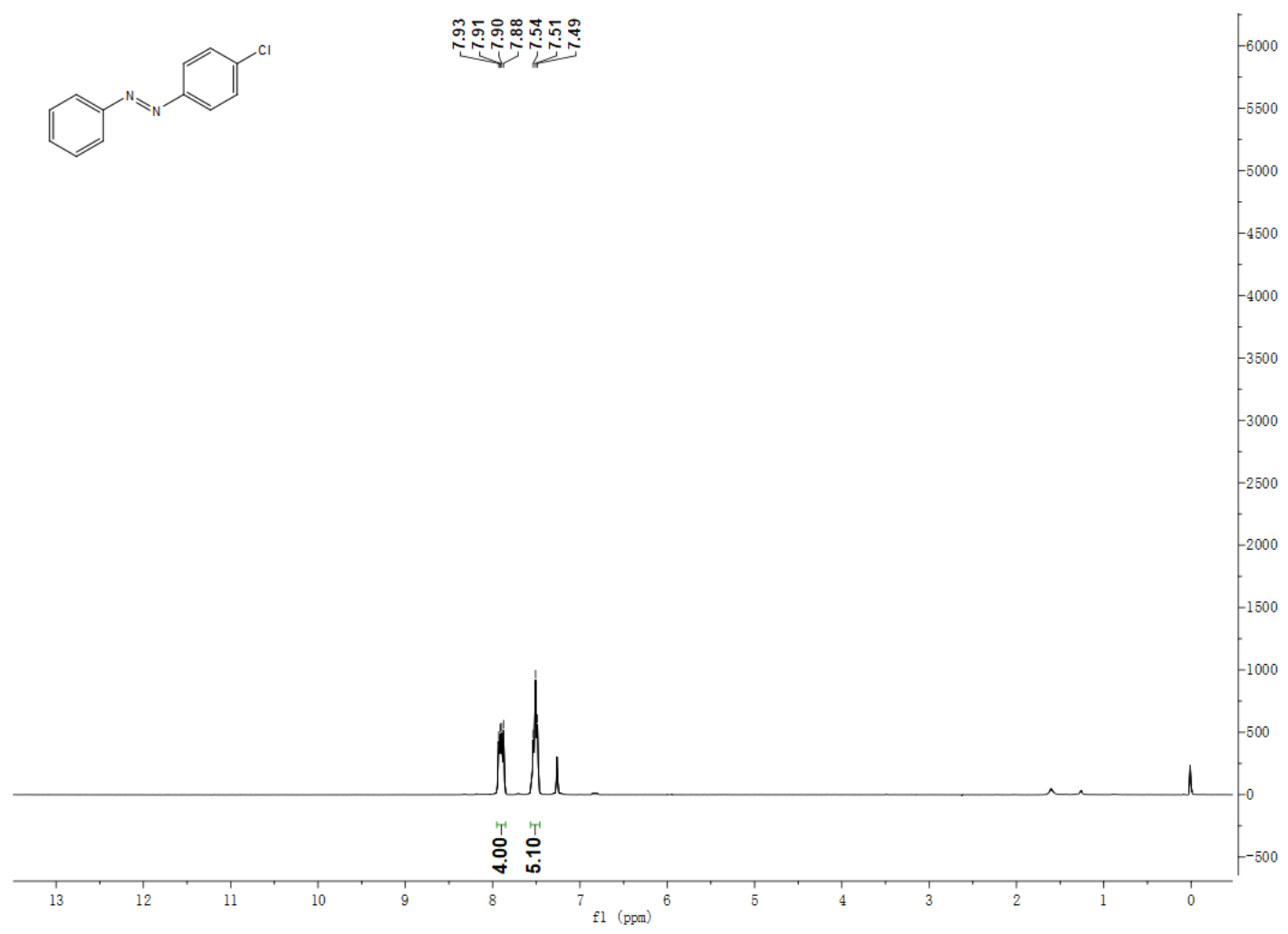


${ }^{13} \mathrm{C}$ NMR spectrum of $1 \mathrm{j}$

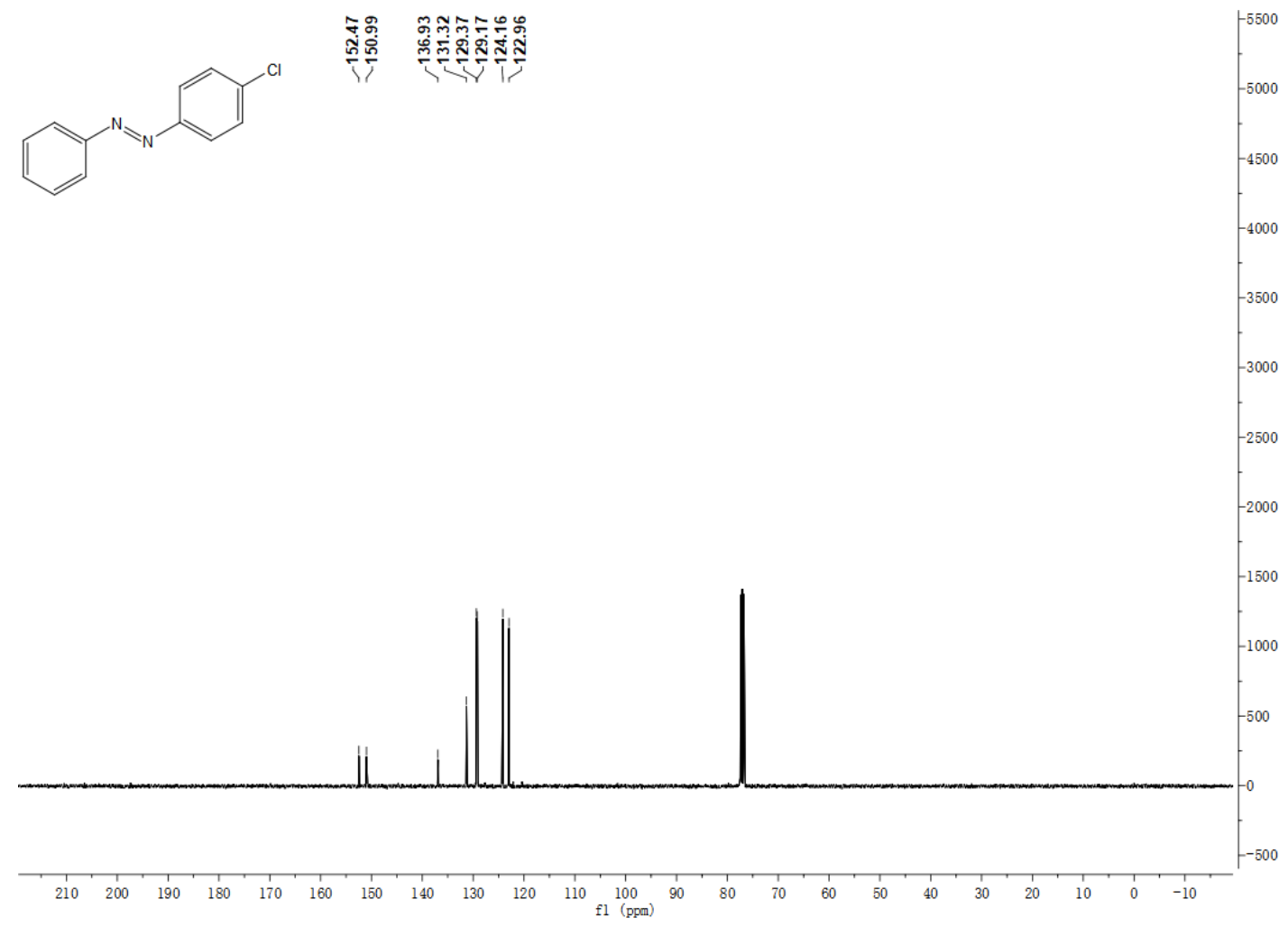

HRMS spectra of $1 \mathrm{j}$

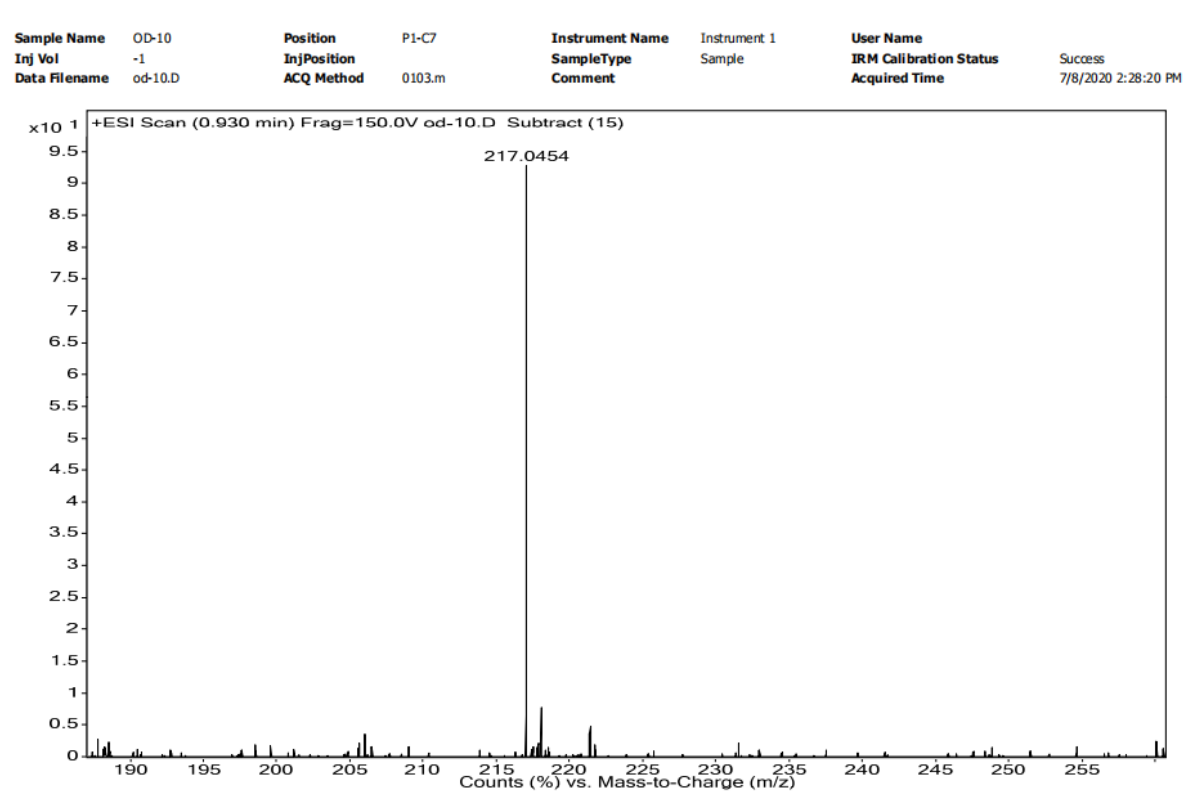


${ }^{1} \mathrm{H}$ NMR spectrum of $1 \mathrm{k}$

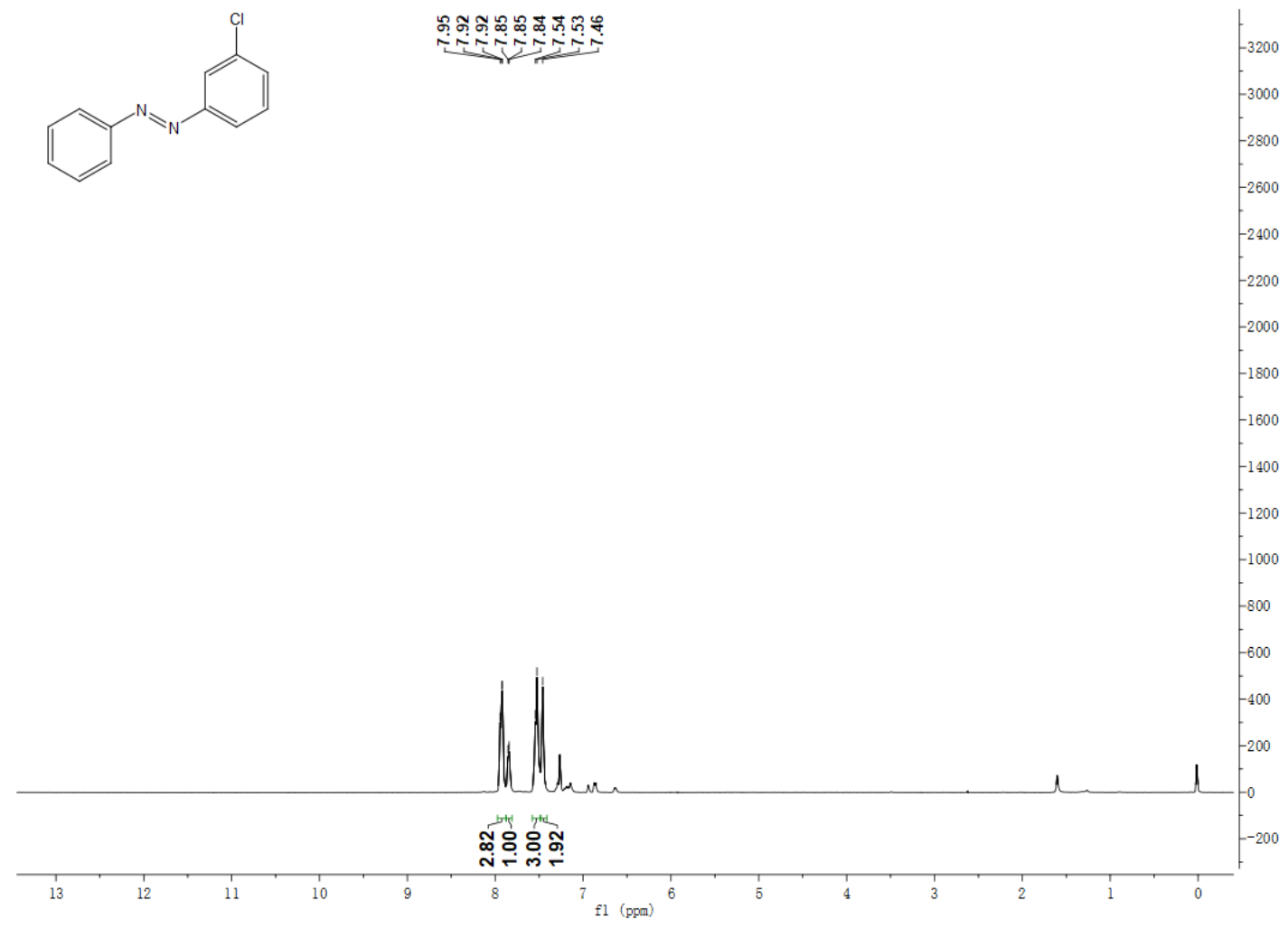

${ }^{13} \mathrm{C}$ NMR spectrum of $1 \mathrm{k}$

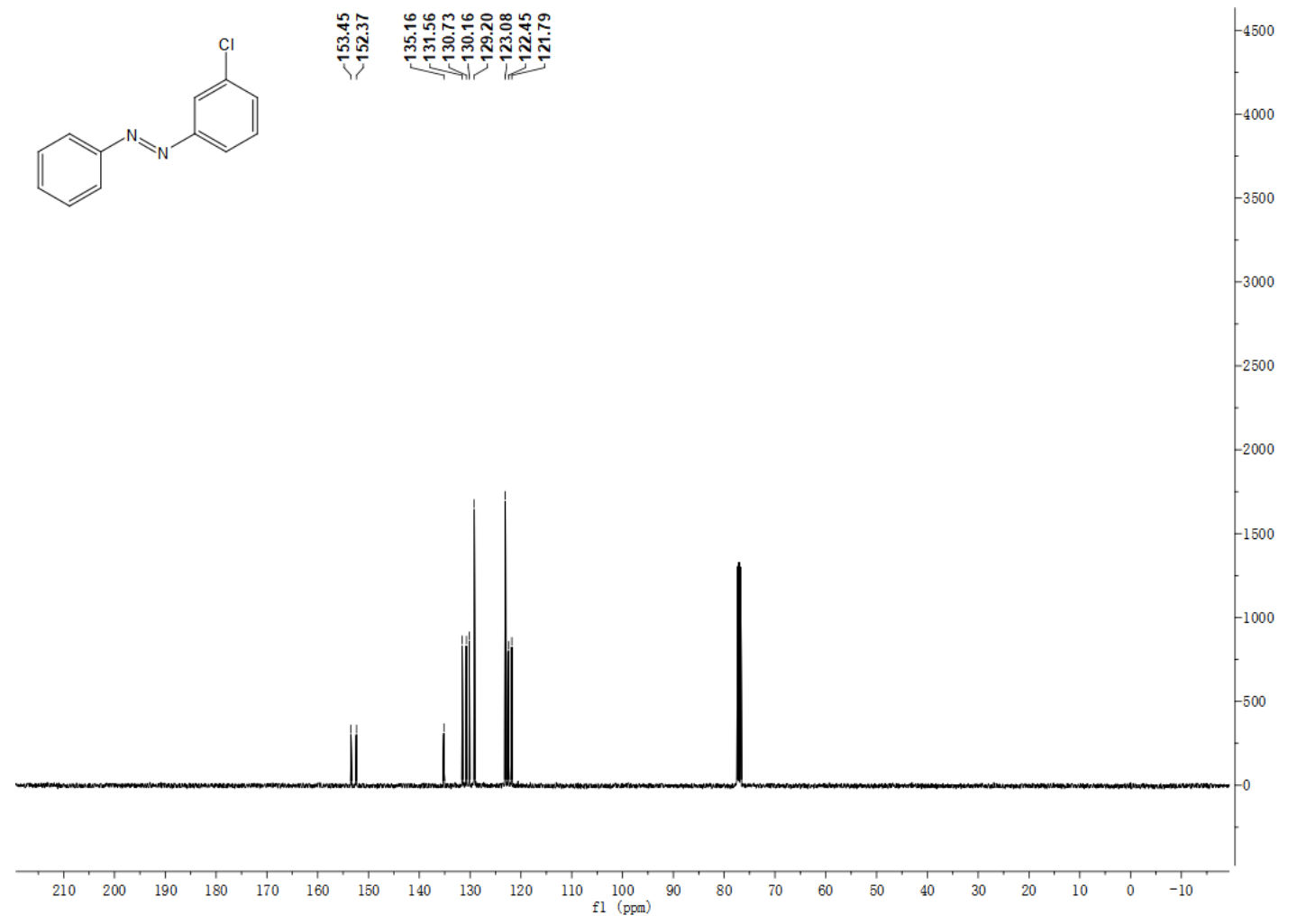


HRMS spectra of $1 \mathrm{k}$

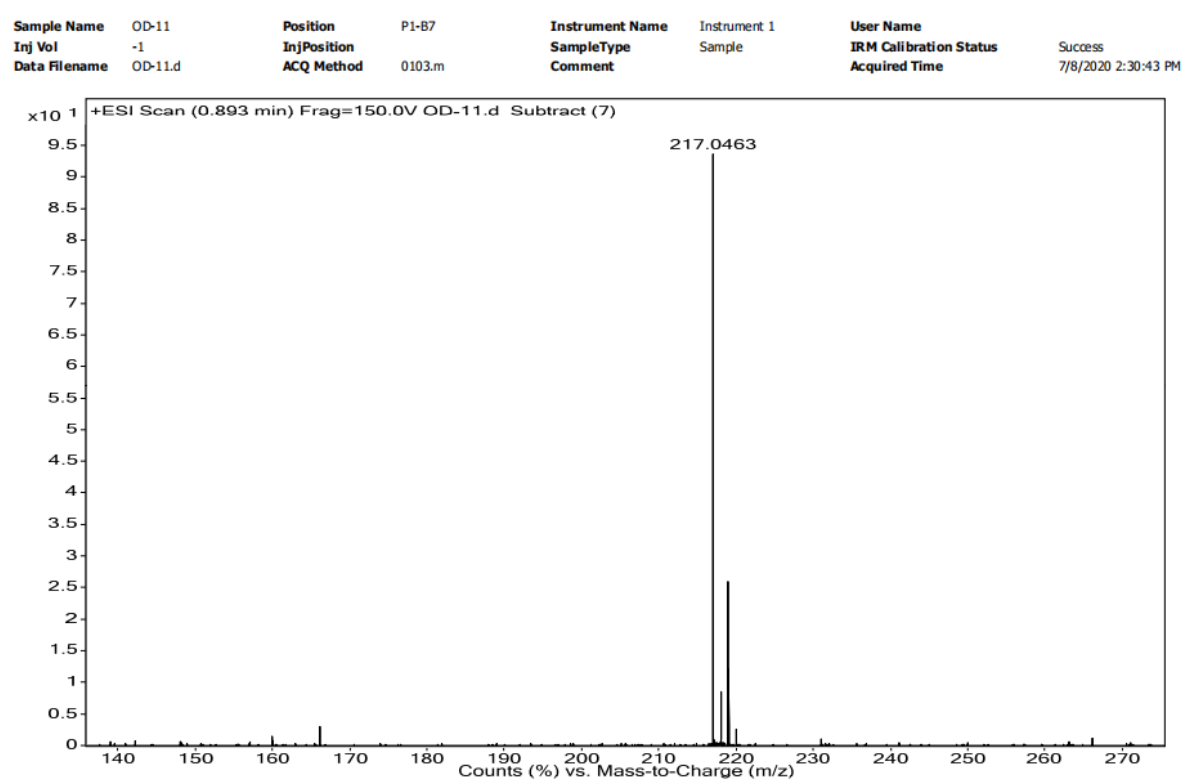

${ }^{1} \mathrm{H}$ NMR spectrum of 11

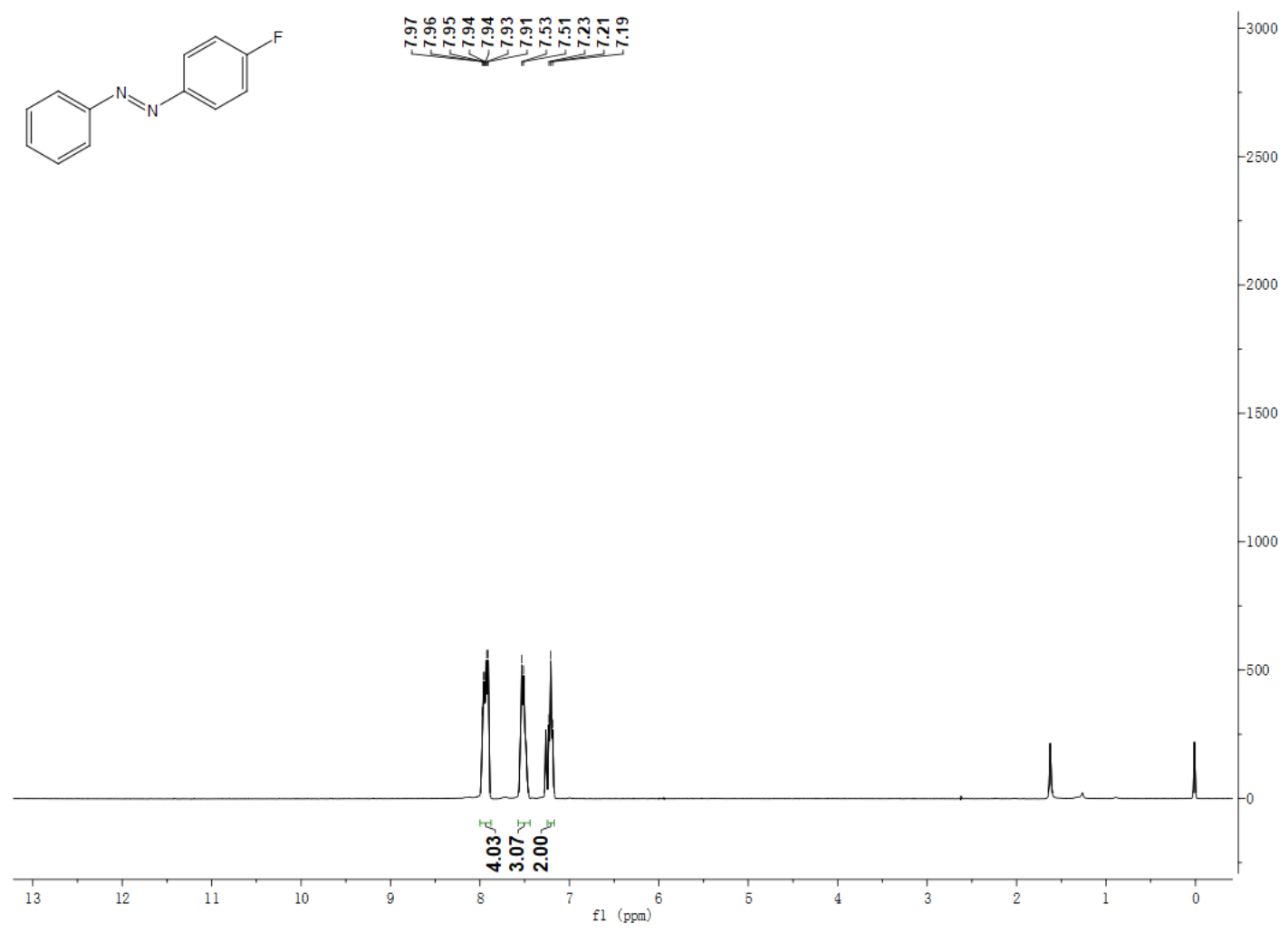


${ }^{13} \mathrm{C}$ NMR spectrum of 11

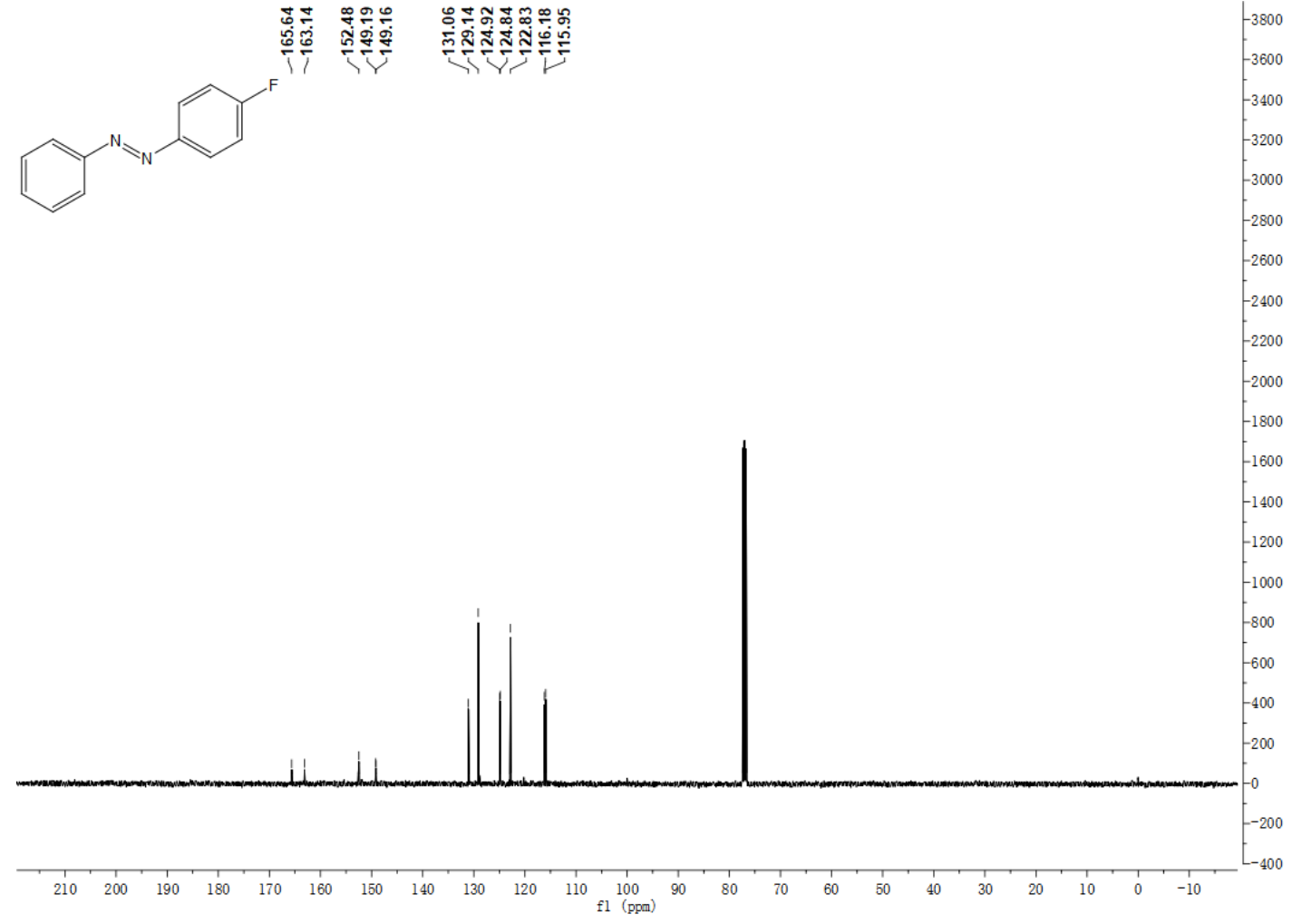

${ }^{19} \mathrm{~F}$ NMR spectrum of 11

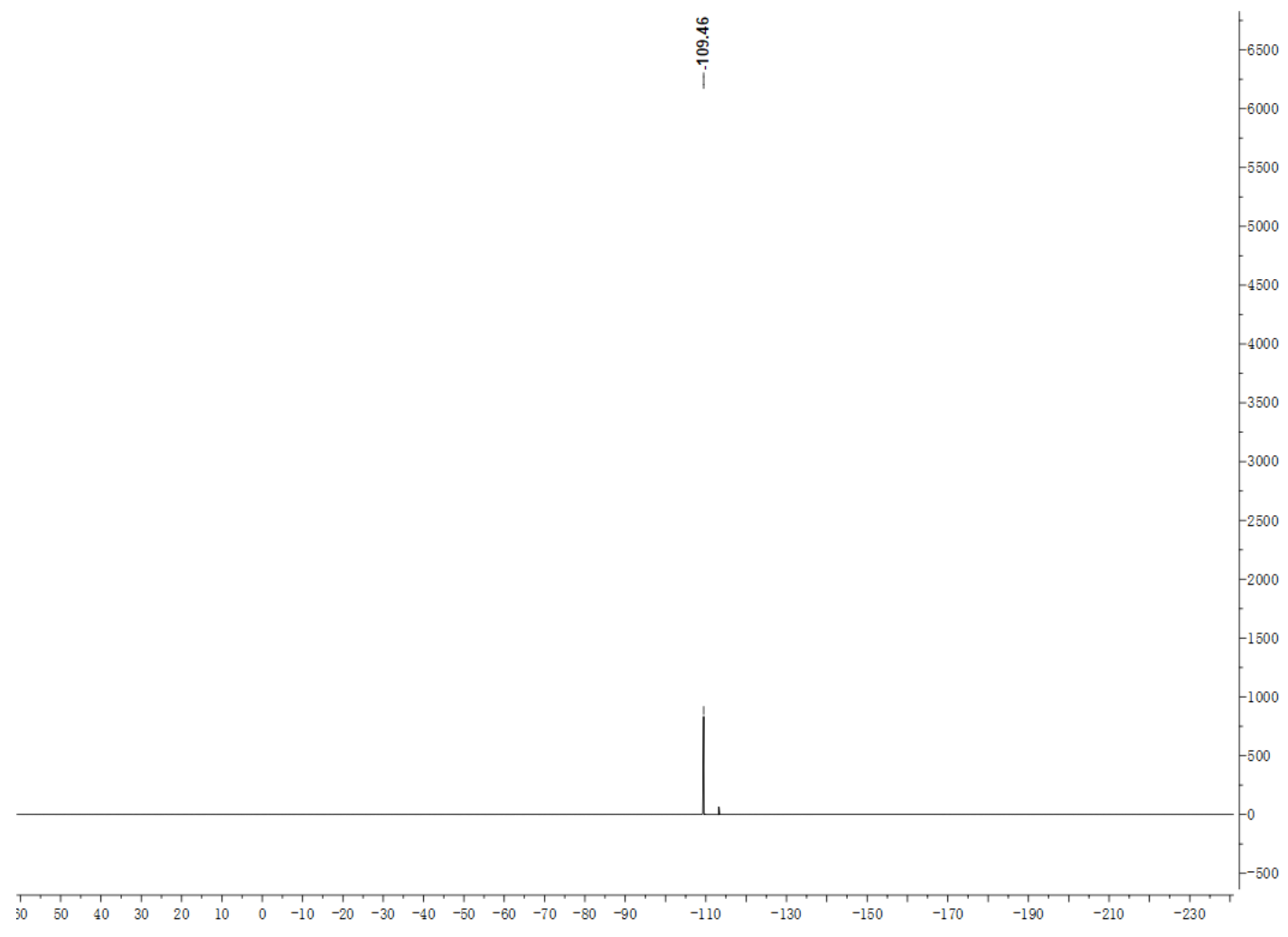


HRMS spectra of 11

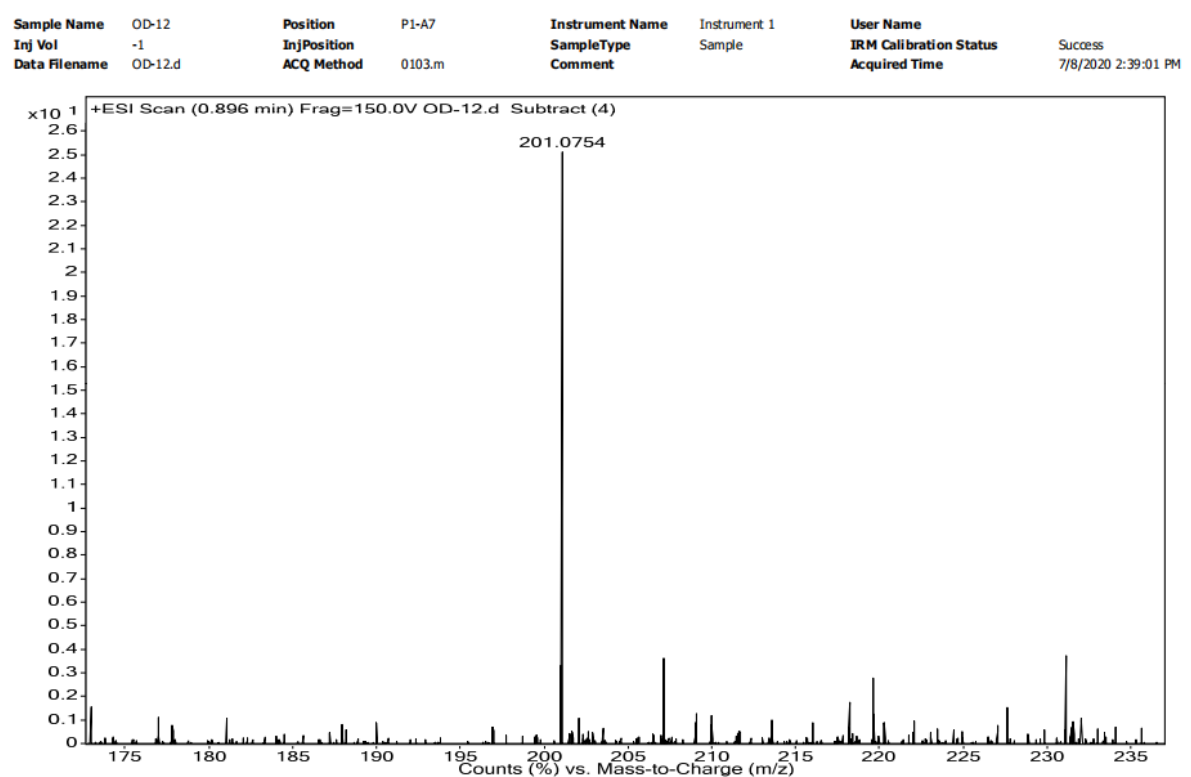

${ }^{1} \mathrm{H}$ NMR spectrum of $1 \mathrm{~m}$

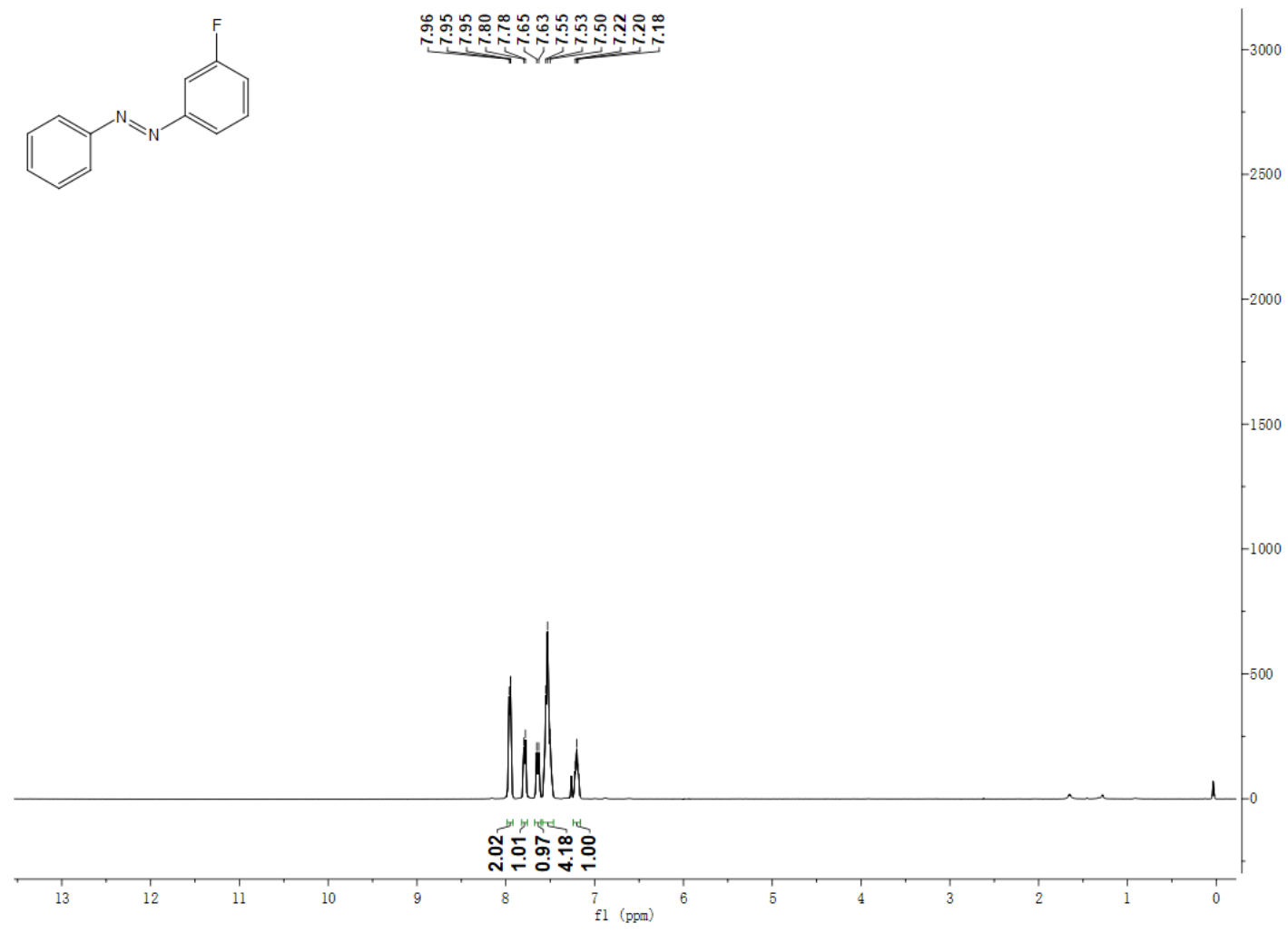


${ }^{13} \mathrm{C}$ NMR spectrum of $1 \mathrm{~m}$

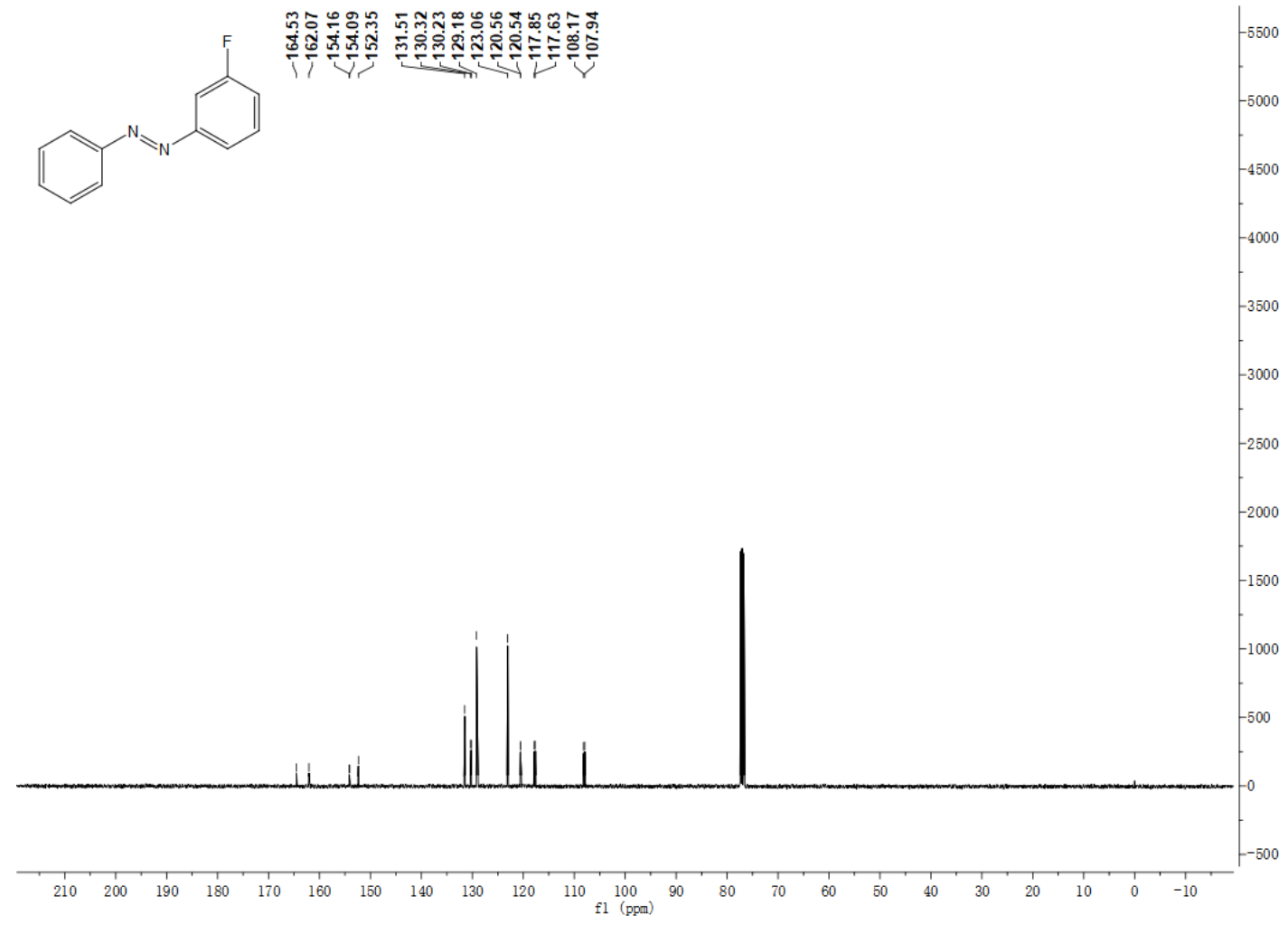

${ }^{19} \mathrm{~F}$ NMR spectrum of $1 \mathrm{~m}$

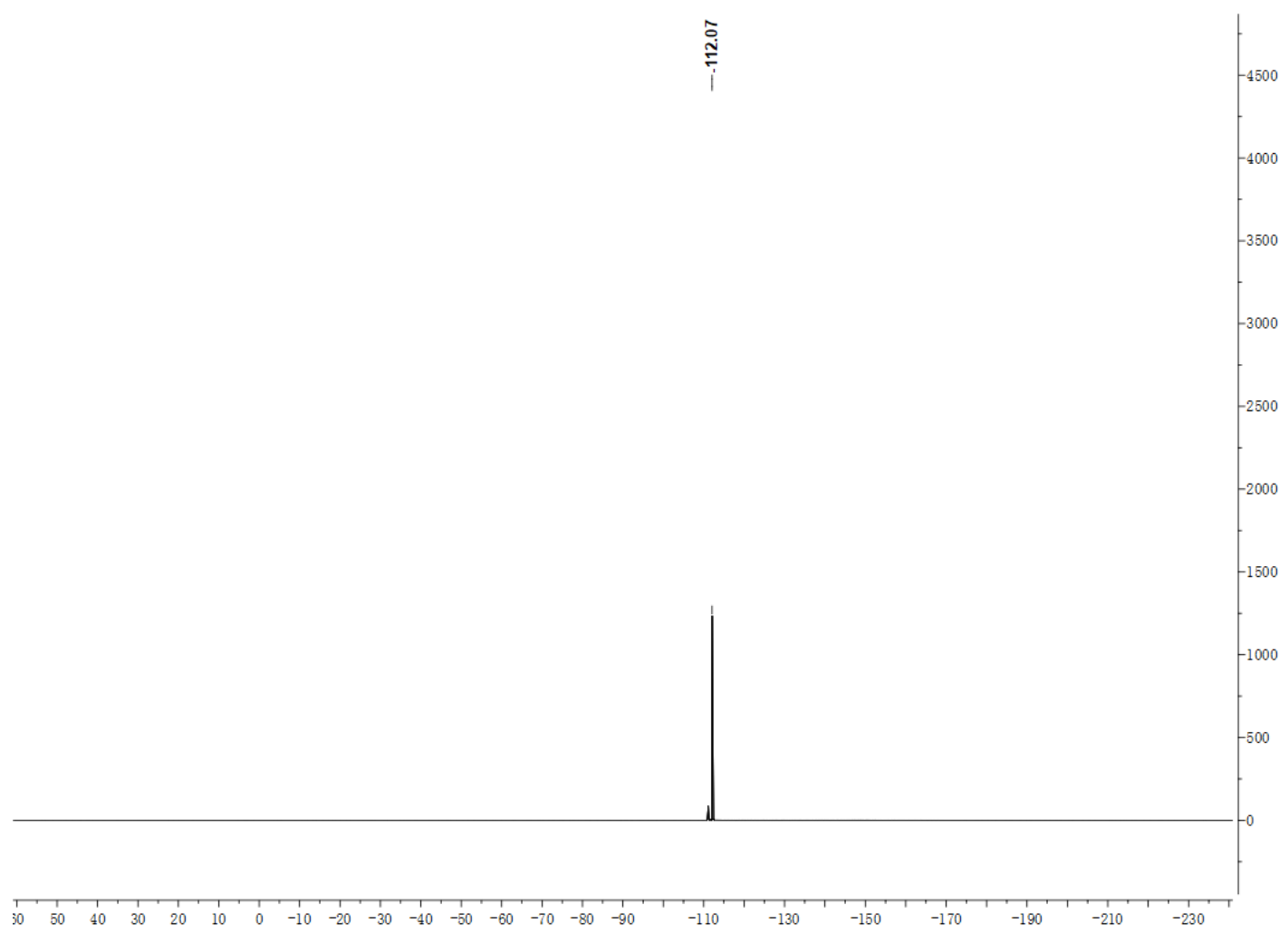


HRMS spectra of $1 \mathrm{~m}$

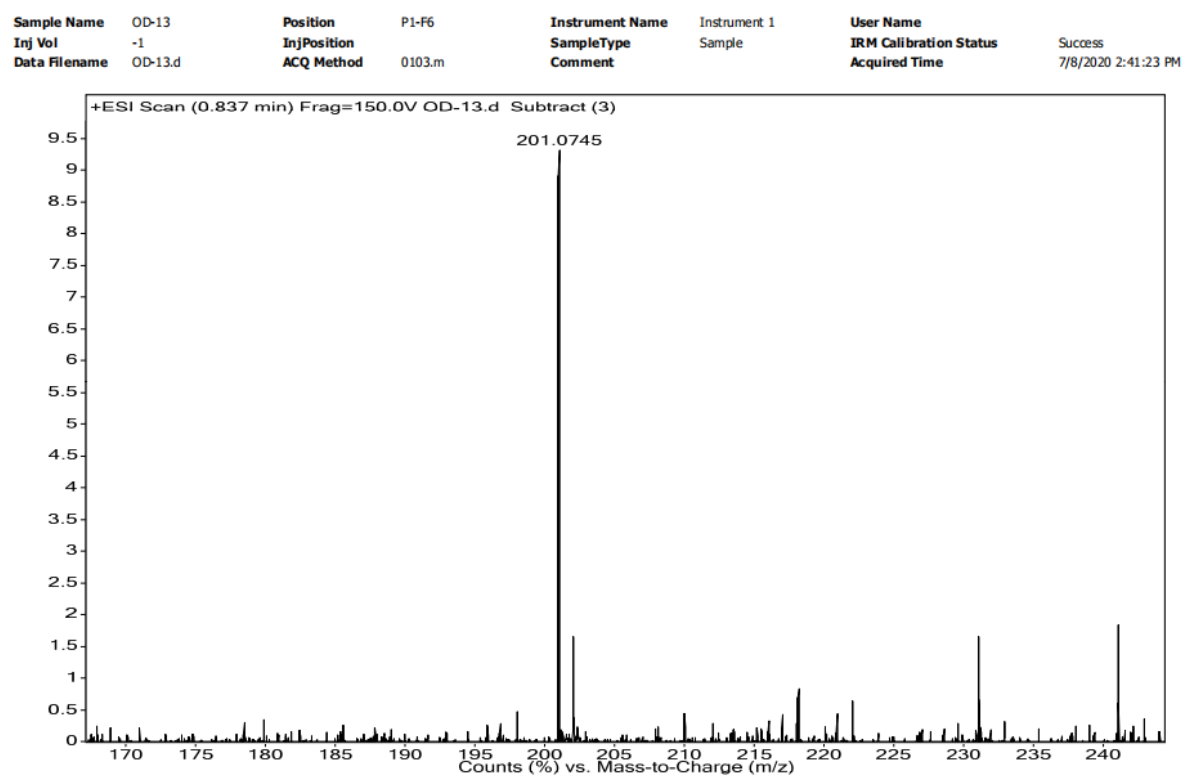

${ }^{1} \mathrm{H}$ NMR spectrum of $1 \mathrm{n}$

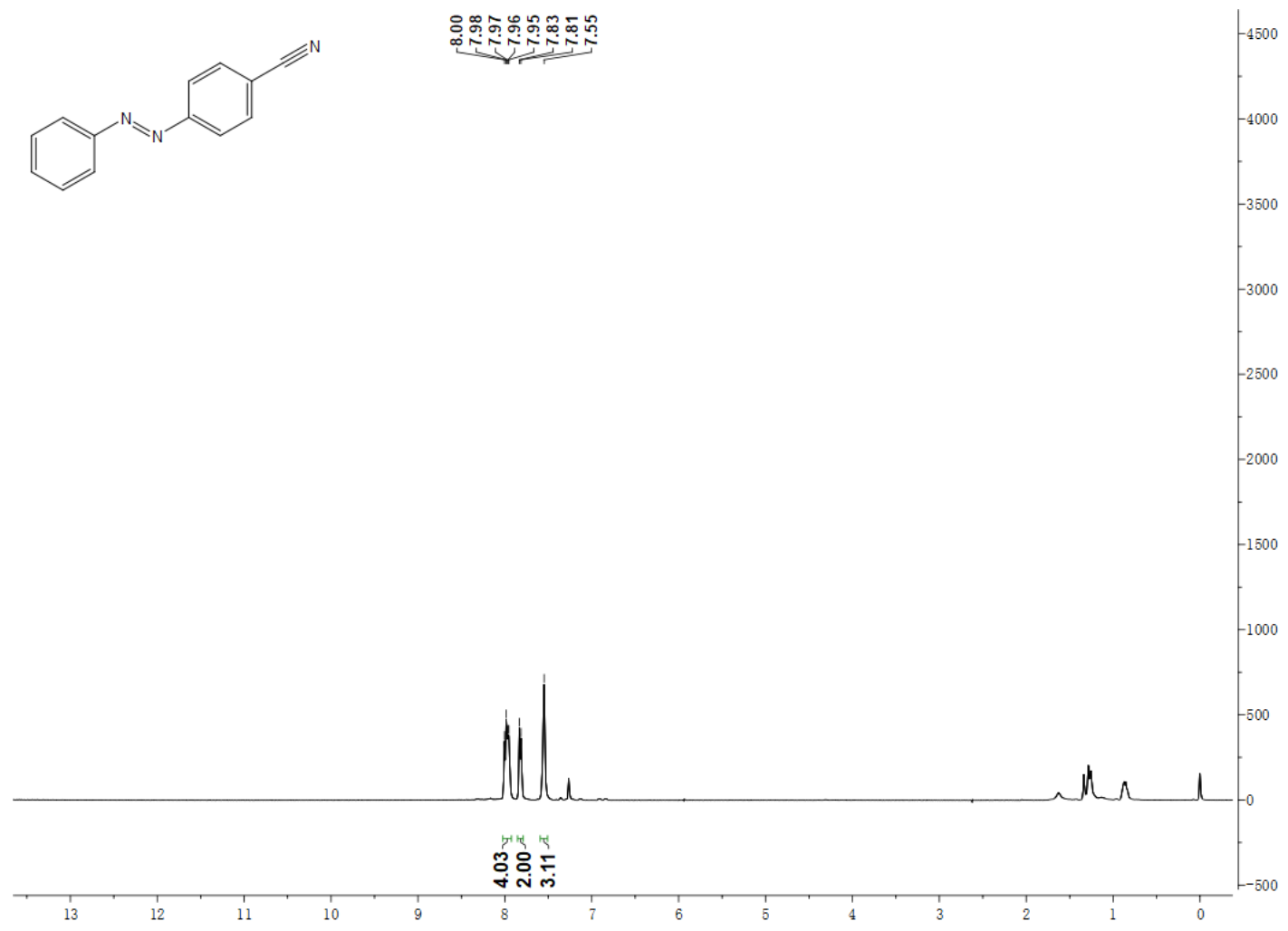


${ }^{13} \mathrm{C}$ NMR spectrum of $1 \mathrm{n}$

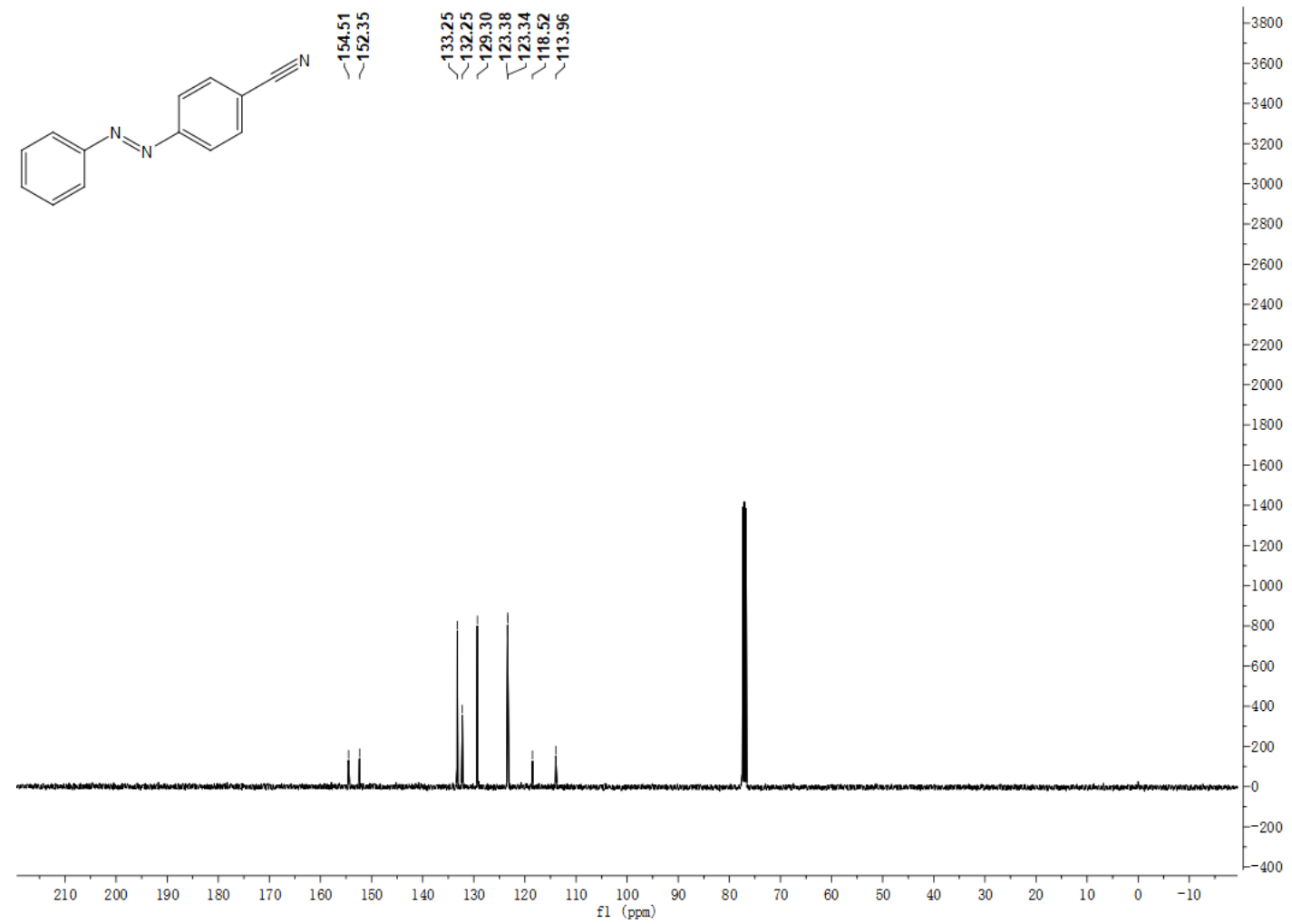

HRMS spectra of $1 n$

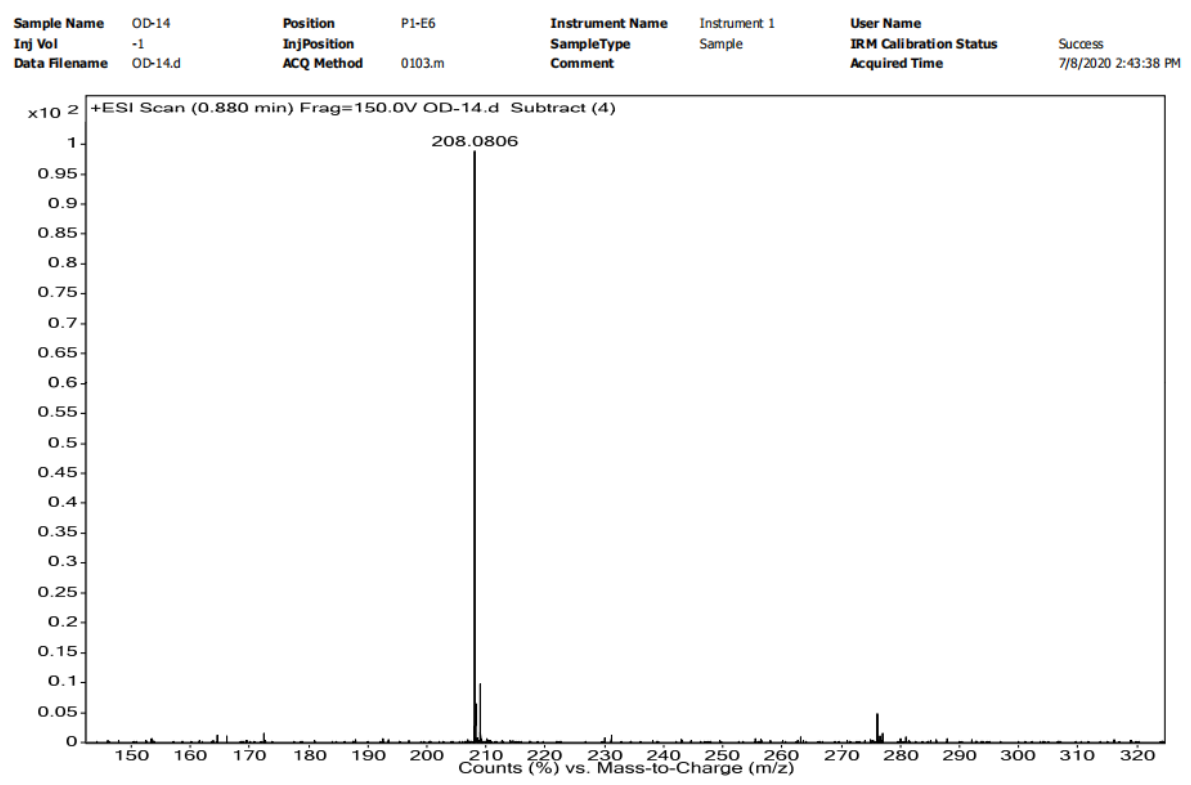


${ }^{1} \mathrm{H}$ NMR spectrum of 10

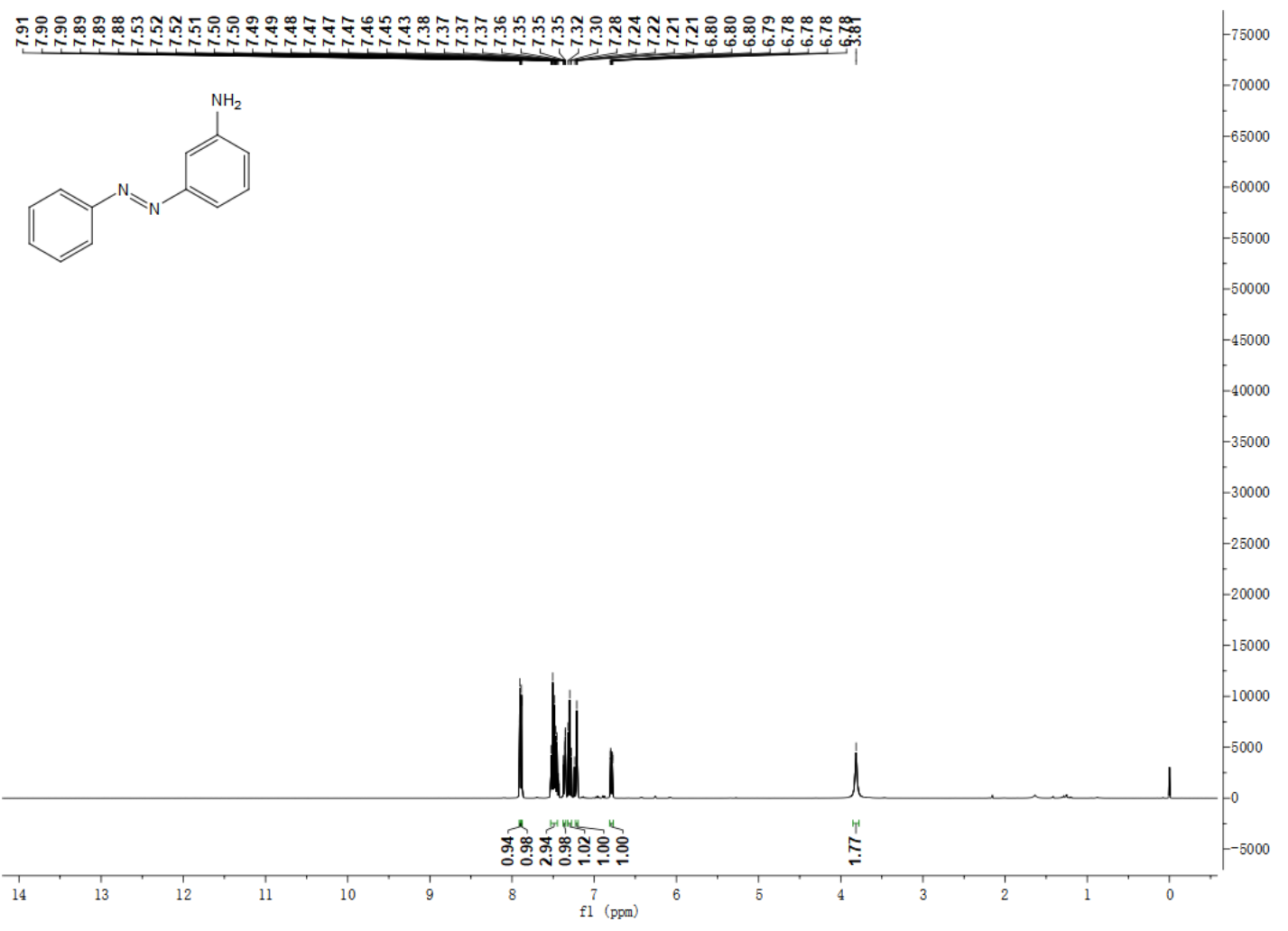

${ }^{13} \mathrm{C}$ NMR spectrum of 10

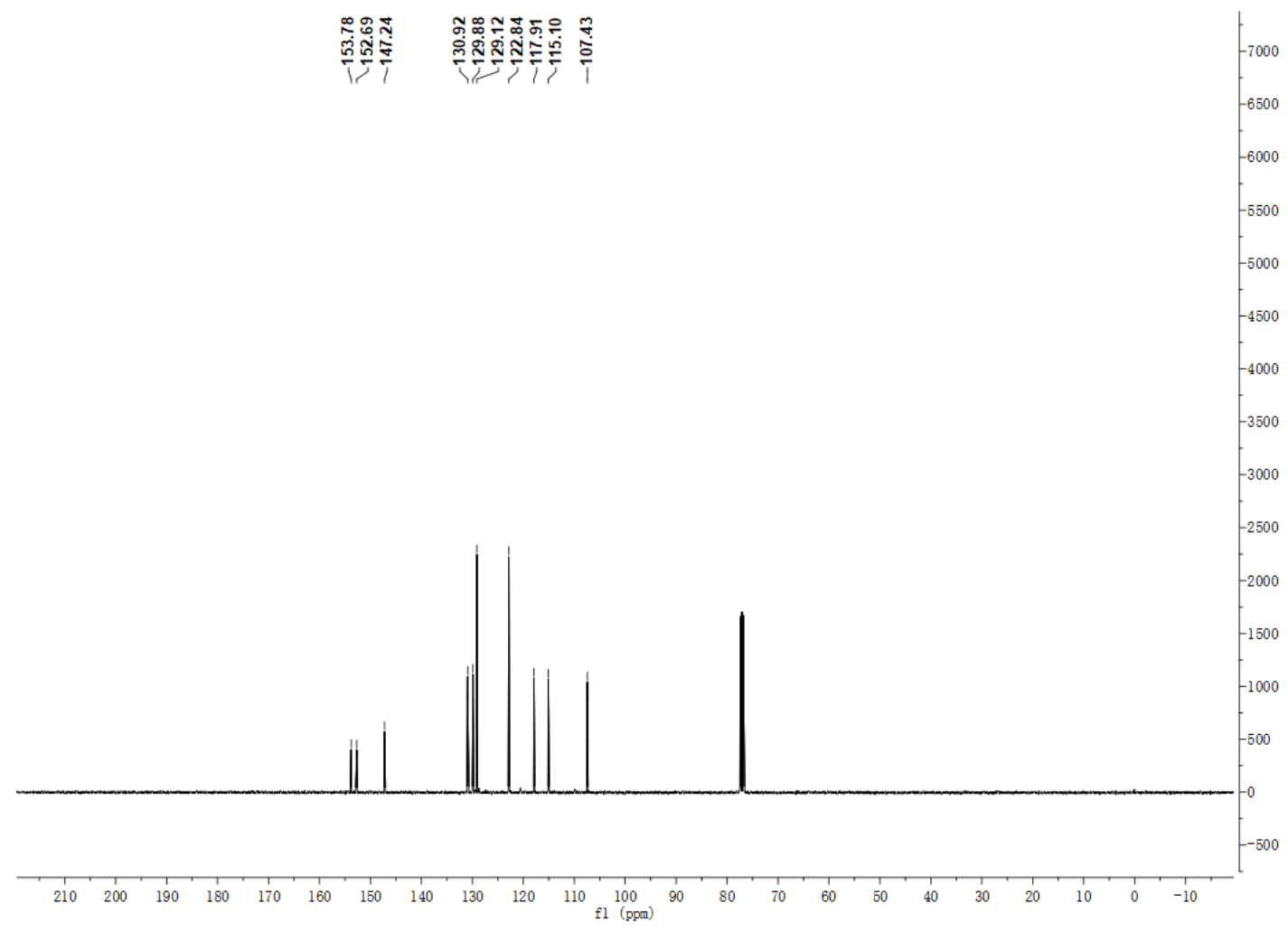


HRMS spectra of 10

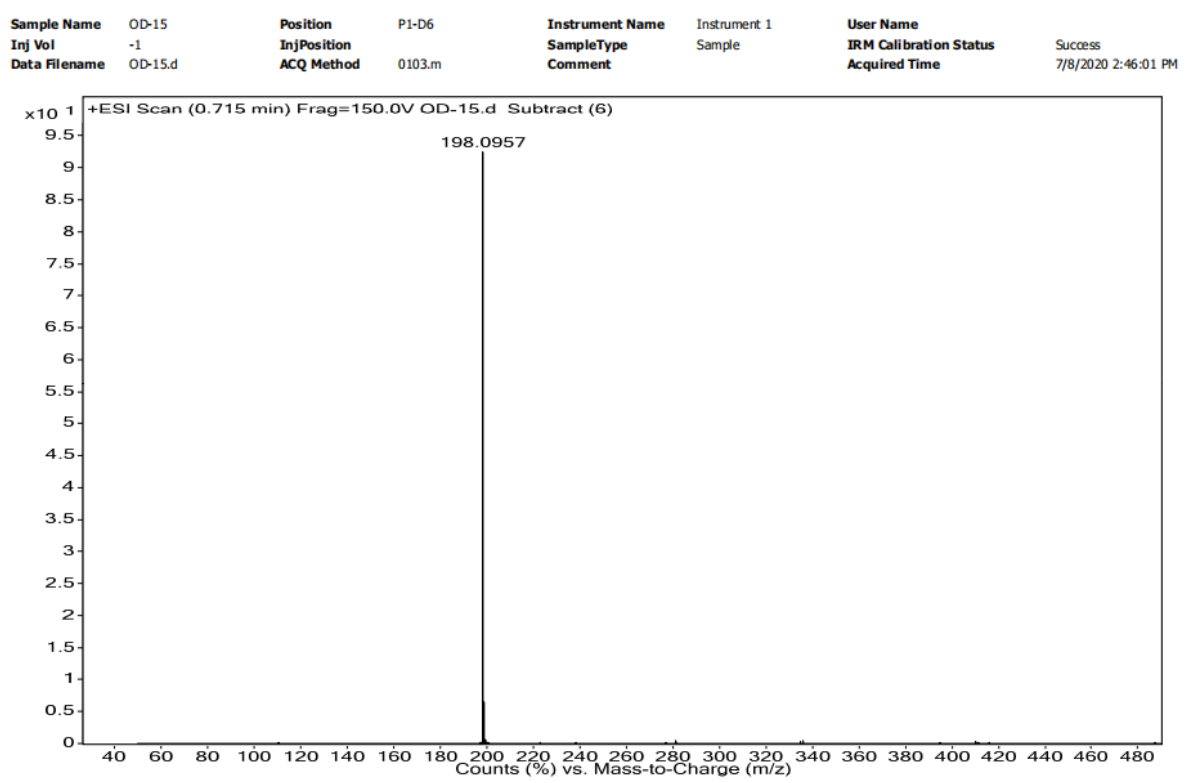

${ }^{1} \mathrm{H}$ NMR spectrum of $2 \mathrm{a}$

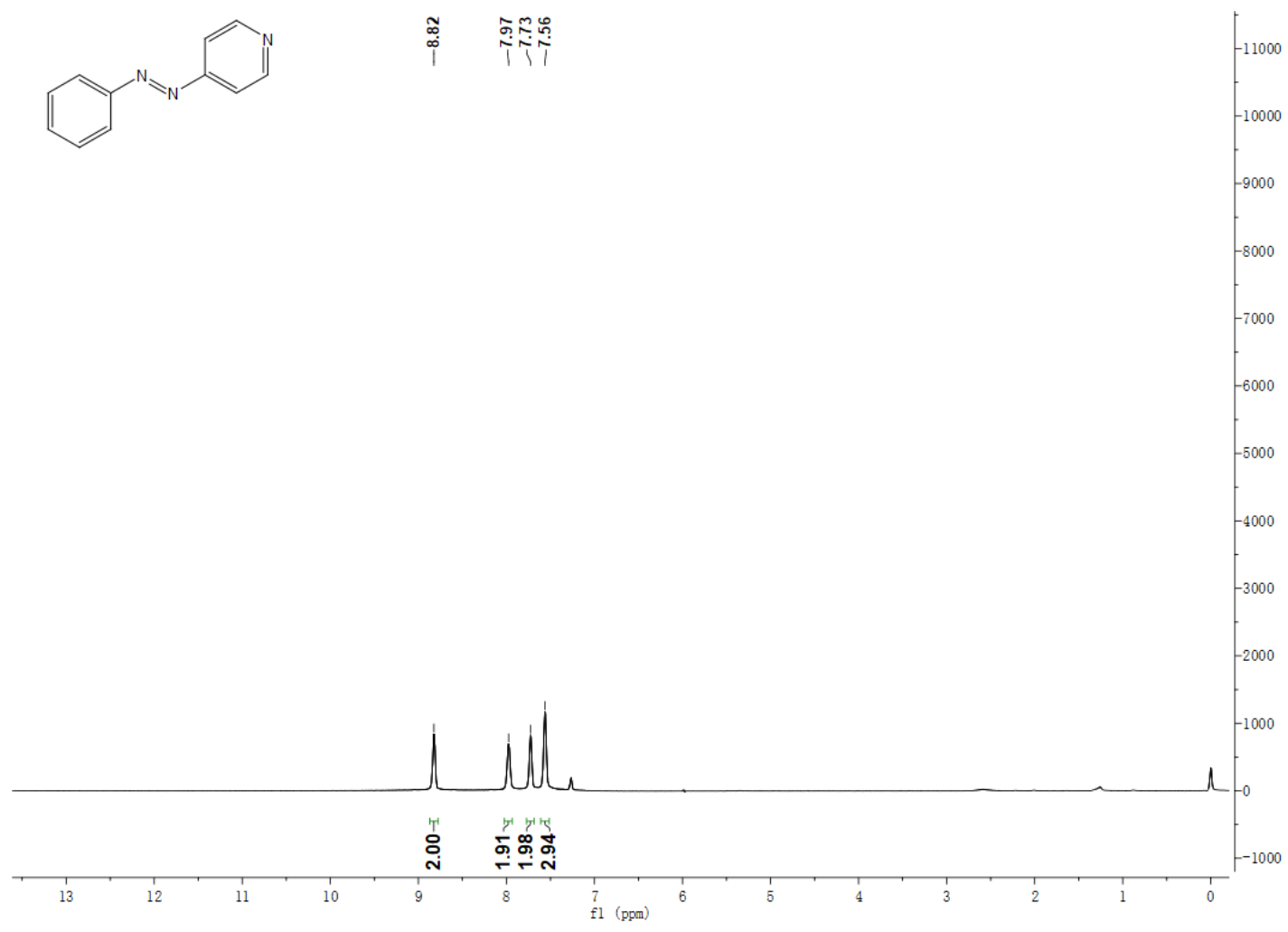


${ }^{13} \mathrm{C}$ NMR spectrum of $2 \mathrm{a}$

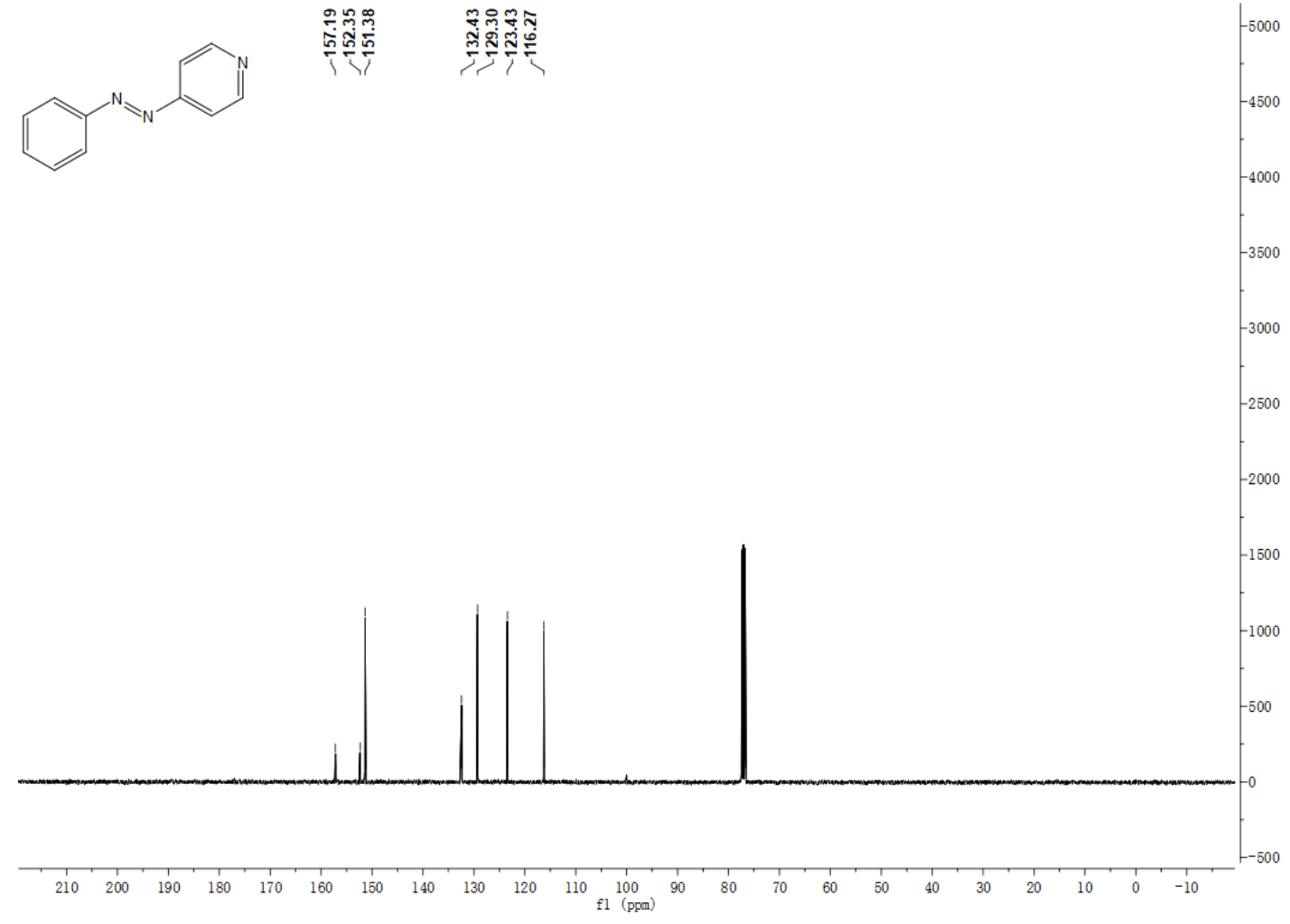

HRMS spectra of $2 \mathrm{a}$

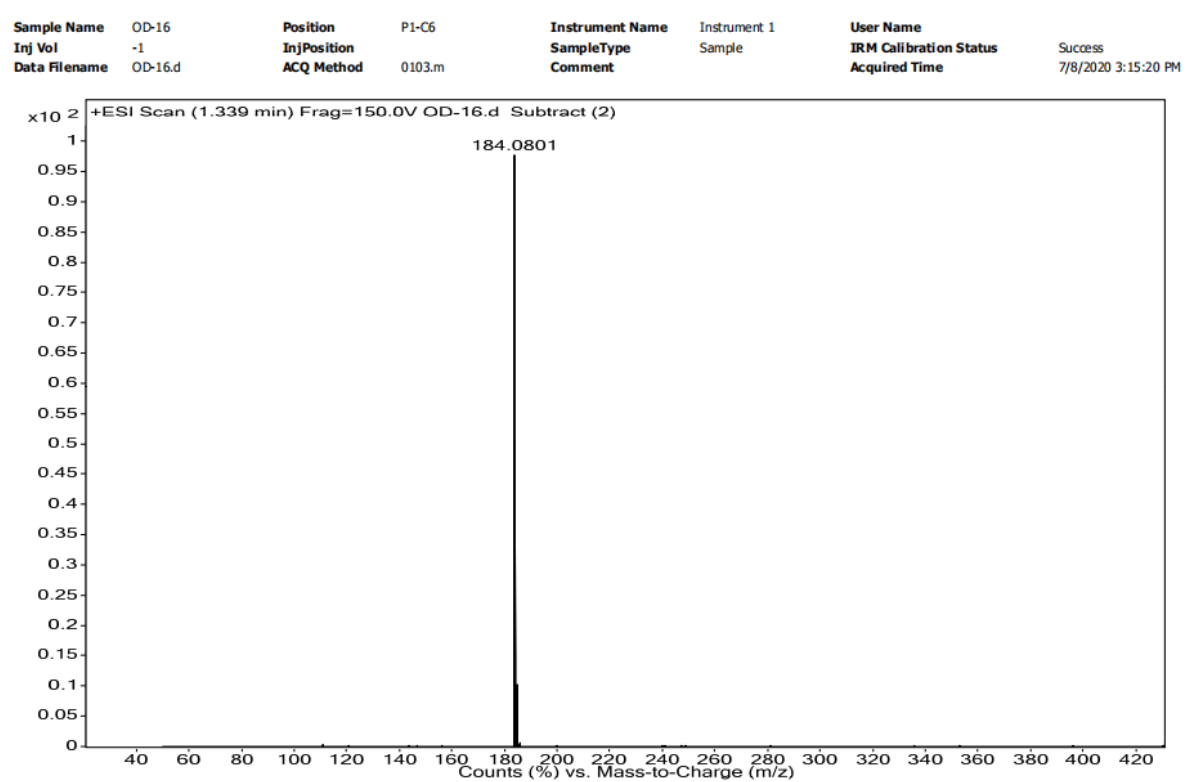


${ }^{1} \mathrm{H}$ NMR spectrum of $2 b$

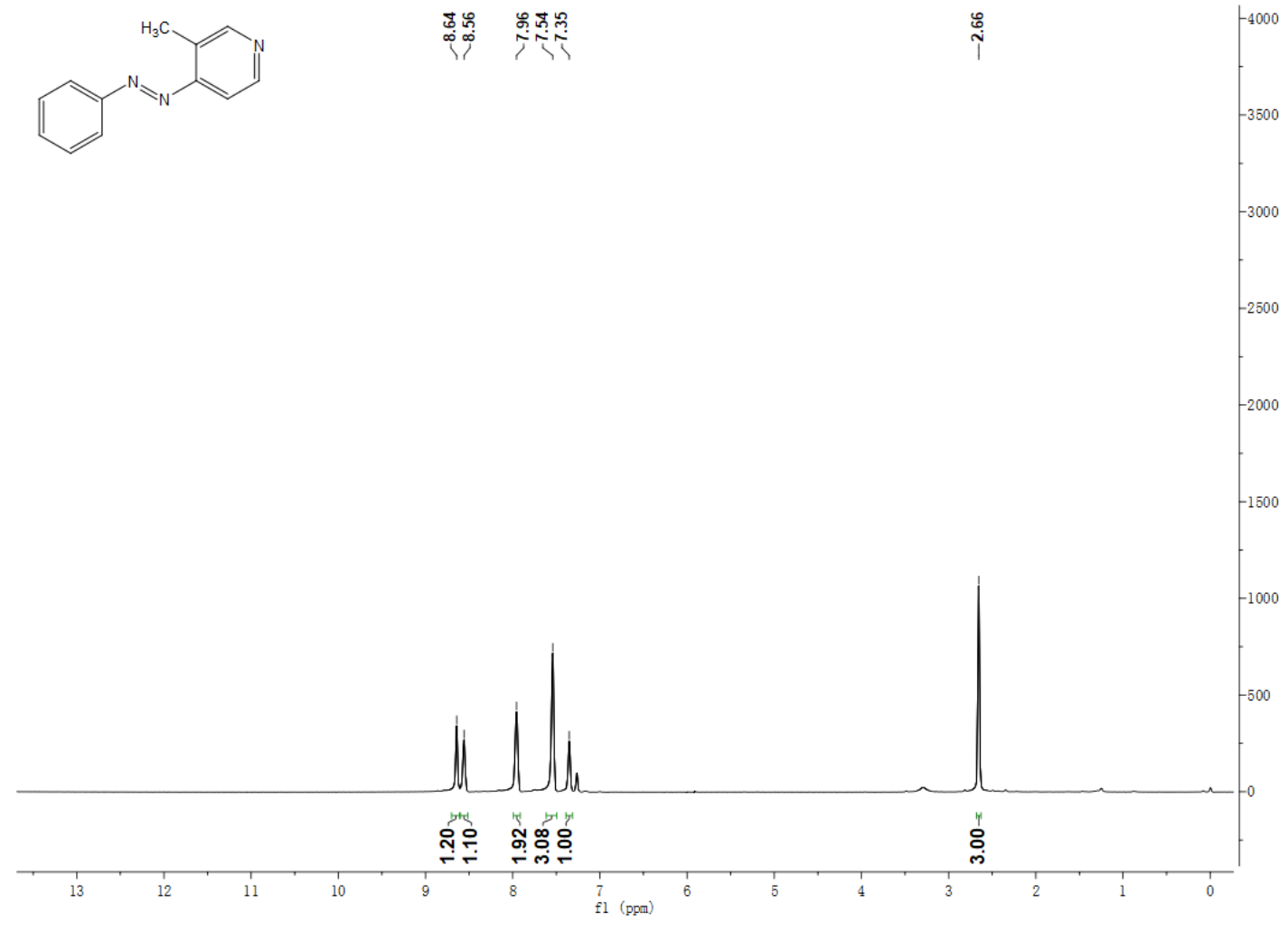

${ }^{13} \mathrm{C}$ NMR spectrum of $2 \mathrm{~b}$

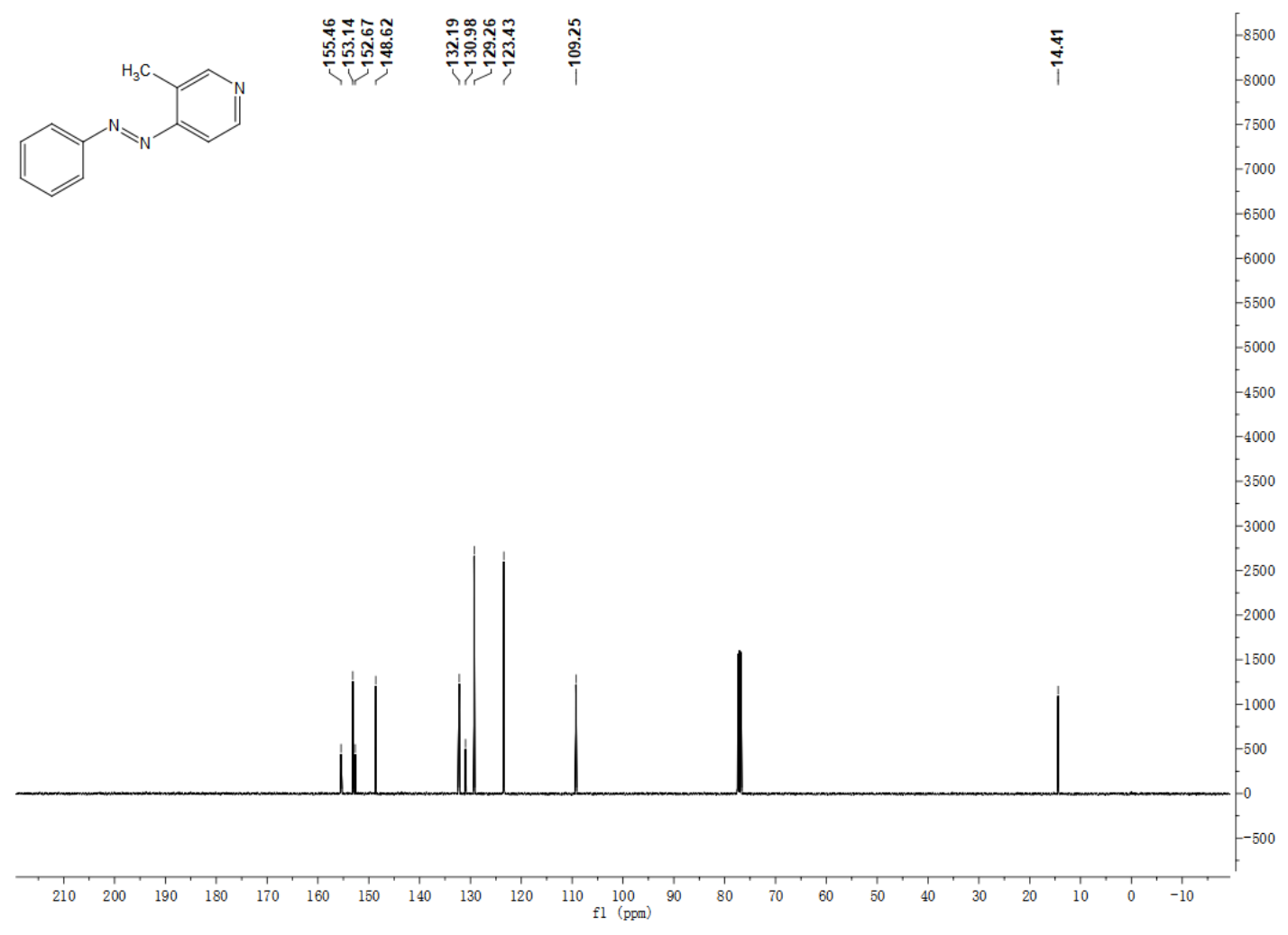


HRMS spectra of $2 b$

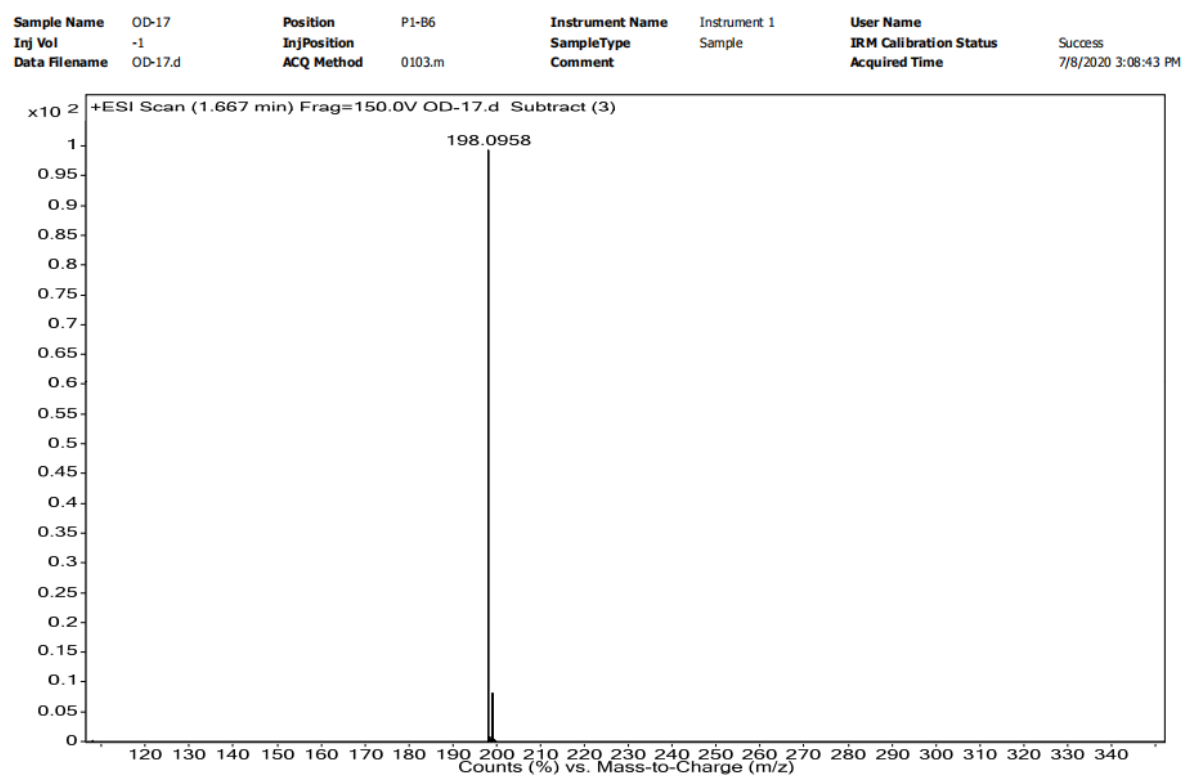

${ }^{1} \mathrm{H}$ NMR spectrum of $2 \mathrm{c}$

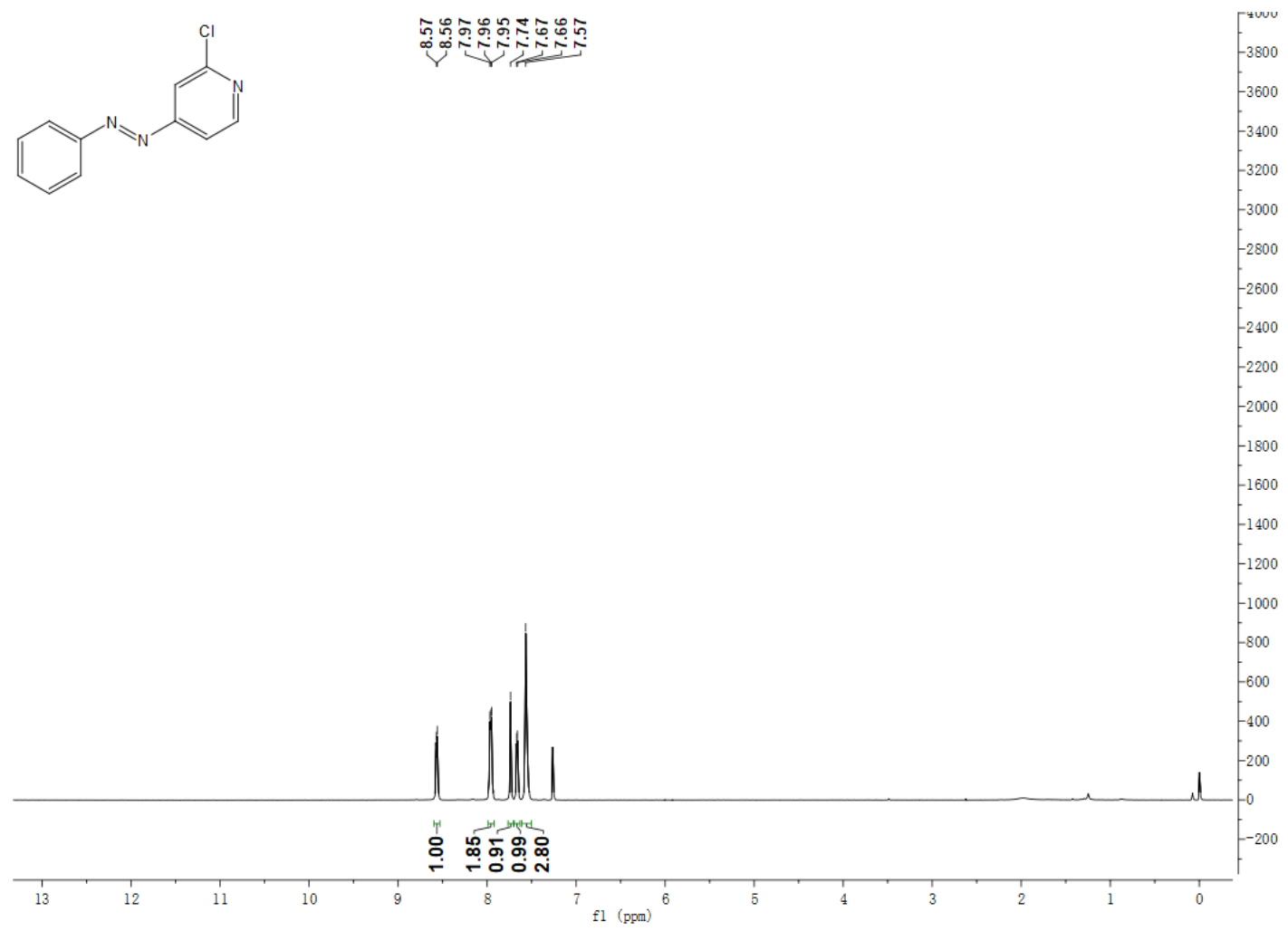


${ }^{13} \mathrm{C}$ NMR spectrum of $2 \mathrm{c}$

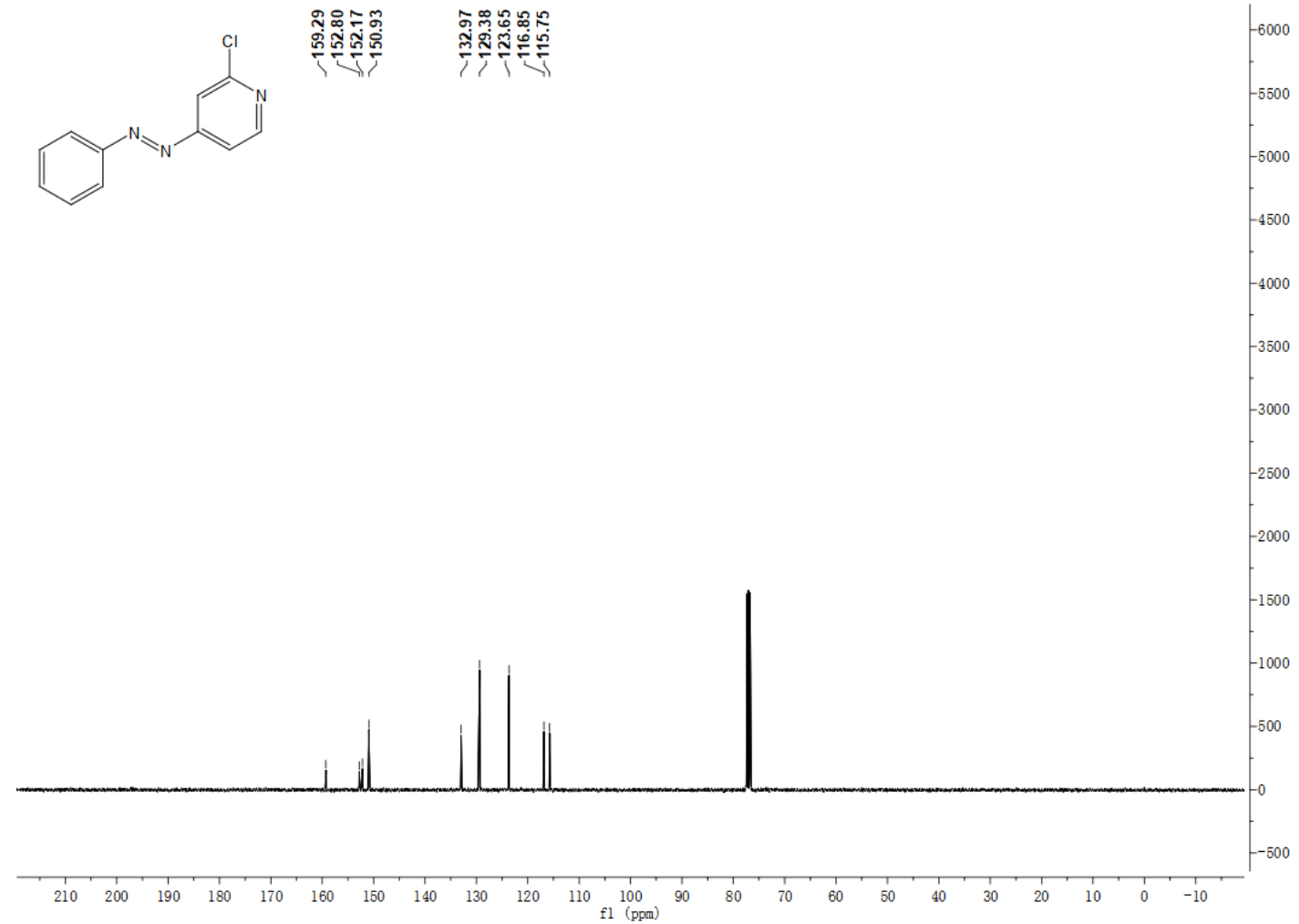

HRMS spectra of $2 \mathrm{c}$

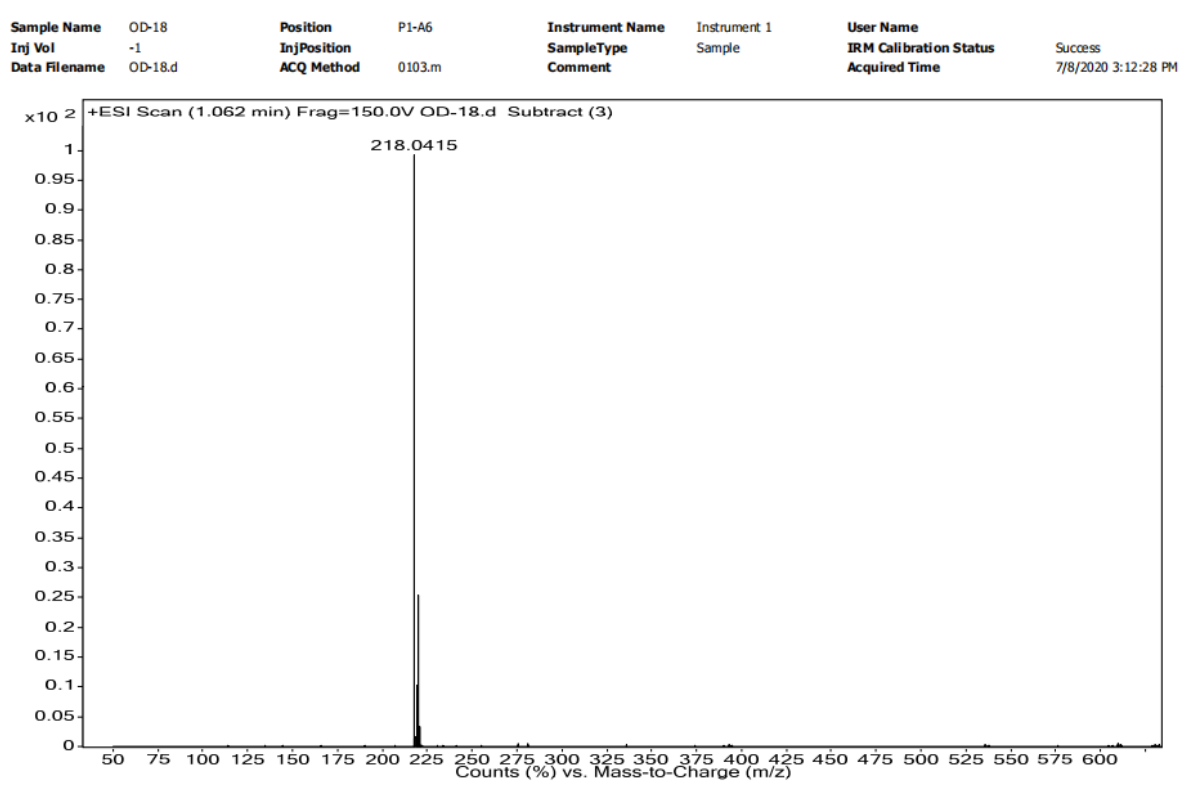




\section{HPLC-Chromatograms of compounds}

Measurements for purity of the compounds were performed by Agilent 1260 HPLC system with methanol/water (40:60 or 95:5) as the eluent $\left(0.1 \% \mathrm{CF}_{3} \mathrm{COOH}\right.$ in water) and a flow rate of 1.0 $\mathrm{mL} / \mathrm{min}$. The compounds were dissolved in $\mathrm{MeOH}$ and filtered through syringe filters.

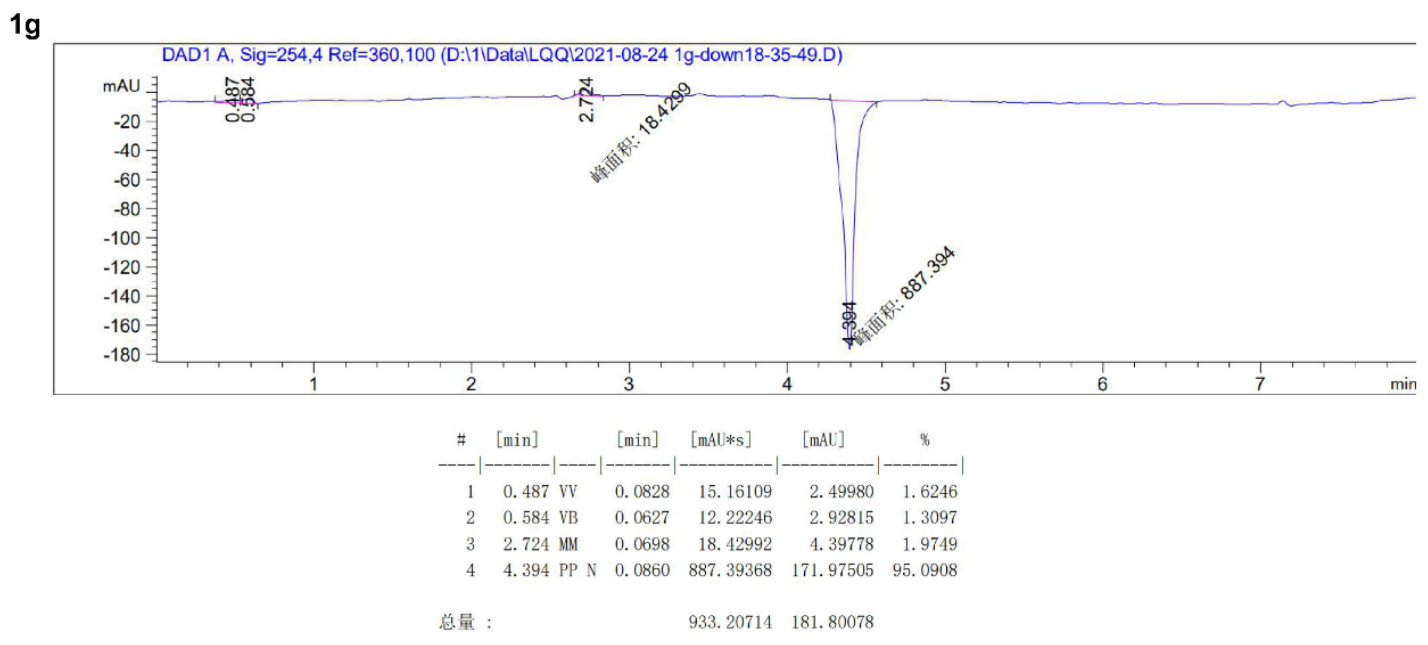


1h

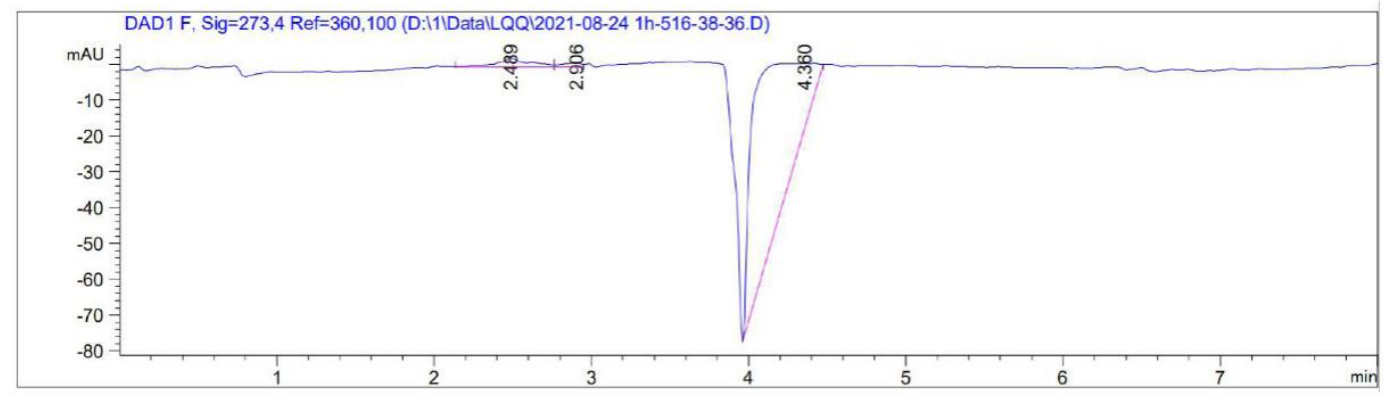

\begin{tabular}{clrrrr}
$\#$ & {$[\mathrm{~min}]$} & {$[\mathrm{min}]$} & \multicolumn{1}{c}{$[\mathrm{mAU} * \mathrm{~s}]$} & \multicolumn{1}{c}{ [mAU] } & \multicolumn{1}{c}{$\%$} \\
\hline 1 & $2.489 \mathrm{BV}$ & 0.1842 & 36.04195 & 2.47080 & 3.4498 \\
2 & $2.906 \mathrm{VV}$ & 0.1126 & 10.71544 & 1.24302 & 1.0257 \\
3 & $4.360 \mathrm{BBA}$ & 0.6782 & 997.98468 & 17.47719 & 95.5245
\end{tabular}

$\begin{array}{lll}\text { 总量： } & 1044.74207 & 21.19102\end{array}$

$1 i$

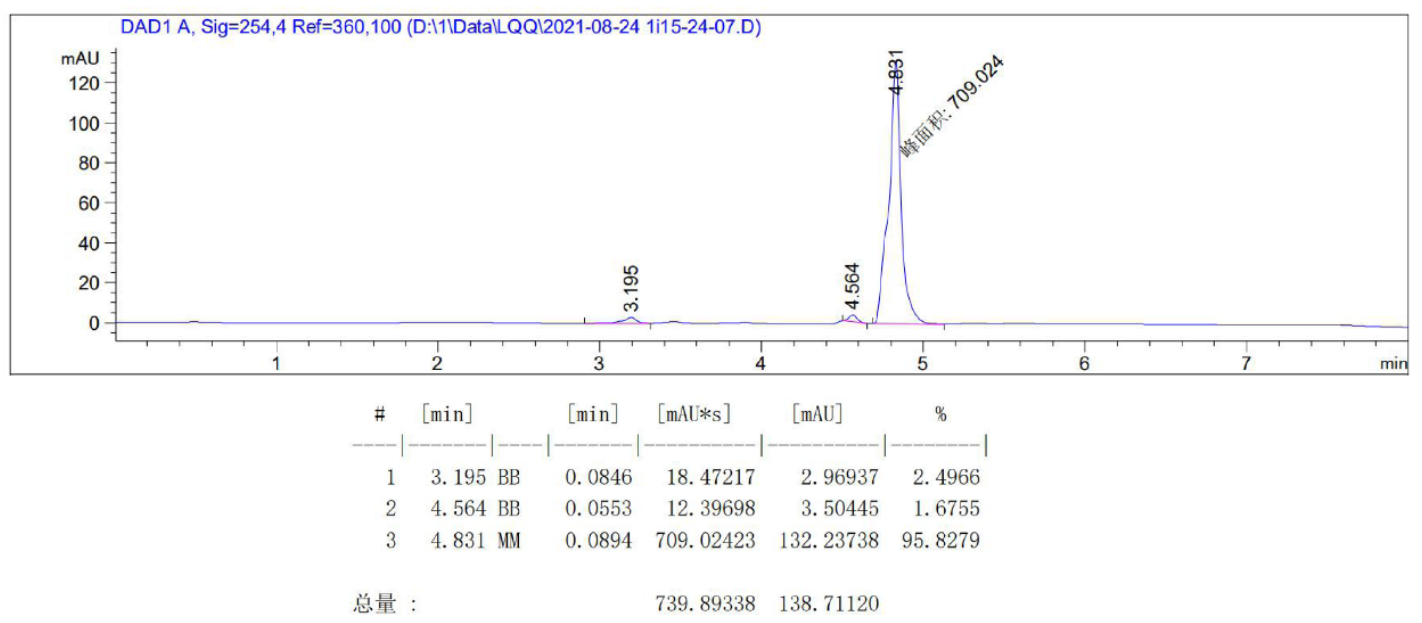

$1 \mathrm{j}$

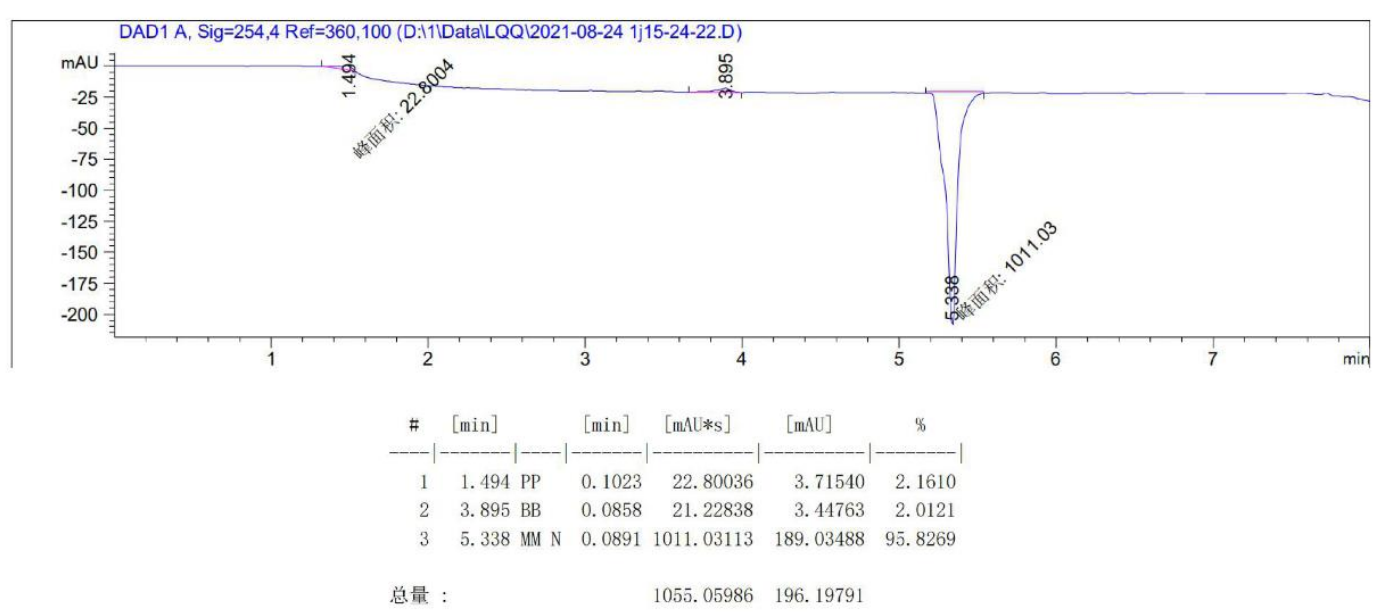


$1 k$
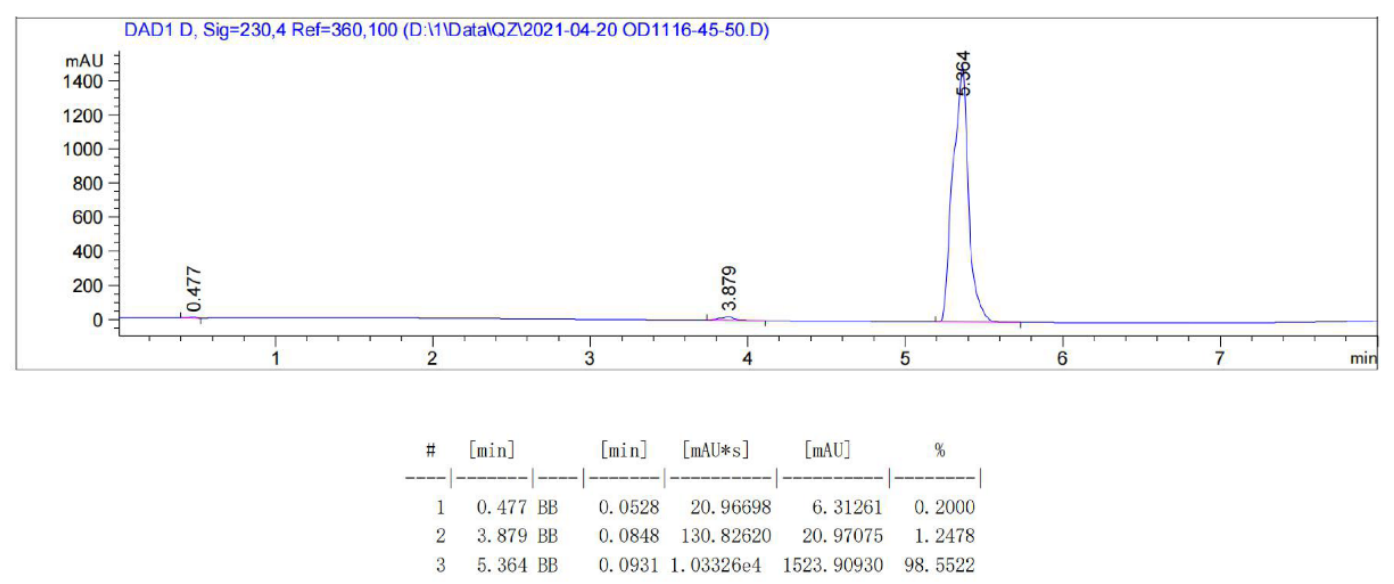

11

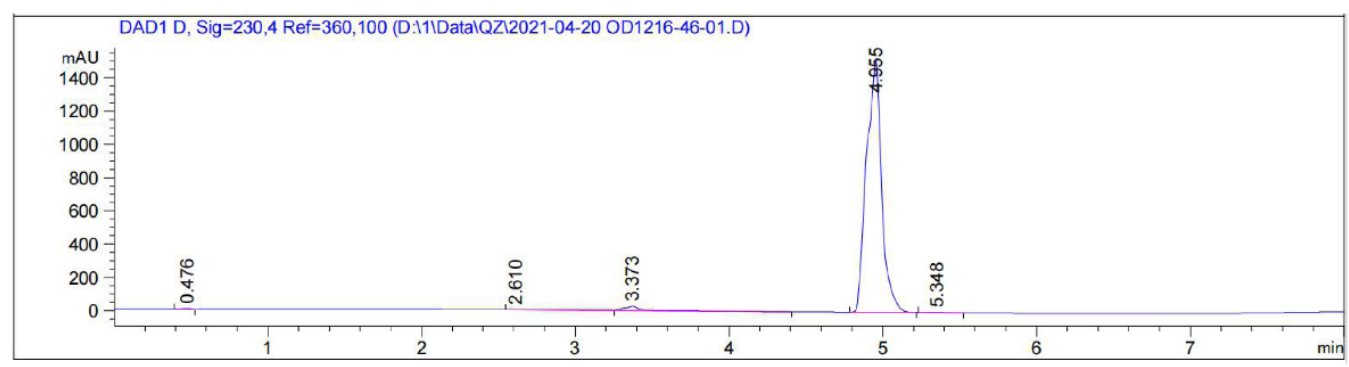

\begin{tabular}{rlrrrr}
$\#$ & \multicolumn{1}{c}{$[\min ]$} & {$[\mathrm{min}]$} & \multicolumn{1}{c}{$[\mathrm{mAU} * \mathrm{~s}]$} & \multicolumn{1}{c}{$[\mathrm{mAU}]$} & \multicolumn{1}{c}{$\%$} \\
\hline 1 & $0.476 \mathrm{BB}$ & 0.0534 & 21.35131 & 6.32416 & 0.1977 \\
2 & $2.610 \mathrm{BV} \mathrm{E}$ & 0.4205 & 91.09829 & 2.61463 & 0.8436 \\
3 & $3.373 \mathrm{VB} \mathrm{R}$ & 0.1101 & 216.28267 & 25.71904 & 2.0028 \\
4 & $4.955 \mathrm{BB}$ & 0.0944 & $1.04549 \mathrm{e} 4$ & 1517.25330 & 96.8125 \\
5 & $5.348 \mathrm{BB}$ & 0.1068 & 15.48794 & 2.29429 & 0.1434
\end{tabular}

$1 \mathrm{~m}$

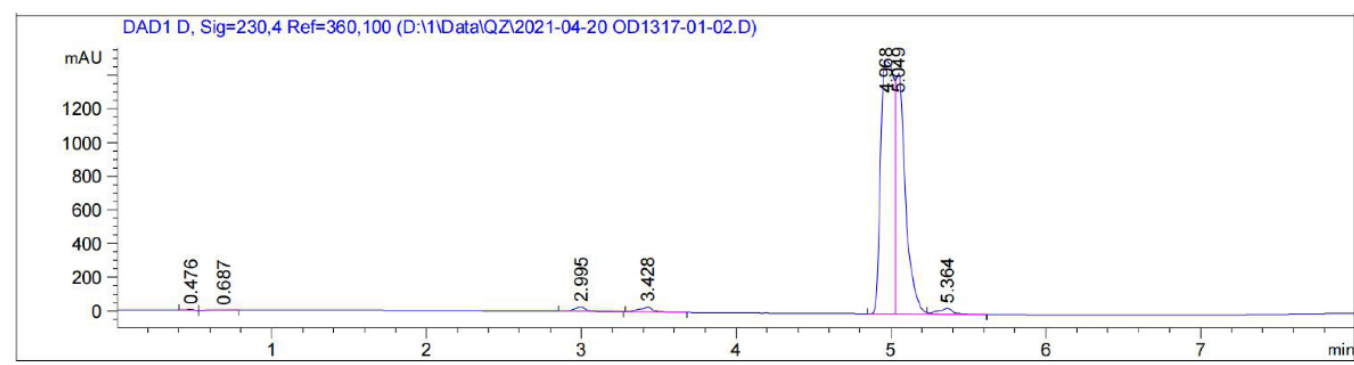

\begin{tabular}{rlrrrr}
$\#$ & {$[\mathrm{~min}]$} & \multicolumn{1}{c}{$[\mathrm{min}]$} & \multicolumn{1}{c}{$[\mathrm{mAU} * \mathrm{~s}]$} & \multicolumn{1}{c}{ [mAU] } & \multicolumn{1}{c}{$\%$} \\
\hline 1 & $0.476 \mathrm{BB}$ & 0.0499 & 19.80816 & 6.09747 & 0.1255 \\
2 & $0.687 \mathrm{BB}$ & 0.1784 & 20.93885 & 1.56171 & 0.1327 \\
3 & $2.995 \mathrm{BB}$ & 0.0742 & 136.24782 & 26.40248 & 0.8632 \\
4 & $3.428 \mathrm{BB}$ & 0.0877 & 179.92867 & 28.48131 & 1.1400 \\
5 & $4.968 \mathrm{BV}$ & 0.0823 & 8823.90039 & 1507.26392 & 55.9044 \\
6 & 5.049 VV R & 0.0640 & 6374.31689 & 1430.19885 & 40.3849 \\
7 & 5.364 VB E & 0.0845 & 228.75899 & 36.83318 & 1.4493
\end{tabular}




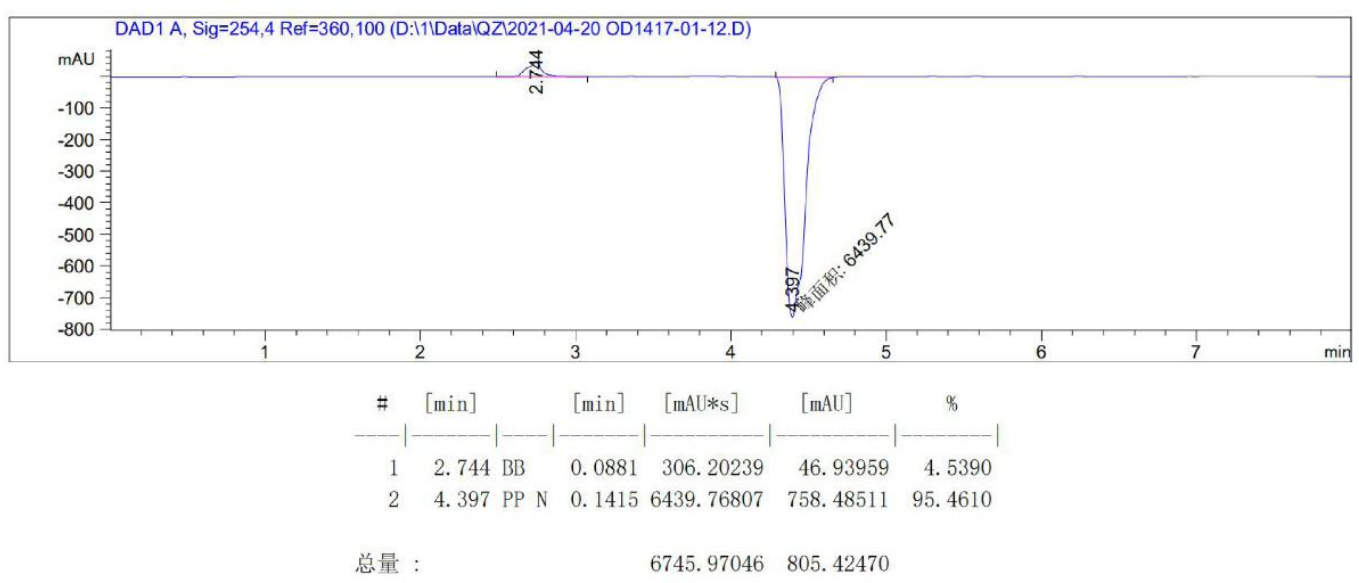

10

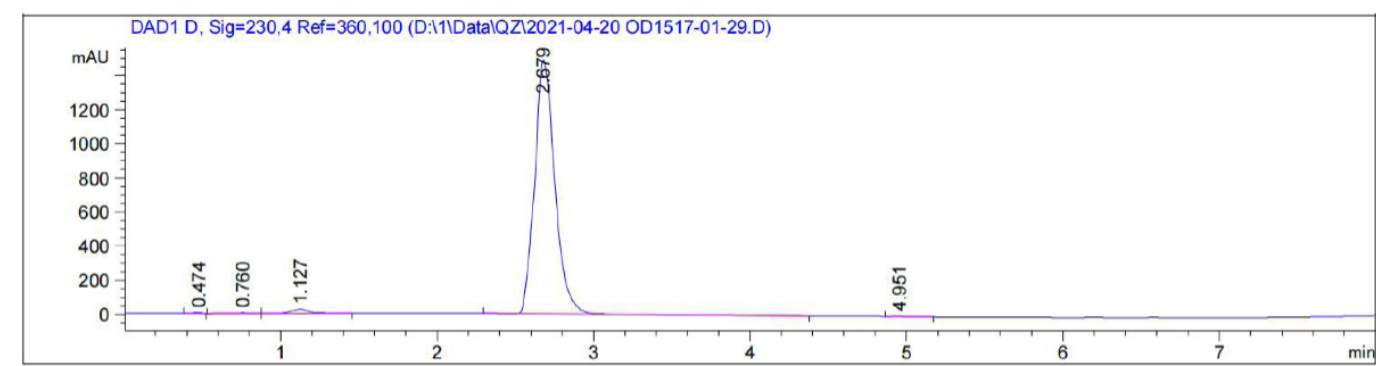

\begin{tabular}{clccrr}
$\#$ & [min] & [min] & \multicolumn{1}{c}{ [mAU**s] } & \multicolumn{1}{c}{ [mAU] } & \multicolumn{1}{c}{$\%$} \\
\hline 1 & 0.474 BB & 0.0595 & 29.43897 & 7.55616 & 0.2139 \\
2 & $0.760 \mathrm{BV}$ & 0.1867 & 75.98151 & 5.07340 & 0.5522 \\
3 & $1.127 \mathrm{VB}$ & 0.1265 & 209.46321 & 24.80383 & 1.5221 \\
4 & $2.679 \mathrm{VV} \mathrm{R}$ & 0.1334 & $1.34375 \mathrm{e} 4$ & 1486.86035 & 97.6494 \\
5 & $4.951 \mathrm{BB}$ & 0.0971 & 8.58533 & 1.20539 & 0.0624
\end{tabular}




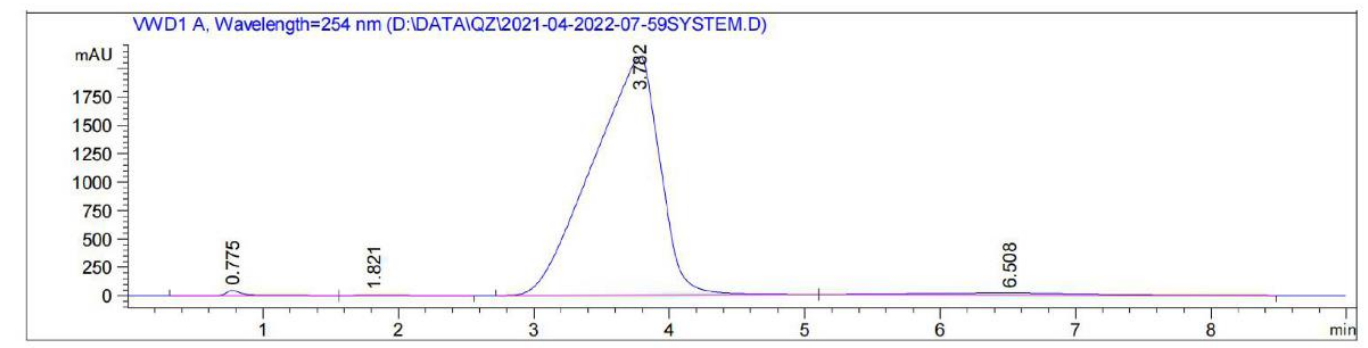

Signal 2: VWD1 A, Wavelength $=254 \mathrm{~nm}$

\begin{tabular}{|c|c|c|c|c|c|c|}
\hline $\begin{array}{c}\text { Peak } \\
\quad \#\end{array}$ & $\begin{array}{c}\text { RetTime } \\
\text { [min] }\end{array}$ & Type & $\begin{array}{l}\text { Width } \\
\text { [min] }\end{array}$ & $\begin{array}{c}\text { Area } \\
{\left[\mathrm{mAU}^{\star} \mathrm{s}\right]}\end{array}$ & $\begin{array}{l}\text { Height } \\
\text { [MAU] }\end{array}$ & $\begin{array}{c}\text { Area } \\
\quad:\end{array}$ \\
\hline 1 & 0.775 & $\mathrm{BB}$ & 0.1404 & 439.48148 & 44.80853 & 0.5940 \\
\hline 2 & 1.821 & BB & 0.3027 & 66.06879 & 3.17553 & 0.0893 \\
\hline 3 & 3.782 & $\mathrm{BB}$ & 0.5494 & $7.21913 \mathrm{e} 4$ & 2098.33521 & 97.5804 \\
\hline 4 & 6.508 & BBA & 1.0267 & 1284.48743 & 16.17155 & 1.7362 \\
\hline Tota] & : & & & $7.39813 \mathrm{e} 4$ & 2162.49081 & \\
\hline
\end{tabular}

2b

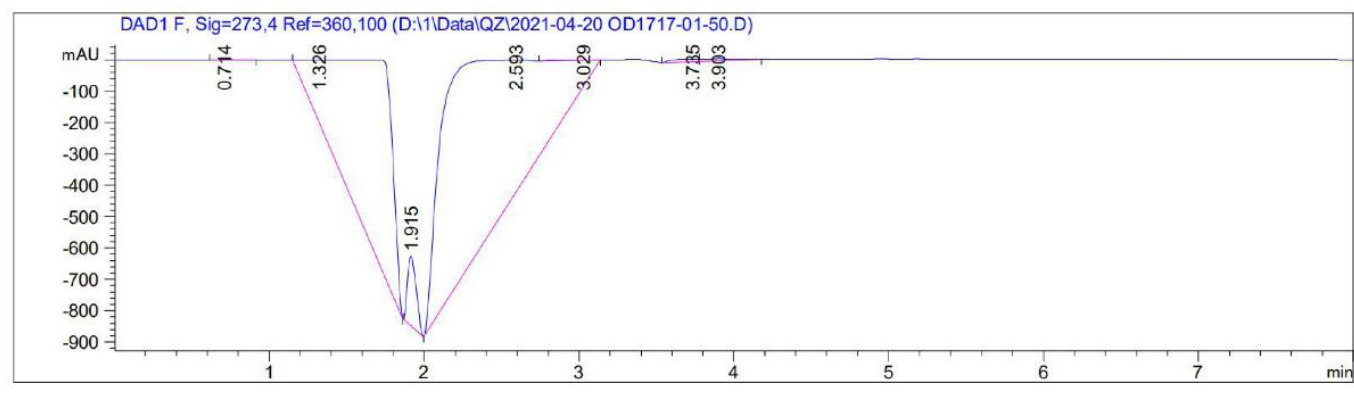

\begin{tabular}{cccccr}
$\#$ & {$[\mathrm{~min}]$} & {$[\mathrm{min}]$} & {$[\mathrm{mAU} * \mathrm{~s}]$} & \multicolumn{1}{c}{$[\mathrm{mAU}]$} & $\%$ \\
\hline 1 & 0.712 BV R & 0.0841 & 50.41353 & 8.89912 & 0.3038 \\
2 & 1.064 VB E & 0.1140 & 9.25938 & 1.31750 & 0.0558 \\
3 & 1.987 PP N & 0.2534 & $1.62937 \mathrm{e} 4$ & 1071.53149 & 98.2010 \\
4 & 2.335 PM & 0.0510 & 51.27263 & 16.74997 & 0.3090 \\
5 & 3.845 BV & 0.2723 & 158.35049 & 7.04432 & 0.9544 \\
6 & 3.898 VB & 0.0718 & 29.19352 & 5.69990 & 0.1759
\end{tabular}

2c

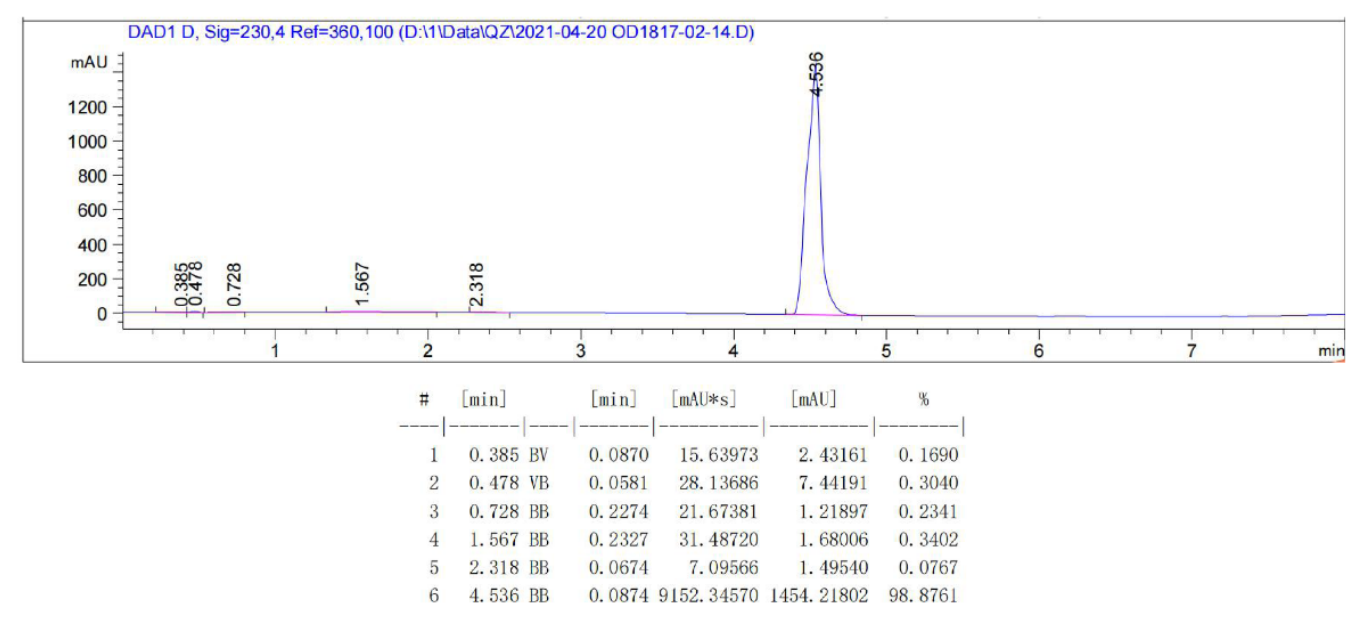

